\title{
Reversible Electrochemical Ion Intercalation at an Electrified Liquid|liquid Interface Functionalised with Porphyrin Nanostructures
}

\author{
Andrés F. Molina-Osorio, José A. Manzanares, Alonso Gamero-Quijano, Micheal D. Scanlon
}

Submitted date: 09/05/2020 - Posted date: 13/05/2020

Licence: CC BY-NC-ND 4.0

Citation information: Molina-Osorio, Andrés F.; Manzanares, José A.; Gamero-Quijano, Alonso; Scanlon, Micheal D. (2020): Reversible Electrochemical Ion Intercalation at an Electrified Liquid|liquid Interface Functionalised with Porphyrin Nanostructures. ChemRxiv. Preprint.

https://doi.org/10.26434/chemrxiv.12276464.v1

Ion intercalation into solid matrices influences the performance of key components in most energy storage devices (Li-ion batteries, supercapacitors, fuel cells, etc.). Electrochemical methods provide key information on the thermodynamics and kinetics of these ion transfer processes but are restricted to matrices supported on electronically conductive substrates. In this article, the electrified liquid|liquid interface is introduced as an ideal platform to probe the thermodynamics and kinetics of reversible ion intercalation with non-electronically active matrices. Zinc(II) meso-tetrakis(4-carboxyphenyl)porphyrins were self-assembled into floating films of ordered nanostructures at the water|a,a,a-trifluorotoluene interface. Electrochemically polarising the aqueous phase negatively with respect to the organic phase lead to organic ammonium cations intercalating into the zinc porphyrin nanostructures by binding to anionic carboxyl sites and displacing protons through ion exchange at neutral carboxyl sites. The cyclic voltammograms suggested a positive cooperativity mechanism for ion intercalation linked with structural rearrangements of the porphyrins within the nanostructures, and were modelled using a Frumkin isotherm. The model also provided a robust understanding of the dependence of the voltammetry on the $\mathrm{pH}$ and organic electrolyte concentration. Kinetic analysis was performed using potential step chronoamperometry, with the current transients composed of "adsorption" and nucleation components. The latter were associated with domains within the nanostructures where, due to structural rearrangments, ion binding and exchange took place faster. This work opens opportunities to study the thermodynamics and kinetics of purely ionic ion intercalation reactions (not induced by redox reactions) in floating solid matrices using any desired electrochemical method.

File list (3)

Electronic Supporting Information.pdf (1.33 MiB)

view on ChemRxiv • download file 


\section{$\dagger$ Electronic Supporting Information}

\section{Reversible electrochemical ion intercalation at an electrified liquid|liquid interface functionalised with porphyrin nanostructures}

Andrés F. Molina-Osorio, ${ }^{\mathrm{a}}$ José A. Manzanares, ${ }^{\mathrm{b}}$ Alonso Gamero-Quijano ${ }^{\mathrm{a}}$ and Micheál D. Scanlon*,a,c

${ }^{a}$ The Bernal Institute and Department of Chemical Sciences, School of Natural Sciences, University of Limerick (UL), Limerick V94 T9PX, Ireland.

${ }^{\mathrm{b}}$ Department of Thermodynamics, Faculty of Physics, University of Valencia, c/Dr. Moliner, 50, E-46100 Burjasot, Spain.

${ }^{c}$ Advanced Materials and Bioengineering (AMBER) Centre, Ireland.

.*E-mail: micheal.scanlon@ul.ie 


\section{Section S1. Experimental Section}

\section{S1.1 Materials}

All reagents were used as received without further purification. Zinc(II) 5,10,15,20-(tetra4-carboxyphenyl)porphyrin (ZnPor, $\geq 98 \%$ ) was purchased from Porphychem. All aqueous solutions were prepared with ultra-pure water (Millipore Milli-Q, resistivity $18.2 \mathrm{M} \Omega \cdot \mathrm{cm}$ ). Bis(triphenylphosphoranylidene)ammonium chloride $\left(\mathrm{R}_{2} \mathrm{NCl}, 97 \%\right.$ with $\mathrm{R}=$ triphenylphosphoranylidene) and lithium tetrakis(pentafluorophenyl)borate diethyletherate ([Li(OEt 2$)] \mathrm{TB})$ were obtained from Sigma-Aldrich and Boulder Scientific Company, respectively. Bis(triphenylphosphoranylidene)ammonium tetrakis(pentafluorophenyl)borate $\left(\mathrm{R}_{2} \mathrm{NTB}\right)$ was prepared by metathesis of equimolar solutions of $\mathrm{R}_{2} \mathrm{NCl}$ and $\left[\mathrm{Li}\left(\mathrm{OEt}_{2}\right)\right] \mathrm{TB}$ in a methanol-water $(2: 1 \mathrm{v} / \mathrm{v})$ mixture. The resulting precipitates were filtered, washed, recrystallised from acetone and finally washed 5 times with a methanol-water $(2: 1 \mathrm{v} / \mathrm{v})$ mixture. Lithium chloride $(\mathrm{LiCl}, \geq 99 \%$ ), lithium hydroxide $(\mathrm{LiOH}, \geq 98 \%)$, tetraethylammonium chloride $(\mathrm{TEACl}, \geq 98 \%)$ and citric acid $\left(\mathrm{H}_{3} \mathrm{Cit}, \geq 99.5 \%\right)$ were obtained from Sigma-Aldrich. The organic solvent $\alpha, \alpha, \alpha$-trifluorotoluene (TFT, $\geq 99 \%$ ) was obtained from Acros Organics.

\section{S1.2 Functionalising the liquid|liquid interface}

Aqueous solutions of ZnPor were prepared by directly dissolving the solid in a lithium citrate ( $\mathrm{Li}_{2} \mathrm{HCit}$ ) buffer pre-adjusted to the desired $\mathrm{pH}$, followed by sonication of the solution for three minutes. Depending on the experiment, the concentration of $\mathrm{ZnPor}$ was varied in the range of 10 to $100 \mu \mathrm{M}$ and the ionic strength of the $\mathrm{Li}_{2} \mathrm{HCit}$ buffer solution was maintained at $10( \pm 2) \mathrm{mM}$. The selective formation of $\mathrm{ZnPor}$ nanostructures at the interface between water and TFT in the four-electrode electrochemical cell was observed upon contacting the ZnPor aqueous solution with the TFT electrolyte. As rationalised in detail recently, ${ }^{1}$ self-assembly was observed only at $\mathrm{pH}=5.8=\mathrm{p} K_{\mathrm{a}}(\mathrm{COOH})$, where the ratio between neutral (fully protonated) and tetra-anionic species was close to 1 . The self-assembly process was carried out at open circuit potential conditions for $30 \mathrm{~min}$ unless stated otherwise. To isolate the ZnPorINs at the interface, as shown in Figure S1, the upper 50\% of the volume of the aqueous phase was carefully removed by a pipette and replaced with porphyrin-free aqueous electrolyte. This procedure was repeated until no porphyrin was detectable in the aqueous phase by UV/vis spectroscopy. 


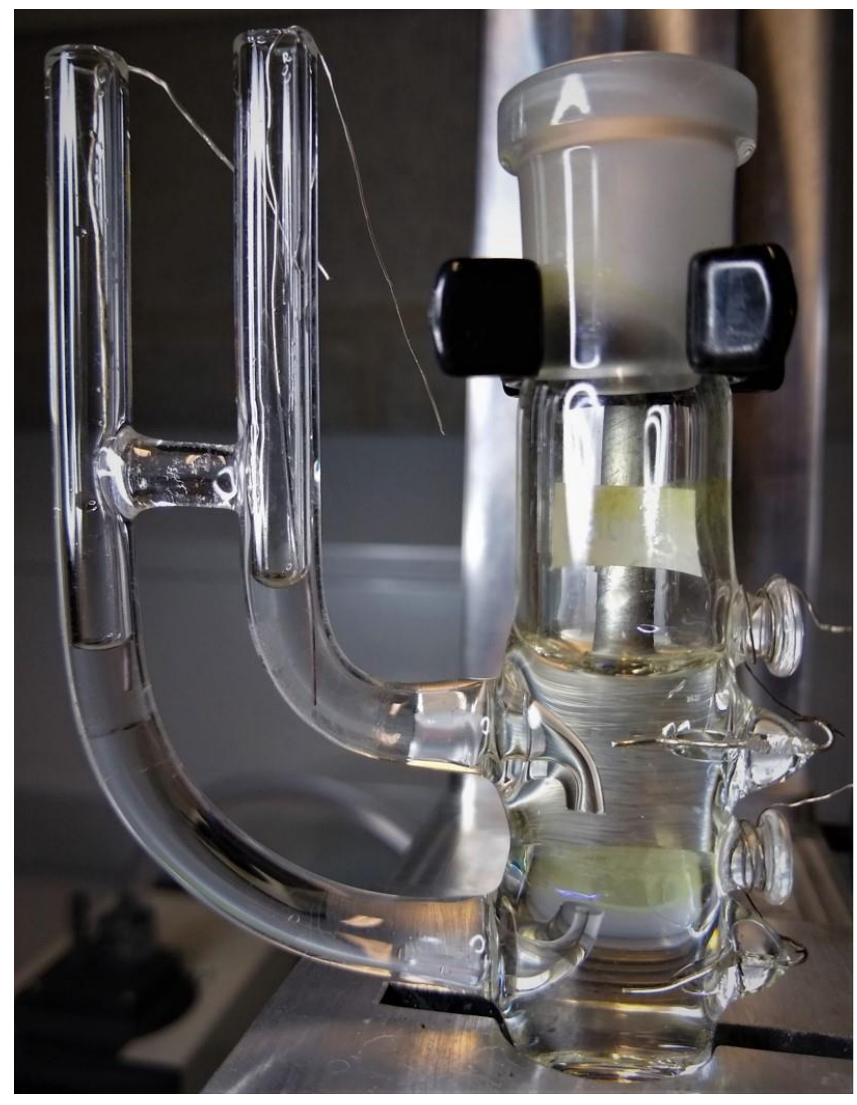

\section{Aqueous phase \\ ZnPor-IN \\ Organic phase}

Figure S1. Image of a four-electrode electrochemical cell with the yellow/green ZnPor-IN film floating at the ITIES formed between a $\mathrm{Li}_{2} \mathrm{HCit}$ buffered aqueous solution and an organic solution of $\mathrm{R}_{2} \mathrm{NTB}$ in TFT (see Scheme 2, main text).

\section{S1.3 Spectroscopic determination of the interfacial concentration $\Gamma$ ZnPor of $\mathrm{ZnPor}$-INs}

The surface concentration $\Gamma_{\mathrm{ZnPor}}$ of the $\mathrm{ZnPor}-\mathrm{IN}$ was measured following a procedure described recently. ${ }^{1}$ Vials containing biphasic systems of ZnPor in lithium citrate buffer (10 mM ionic strength, $\mathrm{pH} 5.8$ ) at different initial concentrations [ZnPor] in the bulk aqueous phase, and $5 \mathrm{mM} \mathrm{R} \mathrm{R}_{2} \mathrm{NTB}$ in TFT as the organic phase were prepared and left to stand for $30 \mathrm{~min}$. After this time, the porphyrin not adsorbed at the interface was extracted and analysed by $\mathrm{UV} /$ vis absorbance spectroscopy to quantify the porphyrin concentration therein (final bulk concentration). By subtracting the final from the initial bulk concentrations, the surface concentration (number of moles adsorbed per geometric area of aqueous|organic interface) was determined. A linear relationship between $\Gamma_{\mathrm{ZnPor}}$ and $[\mathrm{ZnPor}]$ was observed as presented in Figure S2a. Quantification of [ZnPor] not adsorbed at the interface was performed using the calibration curve presented in Figure S2b. 

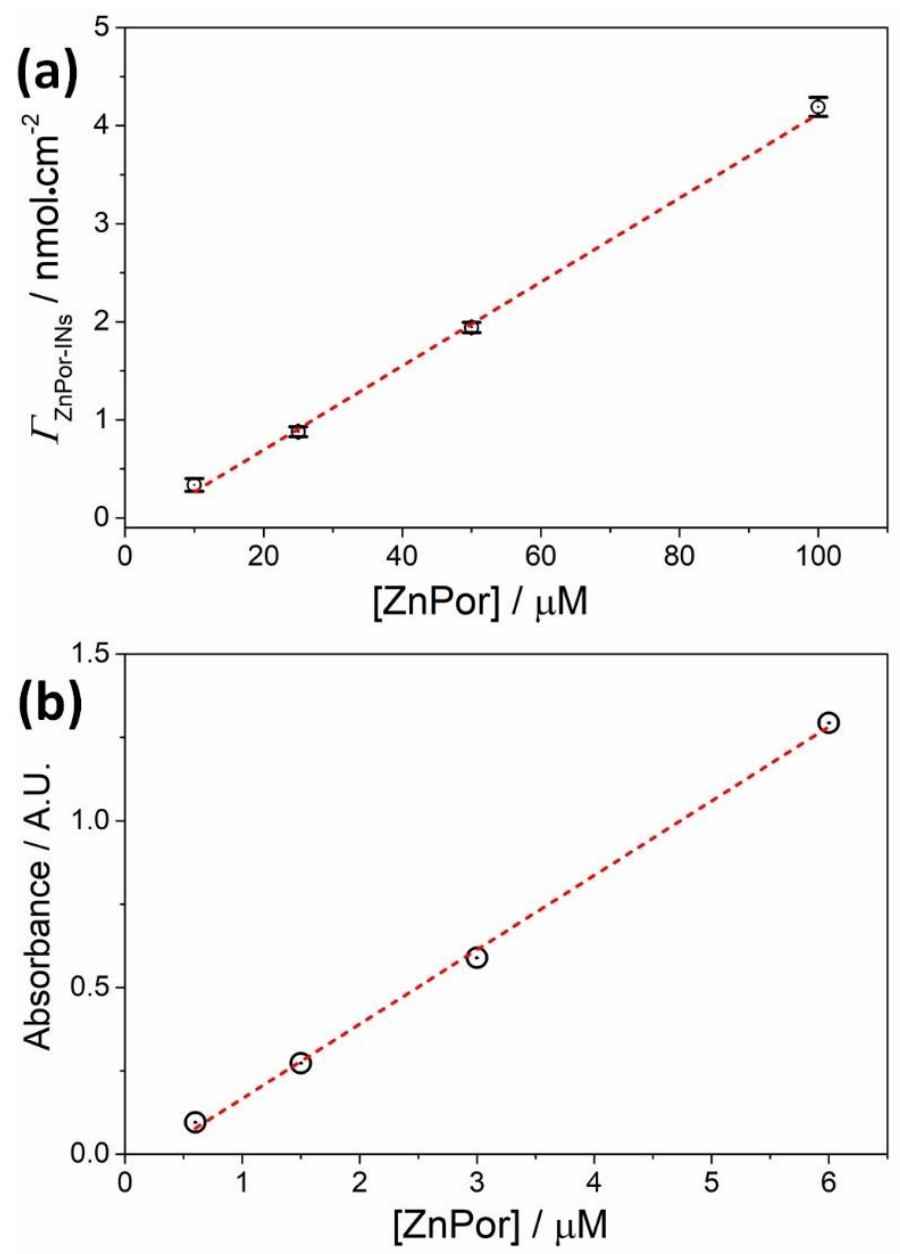

Figure S2. (a) Surface concentration $\Gamma_{\mathrm{ZnPor}}$ of $\mathrm{ZnPor}-\mathrm{INs}$ as a function of ZnPor concentration [ZnPor] in the bulk aqueous phase. The surface concentration was measured after 30 min of ZnPor self-assembly at pH 5.8 as described in the Experimental Section. (b) UV/vis calibration curve used for the quantification of [ZnPor] not adsorbed at the interface. The absorbance was measured at $\lambda_{\max }=422 \mathrm{~nm}$.

\section{S1.4 Electrochemical measurements}

Electrochemical experiments at the ZnPor-IN functionalised water-TFT interface were performed using an Autolab PGSTAT204 potentiostat. The general configuration of the biphasic system were outlined in Scheme 2, main text. The four-electrode electrochemical cell had a geometric area of $1.87 \mathrm{~cm}^{2}$. To supply the current flow, platinum counter electrodes were positioned in the organic and aqueous phases. The potential drop at the liquid|liquid interface was measured by means of a silver/silver citrate ( $\mathrm{Ag} / \mathrm{AgCit})$ reference electrode immersed in the aqueous phase and a silver/silver chloride $(\mathrm{Ag} / \mathrm{AgCl})$ reference electrode immersed in the organic reference solution (an aqueous solution of $10 \mathrm{mM} \mathrm{LiCl}$ and $1 \mathrm{mM} \mathrm{R} \mathrm{R}_{2} \mathrm{NCl}$ ). Both 
reference electrodes were connected to the aqueous phase and organic reference solution, respectively, through Luggin capillaries. The organic phase was composed of a highly hydrophobic salt $\mathrm{R}_{2} \mathrm{NTB}$, dissolved in TFT. The aqueous phase consisted of a $\mathrm{Li}_{2} \mathrm{HCit}$ solution at different $\mathrm{pH}$ values. By introducing a salt in each phase, the interfacial Galvani potential difference $\Delta_{\mathrm{o}}^{\mathrm{w}} \phi$ was varied by external polarisation with a polarisable potential window ranging from -0.3 to $+0.6 \mathrm{~V}$. The voltammetry was adjusted to the Galvani potential scale by assuming the formal ion transfer potential of $\mathrm{TEA}^{+}$to be $0.149 \mathrm{~V}^{2}$

Cyclic voltammetry and potential step chronoamperometry experiments were performed using $i R$ drop compensation (1000 $\Omega$ ). Differential capacitances at different applied voltages were measured using alternating current voltammetry, also known as potentiodynamic electrochemical impedance spectroscopy, at $80 \mathrm{~Hz}$ and assuming the cell behaves as a series $\mathrm{R}-\mathrm{C}$ circuit. At this frequency, the contribution of Faradaic processes was significant only at the edge of the potential window. 


\section{Section S2. Electrochemistry of the floating film of ZnPor-INs at the ITIES}
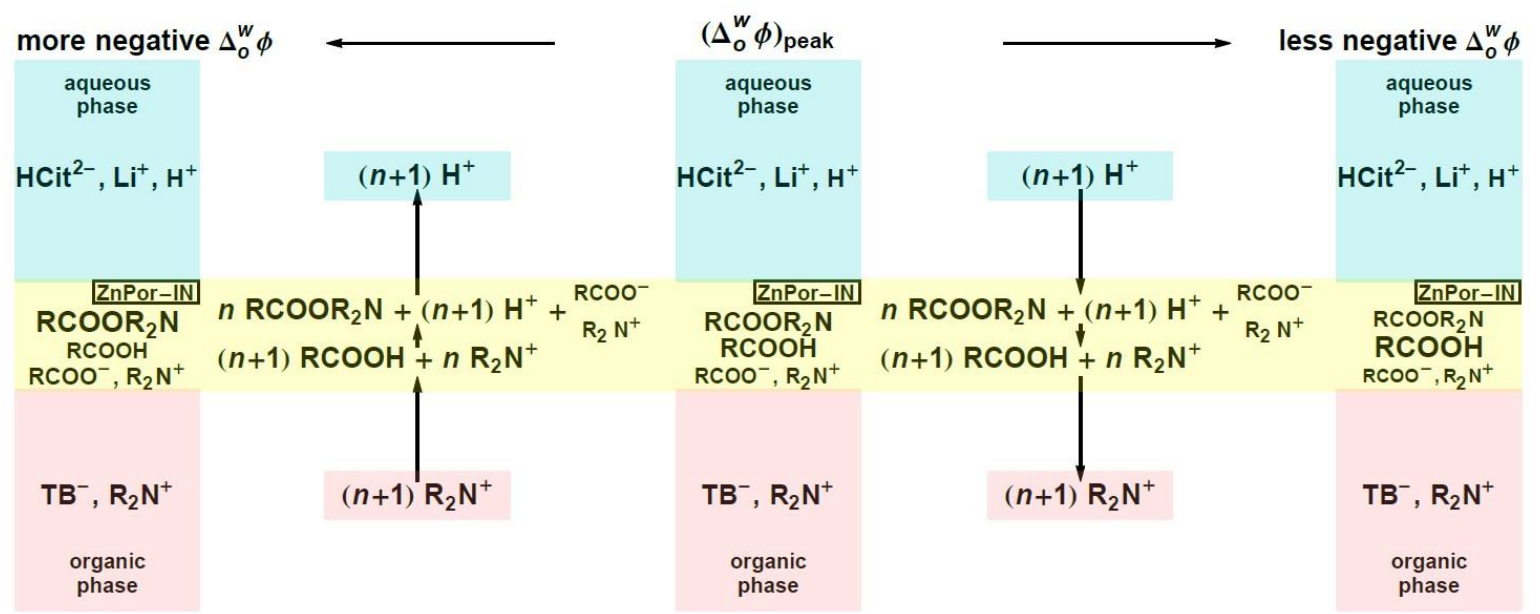

Scheme S1. Detailed schematic of the electrochemically-driven reversible ion intercalation process involving the ZnPor-IN film floating at the electrified liquid|liquid interface, as described in Scheme 1, main text. 


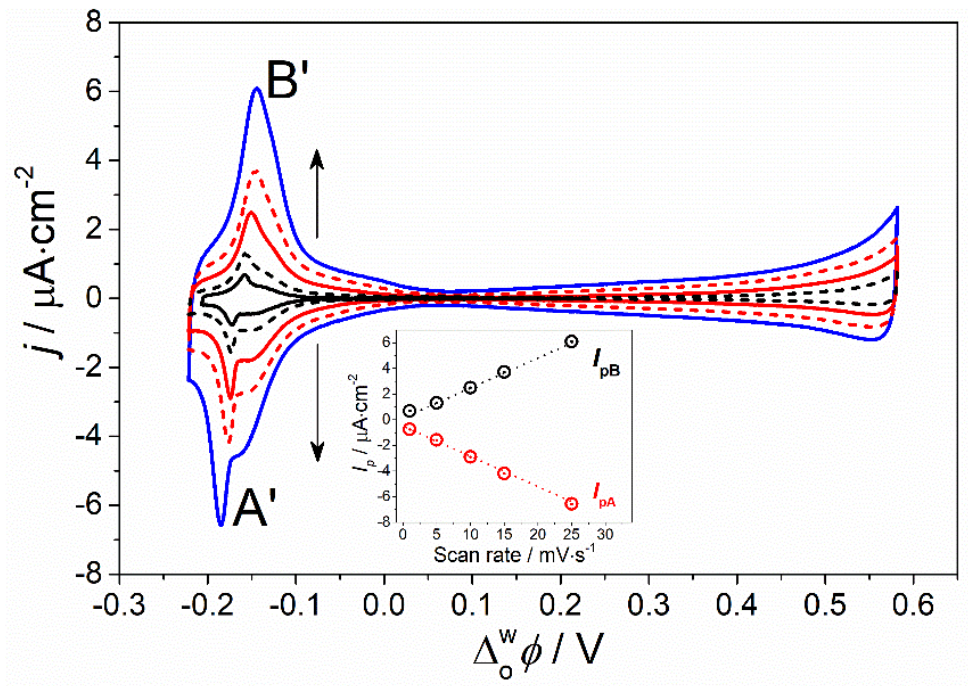

Figure S3. Effect of the scan rate on the electrochemical response of the ZnPor-IN film. The scan rates used were $1,5,10,15$ and $25 \mathrm{mV} \cdot \mathrm{s}^{-1}$ and $\Gamma_{\mathrm{ZnPor}}$ was $0.34 \mathrm{nmol} \cdot \mathrm{cm}^{-2}$. The electrochemical configuration of the cell was as described in Scheme 2, main text. Inset: the peak current $I_{p}$ dependence on the scan rate.

Table S1. Analysis of the voltammetric features observed in Figure S3.

\begin{tabular}{c|c|c}
\hline Scan rate $/\left(\mathrm{mV} \cdot \mathrm{s}^{-1}\right)$ & $\Delta E_{\mathrm{p}} / \mathrm{mV}$ & $Q_{\mathrm{A}} / Q_{\mathrm{B}}$ \\
\hline 1 & 5.9 & 0.63 \\
\hline 5 & 19 & 1.0 \\
\hline 10 & 24 & 1.0 \\
\hline 15 & 30 & 0.99 \\
\hline 25 & 40 & 0.97 \\
\hline 50 & 59 & 0.96 \\
\hline
\end{tabular}



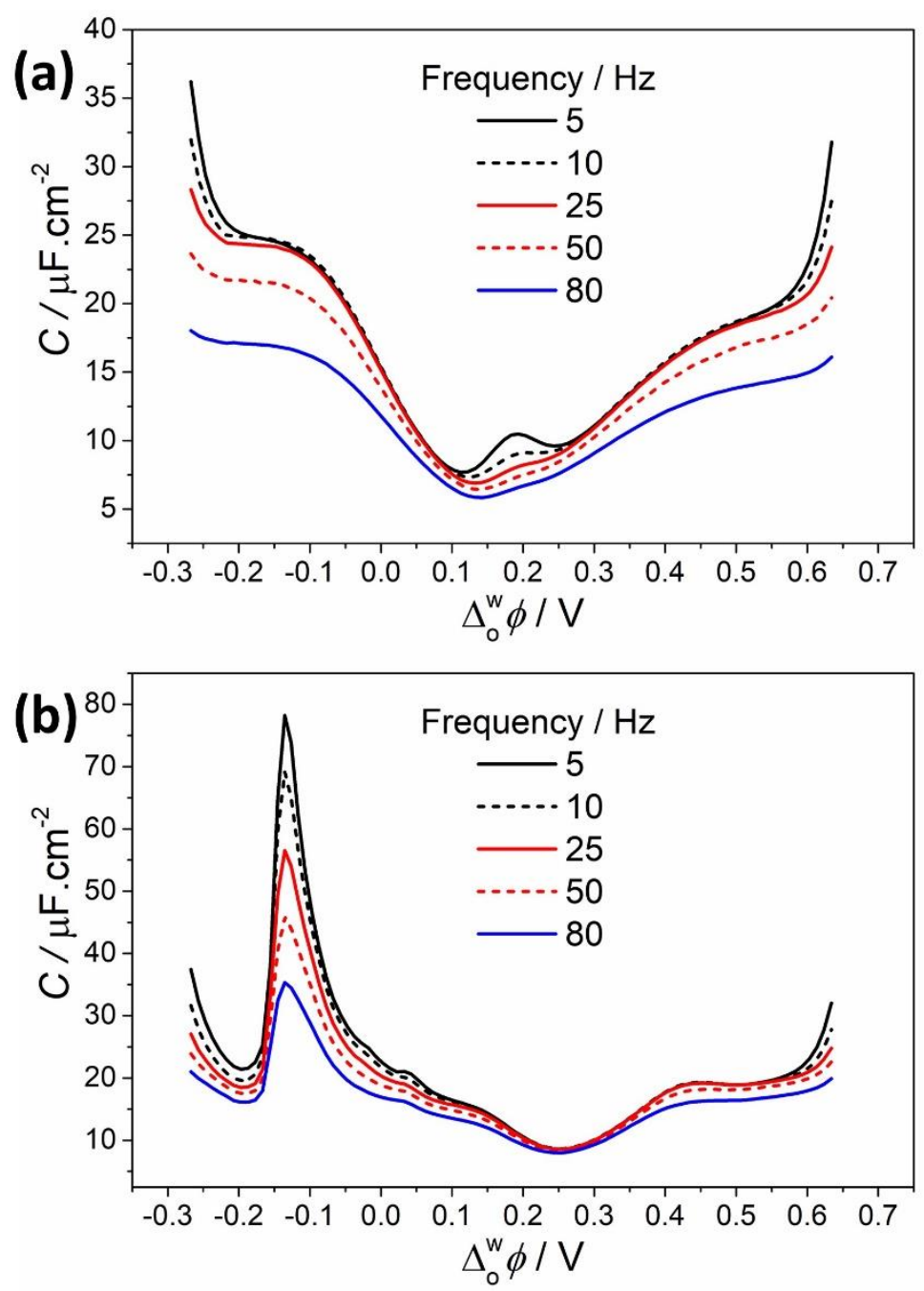

Figure S4. (a) AC voltammetry of the transfer of tetraethylammonium cations $\left(\mathrm{TEA}^{+}\right)$across a bare water|TFT interface at different frequencies. The aqueous phase contained $10 \mathrm{mM}$ $\mathrm{LiH}_{2} \mathrm{Cit}$ at pH 5.8 and $125 \mu \mathrm{M} \mathrm{TEA}^{+}$. The organic phase contained $5 \mathrm{mM}$ of BATB in TFT. The start potential was $-0.3 \mathrm{~V}$. (b) AC voltammetry in the presence of the ZnPor-IN film at different frequencies. The electrochemical configuration of the cell was as described in Scheme 2 , main text. The start potential was $-0.3 \mathrm{~V}$ and $\Gamma_{\mathrm{ZnPor}}$ determined spectroscopically as 0.34 $\mathrm{nmol} \cdot \mathrm{cm}^{-2}$.

Figure S4a demonstrates that at $80 \mathrm{~Hz}$ the contribution of Faradaic processes was significant only at the edge of the potential window, with the Faradaic ion transfer response of $\mathrm{TEA}^{+}$ion transfer entirely filtered out. Meanwhile, in Figure S4b, the peak observed at $-0.15 \mathrm{~V}$ in the presence of the ZnPor-IN remains, indicating that the latter are associated with adsorption and capacitive processes. 

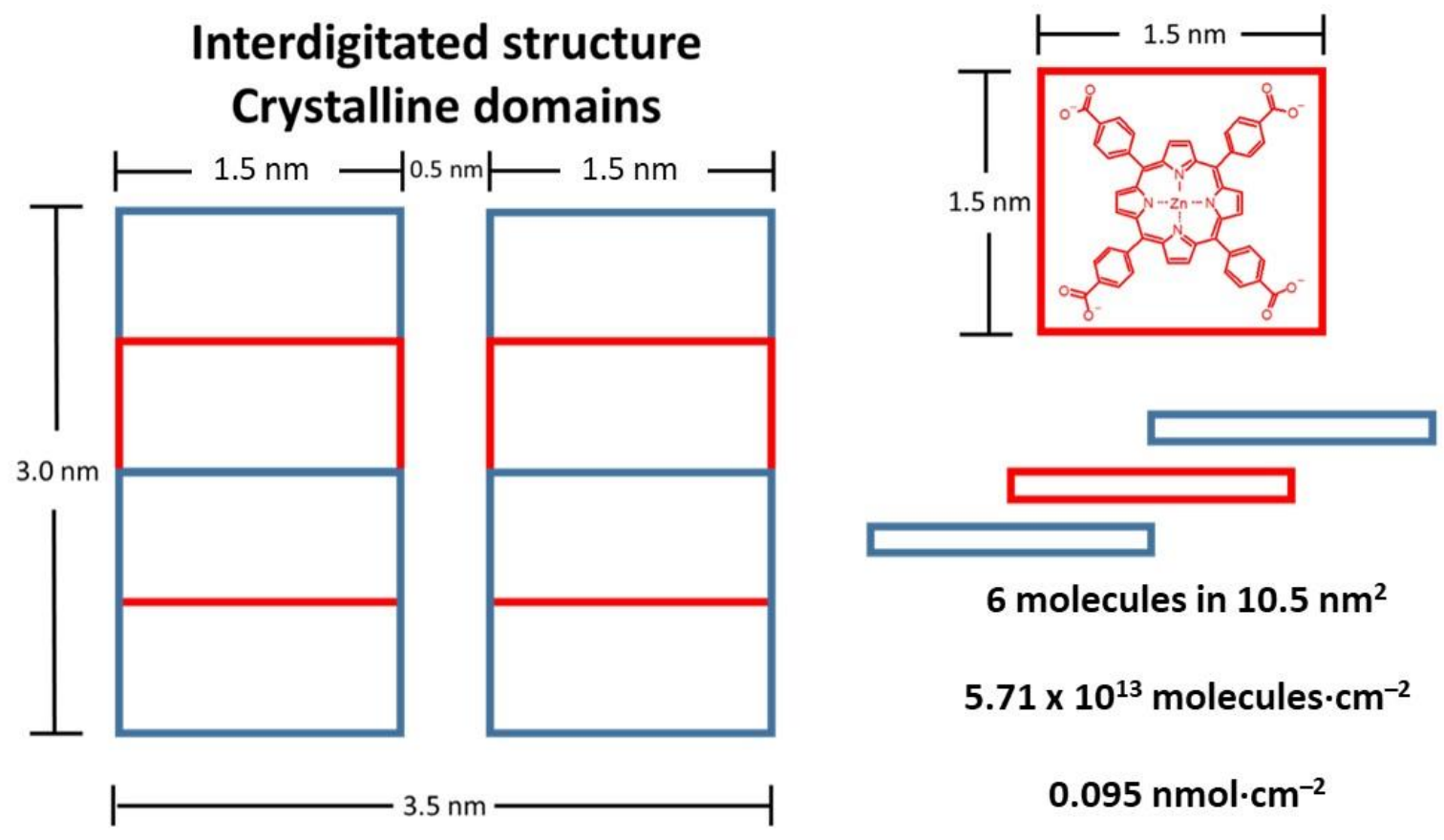

6 molecules in $10.5 \mathrm{~nm}^{2}$

$5.71 \times 10^{13}$ molecules $\cdot \mathrm{cm}^{-2}$

$0.095 \mathrm{nmol} \cdot \mathrm{cm}^{-2}$

Figure S5. The interdigitated clathrate structure was recently obtained from the XRD analysis of the ZnPor-IN film. ${ }^{1}$ The area of a single ZnTPPc molecule is $2.25 \mathrm{~nm}^{2} .{ }^{3}$ Assuming perfectly flat lying ZnTPPc molecules in a monolayer and fully crystalline domains of ZnPor-INs in contact with the liquid|liquid interface (i.e., no amorphous domains), the theoretical monolayer concentration of the ZnPor-INs was calculated as $\Gamma_{\mathrm{m}}=0.095 \mathrm{nmol} \cdot \mathrm{cm}^{-2}$ (equivalent to $5.71 \times 10^{13}$ molecules $\cdot \mathrm{cm}^{-2}$ ). 


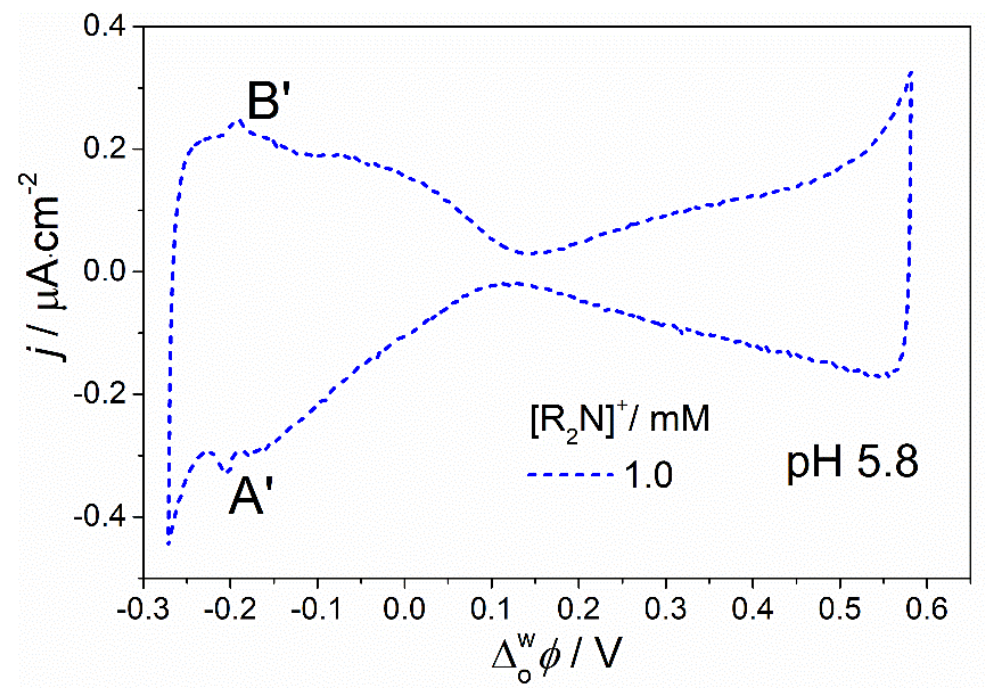

Figure S6. Zoomed version of the CV obtained with $\left[\mathrm{R}_{2} \mathrm{~N}^{+}\right]=1 \mathrm{mM}$ (dashed blue line in Figure $2 \mathrm{~d}$, main text). The scan rate was $5 \mathrm{mV} \cdot \mathrm{s}^{-1}$ and $\Gamma_{\mathrm{ZnPor}}$ was $0.34 \mathrm{nmol} \cdot \mathrm{cm}^{-2}$.

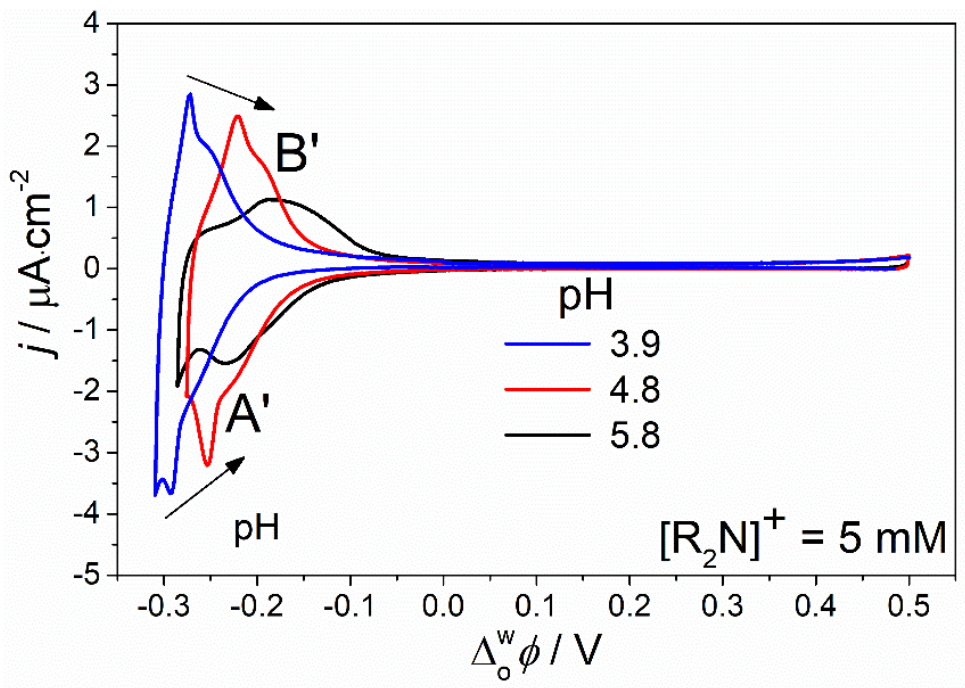

Figure S7. The effect of $\mathrm{pH}$ on the electrochemical response was also investigated when the aqueous anion was changed from citrate to chloride. The cell configuration was as described in Scheme 2, main text, with $\mathrm{LiCl}$ replacing $\mathrm{Li}_{2} \mathrm{HCit}$. The scan rate was $5 \mathrm{mV} \cdot \mathrm{s}^{-1}$ and $\Gamma \mathrm{ZnPor}$ was $0.34 \mathrm{nmol} \cdot \mathrm{cm}^{-2}$. 


\section{Section S3. Modelling the electrochemistry of the floating film of ZnPor-INs at the ITIES}

\section{S3.1 Distribution equilibrium of the ionic species between phase IN and their bulk phases}

The distribution equilibria of the ionic species $\mathrm{R}_{2} \mathrm{~N}^{+}, \mathrm{TB}^{-}, \mathrm{HCit}^{2-}, \mathrm{H}^{+}$and $\mathrm{Li}^{+}$between phase IN and their respective bulk phases are given by the equality of their electrochemical potentials in these phases, $\tilde{\mu}_{\mathrm{R}_{2} \mathrm{~N}}^{\mathrm{O}}=\tilde{\mu}_{\mathrm{R}_{2} \mathrm{~N}}^{\mathrm{IN}}, \tilde{\mu}_{\mathrm{TB}}^{\mathrm{o}}=\tilde{\mu}_{\mathrm{TB}}^{\mathrm{IN}}, \tilde{\mu}_{\mathrm{HCit}}^{\mathrm{w}}=\tilde{\mu}_{\mathrm{HCit}}^{\mathrm{IN}}, \tilde{\mu}_{\mathrm{Li}}^{\mathrm{W}}=\tilde{\mu}_{\mathrm{Li}}^{\mathrm{IN}}$ and $\tilde{\mu}_{\mathrm{H}}^{\mathrm{W}}=\tilde{\mu}_{\mathrm{H}}^{\mathrm{IN}}$. Thus, their concentrations in phase IN can be written as

$$
\begin{aligned}
& c_{\mathrm{R}_{2} \mathrm{~N}}^{\mathrm{IN}}=c^{\mathrm{o}, \mathrm{b}} P_{\mathrm{R}_{2} \mathrm{~N}} \mathrm{e}^{-f \Delta_{\mathrm{o}}^{\mathrm{IN}} \phi} \\
& c_{\mathrm{TB}}^{\mathrm{IN}}=c^{\mathrm{o}, \mathrm{b}} P_{\mathrm{TB}} \mathrm{e}^{f \Delta_{\mathrm{o}}^{\mathrm{IN}} \phi} \\
& c_{\mathrm{HCit}}^{\mathrm{IN}}=c^{\mathrm{w}, \mathrm{b}} P_{\mathrm{HCit}} \mathrm{e}^{-2 f \Delta_{\mathrm{IN}}^{\mathrm{W}} \phi} \\
& c_{\mathrm{H}}^{\mathrm{IN}}=c_{\mathrm{H}}^{\mathrm{w}, \mathrm{b}} P_{\mathrm{H}} \mathrm{e}^{f \Delta_{\mathrm{IN}}^{\mathrm{w}} \phi} \\
& c_{\mathrm{Li}}^{\mathrm{IN}}=\left(2 c^{\mathrm{w}, \mathrm{b}}-c_{\mathrm{H}}^{\mathrm{w}, \mathrm{b}}\right) P_{\mathrm{Li}} \mathrm{e}^{f \Delta_{\mathrm{IN}}^{\mathrm{w}} \phi}
\end{aligned}
$$

where $c^{\mathrm{o}, \mathrm{b}}=c_{\mathrm{R}_{2} \mathrm{~N}}^{\mathrm{o}, \mathrm{b}}=c_{\mathrm{TB}}^{\mathrm{o}, \mathrm{b}}$ and $c^{\mathrm{w}, \mathrm{b}}=c_{\mathrm{HCit}}^{\mathrm{w}, \mathrm{b}}$ are the electrolyte concentrations in the bulk organic and aqueous phases, and $f=F / R T$. The $\mathrm{pH}$ in the bulk aqueous phase determines the $\mathrm{H}^{+}$concentration $c_{\mathrm{H}}^{\mathrm{w}, \mathrm{b}}$, and $c_{\mathrm{Li}}^{\mathrm{w}, \mathrm{b}}=2 c^{\mathrm{w}, \mathrm{b}}-c_{\mathrm{H}}^{\mathrm{w}, \mathrm{b}}$. The chemical partition coefficients $P_{i}$ of the ions are related to their standard transfer potentials and to the Gibbs free energies of transfer,

$$
\begin{aligned}
& R T \ln P_{\mathrm{R}_{2} \mathrm{~N}}=F \Delta_{\mathrm{o}}^{\mathrm{IN}} \phi_{\mathrm{R}_{2} \mathrm{~N}}^{\circ}=\mu_{\mathrm{R}_{2} \mathrm{~N}}^{\circ, \mathrm{o}}-\mu_{\mathrm{R}_{2} \mathrm{~N}}^{\circ, \mathrm{IN}} \\
& R T \ln P_{\mathrm{TB}}=-F \Delta_{\mathrm{o}}^{\mathrm{IN}} \phi_{\mathrm{TB}}^{\circ}=\mu_{\mathrm{TB}}^{\circ, \mathrm{o}}-\mu_{\mathrm{TB}}^{\circ, \mathrm{IN}} \\
& R T \ln P_{\mathrm{HCit}}=2 F \Delta_{\mathrm{IN}}^{\mathrm{w}} \phi_{\mathrm{HCit}}^{\circ}=\mu_{\mathrm{HCit}}^{\circ, \mathrm{w}}-\mu_{\mathrm{HCit}}^{\circ, \mathrm{IN}} \\
& R T \ln P_{\mathrm{H}}=-F \Delta_{\mathrm{IN}}^{\mathrm{w}} \phi_{\mathrm{H}}^{\circ}=\mu_{\mathrm{H}}^{\circ, \mathrm{w}}-\mu_{\mathrm{H}}^{\circ, \mathrm{IN}} \\
& R T \ln P_{\mathrm{Li}}=-F \Delta_{\mathrm{IN}}^{\mathrm{w}} \phi_{\mathrm{Li}}^{\circ}=\mu_{\mathrm{Li}}^{\circ, \mathrm{w}}-\mu_{\mathrm{Li}}^{\circ, \mathrm{IN}}
\end{aligned}
$$

where $\mu_{i}^{0, \varphi}$ is the standard chemical potential of ionic species $i$ in phase $\varphi$.

The ion exchange reaction, Equation (7), main text, can be considered as the combination of the acid dissociation

$-\mathrm{COOH}(\mathrm{IN}) \rightleftarrows-\mathrm{COO}^{-}(\mathrm{IN})+\mathrm{H}^{+}(\mathrm{IN})$

and the binding or adsorption reaction

$-\mathrm{COO}^{-}(\mathrm{IN})+\mathrm{R}_{2} \mathrm{~N}^{+}(\mathrm{IN}) \rightleftarrows-\mathrm{COOR}_{2} \mathrm{~N}(\mathrm{IN})$.

Hence, the ion exchange equilibrium constant can be considered the product of the acid dissociation constant $K_{\mathrm{a}}^{\mathrm{IN}}$ and the $\mathrm{R}_{2} \mathrm{~N}^{+}$binding constant $K_{\mathrm{b}}^{\mathrm{IN}}$, 
$K_{\mathrm{IE}}^{\mathrm{o}, \mathrm{IN}}=K_{\mathrm{a}}^{\mathrm{IN}} K_{\mathrm{b}}^{\mathrm{IN}} c^{\circ}$.

These constants are defined by the standard reaction Gibbs energies,

$\Delta G_{\mathrm{IE}}^{\circ, \mathrm{IN}}=-R T \ln K_{\mathrm{IE}}^{\circ, \mathrm{IN}}=\mu_{\mathrm{COOR}_{2} \mathrm{~N}}^{\circ}+\mu_{\mathrm{H}}^{\circ \mathrm{IN}}-\mu_{\mathrm{COOH}}^{\circ}-\mu_{\mathrm{R}_{2} \mathrm{~N}}^{\circ, \mathrm{IN}}$

$\Delta G_{\mathrm{a}}^{\circ \mathrm{IN}}=-R T \ln K_{\mathrm{a}}^{\mathrm{IN}}=\mu_{\mathrm{COO}^{-}}^{\circ}+\mu_{\mathrm{H}}^{\circ, \mathrm{IN}}-\mu_{\mathrm{COOH}}^{\circ}$

$\Delta G_{\mathrm{b}}^{\circ, \mathrm{IN}}=-R T \ln K_{\mathrm{b}}^{\mathrm{IN}}=\mu_{\mathrm{COOR}_{2} \mathrm{~N}}^{\circ}-\mu_{\mathrm{COO}^{-}}^{\circ}-\mu_{\mathrm{R}_{2} \mathrm{~N}}^{\circ \mathrm{IN}}$.

Using the above equilibrium conditions, the electroneutrality condition (Equation (2), main text) can be written as an equation in the variable $y=\mathrm{e}^{f \Delta \Delta_{\mathrm{IN}}^{\mathrm{W}} \phi}$,

$$
\begin{aligned}
& \frac{K_{\mathrm{a}}^{\mathrm{IN}} c^{\circ} c_{\mathrm{T}, \mathrm{COO}}}{K_{\mathrm{a}}^{\mathrm{IN}} c^{\circ}+\left(c_{\mathrm{H}}^{\mathrm{w}, \mathrm{b}} P_{\mathrm{H}}+K_{\mathrm{IE}}^{\mathrm{o}, \mathrm{IN}} c^{\mathrm{o}, \mathrm{b}} P_{\mathrm{R}_{2} \mathrm{~N}} \mathrm{e}^{-f \Delta_{\mathrm{o}}^{\mathrm{w}} \phi}\right) y}=2 c^{\mathrm{w}, \mathrm{b}}\left(P_{\mathrm{Li}} y-P_{\mathrm{HCit}} y^{-2}\right) \\
& +c^{\mathrm{o}, \mathrm{b}}\left(P_{\mathrm{R}_{2} \mathrm{~N}} \mathrm{e}^{-f \Delta_{\mathrm{o}}^{\mathrm{w}} \phi} y-P_{\mathrm{TB}} \mathrm{e}^{f \Delta_{\mathrm{o}}^{\mathrm{w}} \phi} y^{-1}\right)+c_{\mathrm{H}}^{\mathrm{w}, \mathrm{b}}\left(P_{\mathrm{H}}-P_{\mathrm{Li}}\right) y
\end{aligned}
$$

whose numerical solution allows the determination of the potential drop $\Delta_{\mathrm{IN}}^{\mathrm{W}} \phi=(R T / F) \ln y$. In the case of negligible $c_{\mathrm{COO}^{-}}^{\mathrm{IN}}$ and very negative $\Delta_{\mathrm{o}}^{\mathrm{w}} \phi$, Equation $(\mathrm{S} 17)$ reduces to $2 c_{\mathrm{HCit}}^{\mathrm{IN}}=$ $c_{\mathrm{R}_{2} \mathrm{~N}}^{\mathrm{IN}}$, i.e., $2 c^{\mathrm{w}, \mathrm{b}} P_{\mathrm{HCit}} y^{-2}=c^{\mathrm{o}, \mathrm{b}} P_{\mathrm{R}_{2} \mathrm{~N}} \mathrm{e}^{-f \Delta_{\mathrm{o}}^{\mathrm{w}} \phi} y$, which provides a convenient initial guess

$y_{0}=\mathrm{e}^{f \Delta_{\mathrm{o}}^{\mathrm{w}} \phi / 3}\left(\frac{2 c^{\mathrm{w}, \mathrm{b}} P_{\mathrm{HCit}}}{c^{\mathrm{o}, \mathrm{b}} P_{\mathrm{R}_{2} \mathrm{~N}}}\right)^{1 / 3}$

to solve Equation (S17). That is, $\Delta_{\mathrm{IN}}^{\mathrm{W}} \phi$ is then close to one third of $\Delta_{\mathrm{O}}^{\mathrm{w}} \phi$.

\section{S3.2 Simulating CVs}

The CVs can be simulated using an equivalent electrical circuit consisting of the solution resistance $R_{\text {sol }}$ in series with the parallel combination of the film capacitance $C$ and the charge transfer resistance $R_{\mathrm{ct}}$. The potential applied to this equivalent circuit during a CV scan is

$\Delta_{\mathrm{o}}^{\mathrm{w}} \phi(t)=\varepsilon_{\mathrm{f}}+v\left|t_{\max }-t\right|, \quad\left(0 \leq t \leq 2 t_{\max }\right)$

where $t_{\max }=\left(\varepsilon_{\mathrm{i}}-\varepsilon_{\mathrm{f}}\right) / v$ and $v$ is the scan rate $\left(v=-\mathrm{d} \Delta_{\mathrm{o}}^{\mathrm{w}} \phi / \mathrm{d} t\right.$ for $\left.0 \leq t \leq t_{\max }\right)$. The potential drop across $C$ and $R_{\mathrm{ct}}$ is denoted as $\varepsilon_{\mathrm{c}}(t)$. Note that $C$ is a function of this potential, Equation (10), main text. The sum of the current $\varepsilon_{\mathrm{c}}(t) / R_{\mathrm{ct}}$ across $R_{\mathrm{ct}}$ and the pseudocapacitive current $\mathrm{d} q^{0} / \mathrm{d} t=C \mathrm{~d} \varepsilon_{\mathrm{c}} / \mathrm{d} t$ across $C$ is the observed current density $j(t)=$ $\left(\Delta_{\mathrm{o}}^{\mathrm{w}} \phi-\varepsilon_{\mathrm{c}}\right) / R_{\mathrm{sol}}$,

$\frac{\Delta_{\mathrm{o}}^{\mathrm{w}} \phi(t)-\varepsilon_{\mathrm{c}}(t)}{R_{\mathrm{sol}}}=\frac{\varepsilon_{\mathrm{c}}(t)}{R_{\mathrm{ct}}}+C\left(\varepsilon_{\mathrm{c}}(t)\right) \frac{\mathrm{d} \varepsilon_{\mathrm{c}}}{\mathrm{d} t}$.

The solution of this equation in $\varepsilon_{\mathrm{c}}(t)$, with the initial condition $\varepsilon_{\mathrm{c}}(0)=\varepsilon_{\mathrm{i}}$, allows us to evaluate $j(t)$. The key feature of these CVs is the "adsorption" current $j \approx \mathrm{d} q^{0} / \mathrm{d} t \approx C \nu$. The 
small difference in the peak potentials of the forward and backward scans is mainly determined by $R_{\text {sol }}$.

\section{S3.3 Frumkin binding isotherm}

The equilibrium condition for the $\mathrm{R}_{2} \mathrm{~N}^{+}$adsorption reaction (S12) is $\mu_{\mathrm{COOR}_{2} \mathrm{~N}}=\mu_{\mathrm{COO}^{-}}+\mu_{\mathrm{R}_{2} \mathrm{~N}}^{\mathrm{IN}}$ and can also be presented as

$\frac{c_{\mathrm{COOR}_{2} \mathrm{~N}}}{c_{\mathrm{COOH}}+c_{\mathrm{COO}^{-}}}=\frac{\theta}{1-\theta}=\frac{K_{\mathrm{IE}}^{\mathrm{o}, \mathrm{IN}} c_{\mathrm{R}_{2} \mathrm{~N}}^{\mathrm{IN}}}{K_{\mathrm{a}}^{\mathrm{IN}} c^{\circ}+c_{\mathrm{H}}^{\mathrm{IN}}}$

$\frac{c_{\mathrm{COOR}_{2} \mathrm{~N}}}{c_{\mathrm{COO}^{-}}}=\frac{\theta}{1-\theta} \frac{1}{\alpha}=K_{\mathrm{b}}^{\mathrm{IN}} C_{\mathrm{R}_{2} \mathrm{~N}}^{\mathrm{IN}}$

where $\theta=c_{\mathrm{COOR}_{2} \mathrm{~N}} / c_{\mathrm{T}, \mathrm{COO}}$ is the fraction of sites occupied by $\mathrm{R}_{2} \mathrm{~N}^{+}$ions, $\alpha$ is the degree of acid dissociation defined by $\alpha /(1-\alpha)=c_{\mathrm{COO}^{-}} / c_{\mathrm{COOH}}$, and we have used Equations (6), main text, and (S13). When the species $-\mathrm{COOR}_{2} \mathrm{~N}$ interact, their chemical potential is

$\mu_{\mathrm{COOR}_{2} \mathrm{~N}}=\mu_{\mathrm{COOR}_{2} \mathrm{~N}}^{\circ}+R T \ln \theta+g R T \theta$,

and the Frumkin isotherm

$\frac{\theta}{1-\theta} \mathrm{e}^{g \theta}=\alpha K_{\mathrm{b}}^{\mathrm{IN}} c_{\mathrm{R}_{2} \mathrm{~N}}^{\mathrm{IN}}=\frac{K_{\mathrm{IE}}^{\circ, \mathrm{IN}} c_{\mathrm{R}_{2} \mathrm{~N}}^{\mathrm{IN}}}{K_{\mathrm{a}}^{\mathrm{IN}} c^{\circ}+c_{\mathrm{H}}^{\mathrm{IN}}}=\frac{K_{\mathrm{IE}}^{\circ, \mathrm{IN}} c^{\mathrm{o}, \mathrm{b}} P_{\mathrm{R}_{2} \mathrm{~N}} \mathrm{e}^{-f \Delta_{\mathrm{o}}^{\mathrm{W}} \phi_{\mathrm{e}} \Delta_{\mathrm{IN}}^{\mathrm{W}} \phi}}{K_{\mathrm{a}}^{\mathrm{IN}} c^{\circ}+c_{\mathrm{H}}^{\mathrm{w}, \mathrm{b}} P_{\mathrm{H}} \mathrm{e}^{f \Delta_{\mathrm{IN}}^{\mathrm{W}} \phi}}$

should then be used to describe the cooperative adsorption of $\mathrm{R}_{2} \mathrm{~N}^{+}$ions, i.e., the equilibrium of reaction $(\mathrm{S} 12)$.

Using a lattice model and the mean-field approximation, the interaction energy between adsorbed $\mathrm{R}_{2} \mathrm{~N}^{+}$ions is estimated as $E=(1 / 2) z_{\mathrm{c}} \varepsilon N^{2} / N_{\mathrm{S}}$, where $N_{\mathrm{S}}$ is the number of lattice sites, $z_{\mathrm{c}}$ is the coordination number (i.e., the number of nearest neighbours), $N$ is the number of adsorbed ions, and $\varepsilon$ is the molar interaction energy between ions adsorbed in neighbouring sites. Thence, the chemical potential of species $-\mathrm{COOR}_{2} \mathrm{~N}$ is given by Equation (S23). Negative values of $g=z_{\mathrm{c}} \varepsilon / R T$ correspond to attractive interactions between adsorbed ions, which reduce $\mu_{\mathrm{COOR}_{2} \mathrm{~N}}$, and to positive cooperativity. When $g \leq-4$, i.e., for temperatures below the critical one, $T_{\mathrm{c}}=-z_{\mathrm{c}} \varepsilon / 4 R>0$, phase transitions can occur and to avoid unrealistic predictions, the grand canonical ensemble should then be used to deduce the adsorption isotherm. ${ }^{4}$ 
If the Frumkin adsorption model is used then $K_{\mathrm{IE}}^{\mathrm{o}, \mathrm{IN}} \mathrm{e}^{-g \theta}$ should replace $K_{\mathrm{IE}}^{\mathrm{o}, \mathrm{IN}}$ in Equations (8), (9) and (11) in the main text. For instance, Equation (9) becomes

$\frac{c_{\mathrm{COO}^{-}}}{c_{\mathrm{T}, \mathrm{COO}}}=\frac{K_{\mathrm{a}}^{\mathrm{IN}} c^{\circ}}{K_{\mathrm{a}}^{\mathrm{IN}} c^{\circ}+c_{\mathrm{H}}^{\mathrm{IN}}+K_{\mathrm{IE}}^{\circ \mathrm{IN}} \mathrm{e}^{-g \theta} c_{\mathrm{R}_{2} \mathrm{~N}}^{\mathrm{IN}}}$.

The system formed by Equations (S24) and (S17), with $K_{\mathrm{IE}}^{\circ, \mathrm{IN}} \mathrm{e}^{-g \theta}$ replacing $K_{\mathrm{IE}}^{\circ, \mathrm{IN}}$ in the latter, must be simultaneously solved to determine the unknowns $\Delta_{\mathrm{IN}}^{\mathrm{w}} \phi$ and $\theta$ as functions of $\Delta_{\mathrm{O}}^{\mathrm{w}} \phi$, for given values of $c^{\mathrm{o}, \mathrm{b}}, c^{\mathrm{w}, \mathrm{b}}$ and $c_{\mathrm{H}}^{\mathrm{w}, \mathrm{b}}$. Then, the capacitance $C$ is calculated with Equation (10), main text, and the CV is simulated with Equation (S20).

\section{S3.4 Relations between the equilibrium constants in different phases}

The equilibrium constant of the acid-dissociation reaction

$-\mathrm{COOH}(\mathrm{IN}) \rightleftarrows-\mathrm{COO}^{-}(\mathrm{IN})+\mathrm{H}^{+}(\mathrm{w})$

is the acidity constant $K_{\mathrm{a}}=10^{-5.8}$, and the standard Gibbs energy of reaction is

$\Delta G_{\mathrm{a}}^{\circ}=-R T \ln K_{\mathrm{a}}=\mu_{\mathrm{COO}^{-}}^{\circ}+\mu_{\mathrm{H}^{+}}^{\circ, \mathrm{w}}-\mu_{\mathrm{COOH}}^{\circ}$.

The equilibrium constant of the binding reaction

$-\mathrm{COO}^{-}(\mathrm{IN})+\mathrm{R}_{2} \mathrm{~N}^{+}(\mathrm{o}) \rightleftarrows-\mathrm{COOR}_{2} \mathrm{~N}(\mathrm{IN})$

is the (intrinsic) binding constant $K_{\mathrm{b}}$ which is implicitly defined as

$\Delta G_{\mathrm{b}}^{\circ}=-R T \ln K_{\mathrm{b}}=\mu_{\mathrm{COOR}_{2} \mathrm{~N}}^{\circ}-\mu_{\mathrm{COO}^{-}}^{\circ}-\mu_{\mathrm{R}_{2} \mathrm{~N}}^{\circ}$.

The equilibrium constant of the ion exchange reaction

$-\mathrm{COOH}(\mathrm{IN})+\mathrm{R}_{2} \mathrm{~N}^{+}(\mathrm{o}) \rightleftarrows-\mathrm{COOR}_{2} \mathrm{~N}(\mathrm{IN})+\mathrm{H}^{+}(\mathrm{w})$

is the (intrinsic) ion exchange constant $K_{\mathrm{IE}}^{\circ}$ which is implicitly defined as

$\Delta G_{\mathrm{IE}}^{\circ}=-R T \ln K_{\mathrm{IE}}^{\circ}=\mu_{\mathrm{COOR}_{2} \mathrm{~N}}^{\circ}+\mu_{\mathrm{H}}^{\circ, \mathrm{w}}-\mu_{\mathrm{COOH}}^{\circ}-\mu_{\mathrm{R}_{2} \mathrm{~N}}^{\circ, \mathrm{o}} \cdot$

Its relation with the acidity and the binding constants is $K_{\mathrm{IE}}^{\circ}=K_{\mathrm{a}} K_{\mathrm{b}} c^{\circ}$.

Similarly, in the ZnPor-IN film (phase IN), the equilibrium constant of reaction (S11) is $K_{\mathrm{a}}^{\mathrm{IN}}=K_{\mathrm{a}} P_{\mathrm{H}} \cdot$

The equilibrium constant of reaction (S12) is defined through Eq. (S16) and its relation to that in bulk phase is

$K_{\mathrm{b}}^{\mathrm{IN}}=K_{\mathrm{b}} / P_{\mathrm{R}_{2} \mathrm{~N}}$. 
The equilibrium constant of the ion exchange reaction in the film, Equation (7) in the main text, is defined through Eq. (S14) and its relation to that in bulk phase is $K_{\mathrm{IE}}^{\mathrm{o}, \mathrm{IN}}=K_{\mathrm{a}}^{\mathrm{IN}} K_{\mathrm{b}}^{\mathrm{IN}} C^{\circ}=$ $K_{\mathrm{IE}}^{\circ} P_{\mathrm{H}} / P_{\mathrm{R}_{2} \mathrm{~N}}$. That is, the solvation effects on ion partitioning also affect the binding constant and the ion exchange equilibrium constant.

\section{S3.5 Mathematica code to simulate the CVs in the presence of the ZnPor-IN film}

Files available free of charge on the Chemical Science RSC website.

Table S2. Parameter values for the simulated CVs in Figure 3a, main text. The chemical partition coefficient is $P_{i}=3 \times 10^{-4}$ for all ionic species $\left(i=\mathrm{R}_{2} \mathrm{~N}^{+}, \mathrm{TB}^{-}, \mathrm{HCit}^{2-}, \mathrm{H}^{+}, \mathrm{Li}^{+}\right)$and $\mathrm{p} K_{\mathrm{b}}=-\lg K_{\mathrm{b}}=-\lg \left(K_{\mathrm{b}}^{\mathrm{IN}} P_{\mathrm{R}_{2} \mathrm{~N}}\right)$.

\begin{tabular}{c|c|c|c|c}
\hline$\Gamma_{\text {ZnPor }} /\left(\mathrm{nmol} \cdot \mathrm{cm}^{-2}\right)$ & $c_{\mathrm{T}, \mathrm{COO}} / \mathrm{mM}$ & $\mathrm{p} K_{\mathrm{b}}$ & $R_{\mathrm{sol}} /\left(\mathrm{k} \Omega \cdot \mathrm{cm}^{2}\right)$ & $R_{\mathrm{ct}} /\left(\mathrm{M} \Omega \cdot \mathrm{cm}^{2}\right)$ \\
\hline 0.34 & 42 & 3.3 & 4.5 & 3.5 \\
\hline 0.88 & 100 & 3.3 & 4.5 & 2.0 \\
\hline 1.94 & 214 & 3.1 & 2.8 & 2.0 \\
\hline 4.19 & 416 & 3.1 & 1.4 & 2.0 \\
\hline
\end{tabular}

Table S3. Parameter values for the simulated CVs in Figures $3 b$ and c, main text. As shown in Table S2, $c_{\mathrm{T}, \mathrm{COO}}=42 \mathrm{mM}$ because $\Gamma_{\mathrm{ZnPor}}=0.34 \mathrm{nmol} \cdot \mathrm{cm}^{-2}$. The chemical partition coefficient is $P_{i}=3 \times 10^{-4}$ for all ionic species $\left(i=\mathrm{R}_{2} \mathrm{~N}^{+}, \mathrm{TB}^{-}, \mathrm{HCit}^{2-}, \mathrm{H}^{+}, \mathrm{Li}^{+}\right)$.

\begin{tabular}{c|c|c|c|c}
\hline $\mathrm{pH}$ & $c^{\mathrm{o}, \mathrm{b}} / \mathrm{mM}$ & $\mathrm{p} K_{\mathrm{b}}$ & $R_{\mathrm{sol}} /\left(\mathrm{k} \Omega \cdot \mathrm{cm}^{2}\right)$ & $R_{\mathrm{ct}} /\left(\mathrm{M} \Omega \cdot \mathrm{cm}^{2}\right)$ \\
\hline 5.8 & 5.0 & 3.50 & 4.0 & 3.0 \\
\hline 5.0 & 5.0 & 3.55 & 4.0 & 3.5 \\
\hline 4.5 & 5.0 & 3.65 & 4.0 & 2.5 \\
\hline 4.0 & 5.0 & 3.65 & 4.0 & 2.5 \\
\hline 3.0 & 5.0 & 3.65 & 4.0 & 2.5 \\
\hline 5.8 & 5.0 & 3.60 & 2.8 & 3.0 \\
\hline 5.8 & 2.5 & 3.40 & 2.8 & 3.0 \\
\hline 5.8 & 1.0 & 3.60 & 2.8 & 3.0 \\
\hline
\end{tabular}



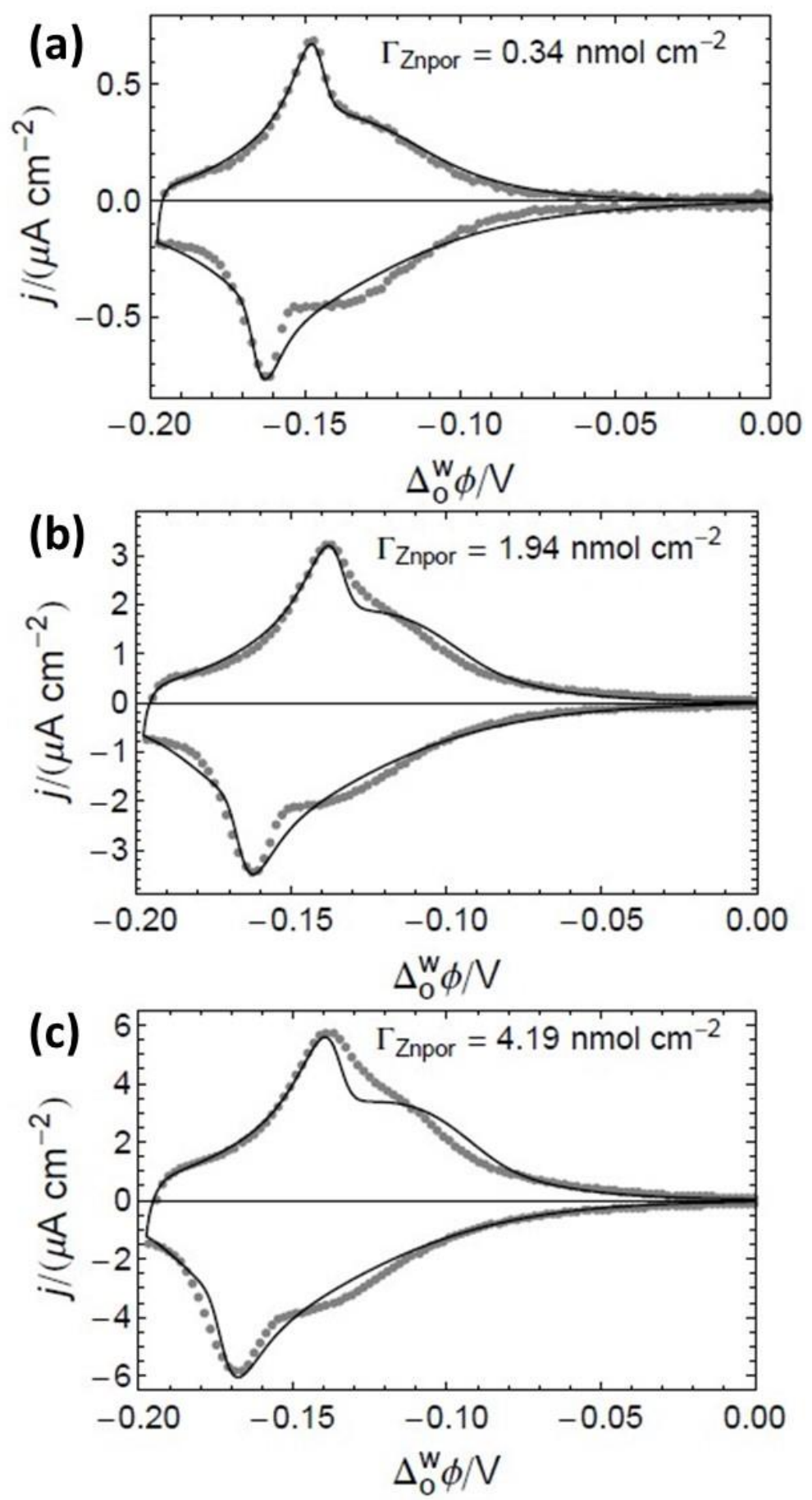

Figure S8. The consideration of two types of binding sites, described by Equation (S24) with $g_{\text {narrow }}=-3.5$ and $g_{\text {broad }}=-0.7$, predicts simulated CVs (lines) at $1 \mathrm{mV} \cdot \mathrm{s}^{-1}$ that resemble more closely the experimental observations (symbols). Comparisons are provided for CVs obtained with $\Gamma_{\mathrm{ZnPor}}$ values of $0.34,1.94$ and $4.19 \mathrm{nmol} \cdot \mathrm{cm}^{-2}$. The parameter values (see Table S4) have been chosen on the basis of a qualitative agreement and not using a fitting algorithm. 
Table S4. Parameter values for the simulated CVs in Figures 4, main text, and S7. The partition coefficient is $P_{i}=3 \times 10^{-5}$ for all ionic species $\left(i=\mathrm{R}_{2} \mathrm{~N}^{+}, \mathrm{TB}^{-}, \mathrm{HCit}^{2-}, \mathrm{H}^{+}, \mathrm{Li}^{+}\right)$. The values of $\mathrm{p} K_{\mathrm{b}}=-\lg K_{\mathrm{b}}=-\lg \left(K_{\mathrm{b}}^{\mathrm{IN}} P_{\mathrm{R}_{2} \mathrm{~N}}\right)$ are shown. The carboxyl groups responsible for the narrow peak have a more negative Frumkin parameter $g_{\text {narrow }}=-3.5$ and a smaller binding constant $K_{\mathrm{b}, \text { narrow }}$, so that the narrow peak appears at more negative $\Delta_{\mathrm{o}}^{\mathrm{w}} \phi$, compared to the broad peak with $g_{\text {broad }}=-0.7$ and larger $K_{\mathrm{b}, \mathrm{broad}}$.

\begin{tabular}{c|c|c|c|c|c|c}
\hline$\Gamma_{\mathrm{ZnPor}} /\left(\mathrm{nmol} \cdot \mathrm{cm}^{-2}\right)$ & $c_{\mathrm{T}, \mathrm{COO}}^{\text {narrow }} / \mathrm{mM}$ & $c_{\mathrm{T}, \mathrm{COO}}^{\text {broad }} / \mathrm{mM}$ & $\mathrm{p} K_{\mathrm{b}}^{\text {narrow }}$ & $\mathrm{p} K_{\mathrm{b}}^{\mathrm{broad}}$ & $R_{\mathrm{sol}} /\left(\mathrm{k} \Omega \cdot \mathrm{cm}^{2}\right)$ & $R_{\mathrm{ct}} /\left(\mathrm{M} \Omega \cdot \mathrm{cm}^{2}\right)$ \\
\hline 0.34 & 10 & 31 & 4.04 & 3.30 & 13 & 7 \\
\hline 0.88 & 24 & 70 & 4.13 & 3.40 & 8 & 5 \\
\hline 1.94 & 46 & 160 & 3.98 & 3.20 & 5.4 & 4 \\
\hline 4.19 & 84 & 295 & 4.05 & 3.20 & 3.7 & 10 \\
\hline
\end{tabular}


Section S4. The kinetics of structural changes in the ZnPor-IN film during electrochemically-driven reversible ion intercalation
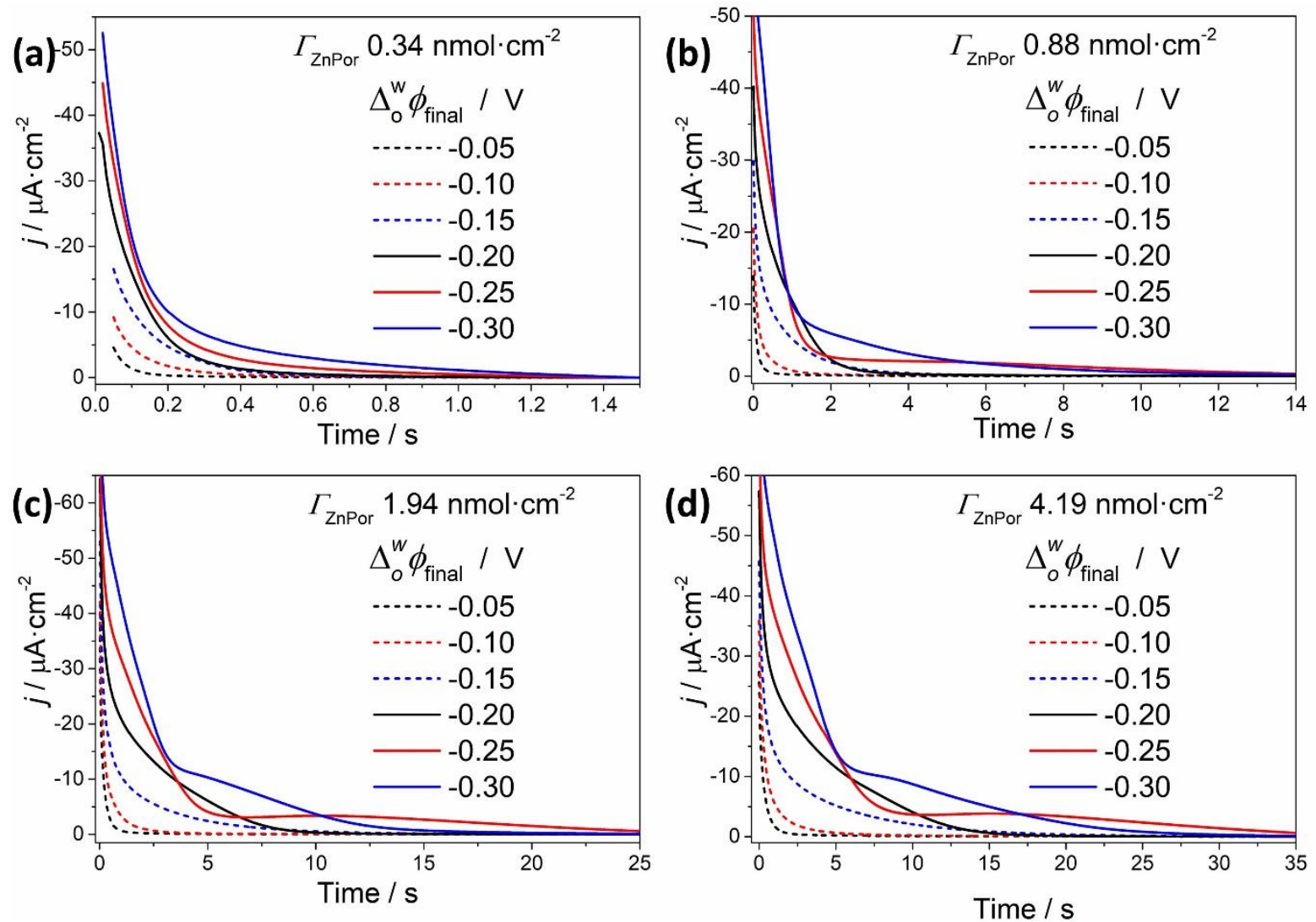

Figure S9. Current transients probing the influence of $\Delta_{\mathrm{o}}^{\mathrm{w}} \phi_{\text {final }}$ were obtained by varying $\Delta_{\mathrm{o}}^{\mathrm{w}} \phi_{\text {final }}$ in $50 \mathrm{mV}$ increments at a constant $\Delta_{\mathrm{o}}^{\mathrm{w}} \phi_{\text {initial }}$ of $+0.25 \mathrm{~V}$ for $30 \mathrm{~s}\left(t_{\text {initial }}\right)$ with $\Gamma_{\mathrm{ZnPor}}$ values of (a) 0.34 , (b) 0.88 , (c) 1.94 and (d) $4.19 \mathrm{nmol} \cdot \mathrm{cm}^{-2}$, respectively. 
Table S5. All $t_{\max }$ values in Table S5 were obtained from the derivative of current transients obtained in the presence of the ZnPor-IN film as a function of both $\Gamma_{\mathrm{ZnPor}}$ and $\Delta_{\mathrm{o}}^{\mathrm{w}} \phi_{\text {initial }}$ with a constant $\Delta_{\mathrm{o}}^{\mathrm{w}} \phi_{\text {initial }}$ of $+0.25 \mathrm{~V}$ for $30 \mathrm{~s}\left(t_{\text {initial }}\right)$.

\begin{tabular}{c|c|c|c|c|c|c|c|c|c}
\hline \multirow{2}{*}{$\Gamma_{\text {ZnPor }}\left(\left(\mathrm{nmol} \cdot \mathrm{cm}^{-2}\right)\right.$} & \multicolumn{3}{|c|}{$t_{\max 1} / \mathrm{s}$} & \multicolumn{3}{c|}{$t_{\max 2} / \mathrm{s}$} & \multicolumn{3}{c}{$t_{\max 3} / \mathrm{s}$} \\
\cline { 2 - 10 } & $-0.25 \mathrm{~V}$ & $-0.30 \mathrm{~V}$ & $-0.35 \mathrm{~V}$ & $-0.25 \mathrm{~V}$ & $-0.30 \mathrm{~V}$ & $-0.35 \mathrm{~V}$ & $-0.25 \mathrm{~V}$ & $-0.30 \mathrm{~V}$ & $-0.35 \mathrm{~V}$ \\
\hline 0.34 & 0.43 & 0.27 & - & - & 0.51 & 0.50 & - & - & - \\
\hline 0.88 & 0.75 & 0.08 & 1.31 & - & 0.33 & 3.29 & - & 1.71 & - \\
\hline 1.94 & 1.03 & 0.7 & 0.66 & 2.87 & 1.73 & 1.3 & - & 10.22 & 4.5 \\
\hline 4.19 & 1.81 & 1.14 & 0.85 & 4.86 & 2.82 & 2.1 & - & 15.21 & 8.13 \\
\hline
\end{tabular}

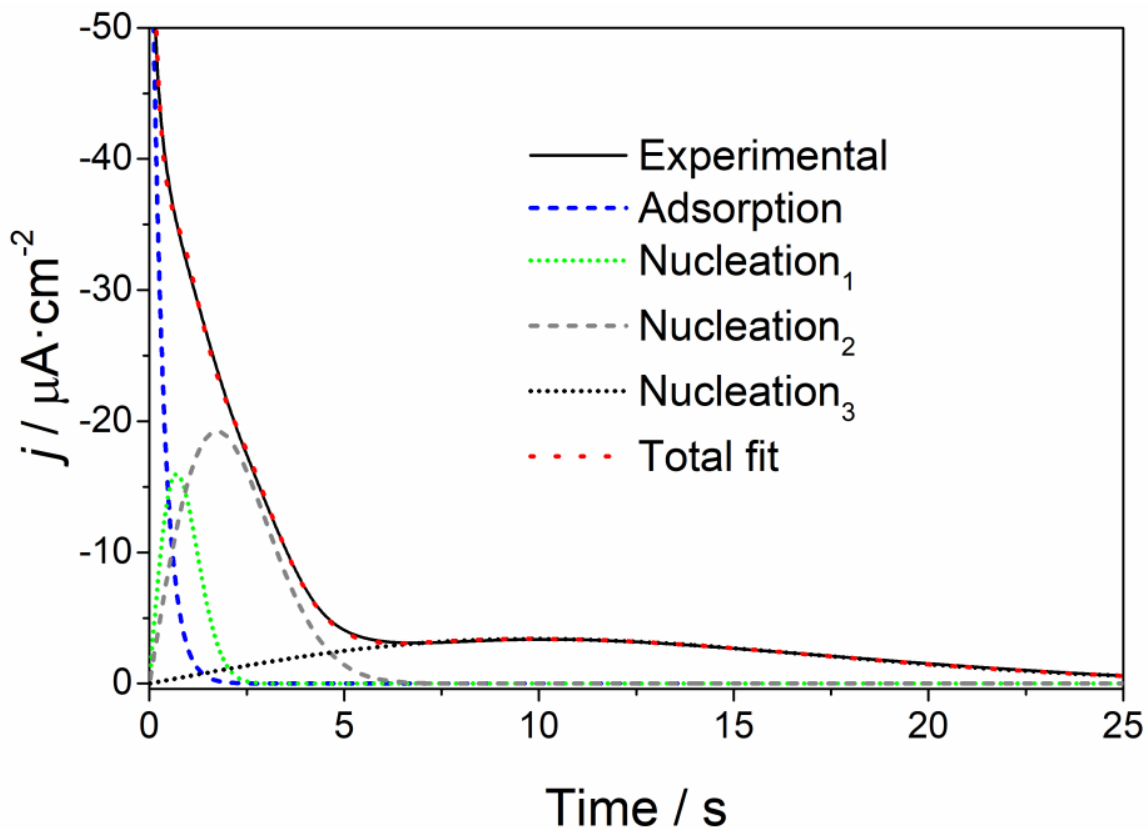

Figure S10. Using the $t_{\max }$ values outlined in Table S5 obtained from the derivative of each current transient, the total fitted current for any transient may be obtained as a summation of the adsorption and three nucleation components using exponential decay and Gaussian-type functions, respectively. In this example, the current transient fitted (dotted red line) is that obtained experimentally (solid black line) with a $\Gamma_{\mathrm{ZnPor}}$ of $1.94 \mathrm{nmol} \cdot \mathrm{cm}^{-2}, \Delta_{\mathrm{o}}^{\mathrm{w}} \phi_{\text {initial }}$ of $+0.25 \mathrm{~V}$ for $30 \mathrm{~s}$, and $\Delta_{\mathrm{o}}^{\mathrm{w}} \phi_{\text {final }}$ of $-0.25 \mathrm{~V}$. 

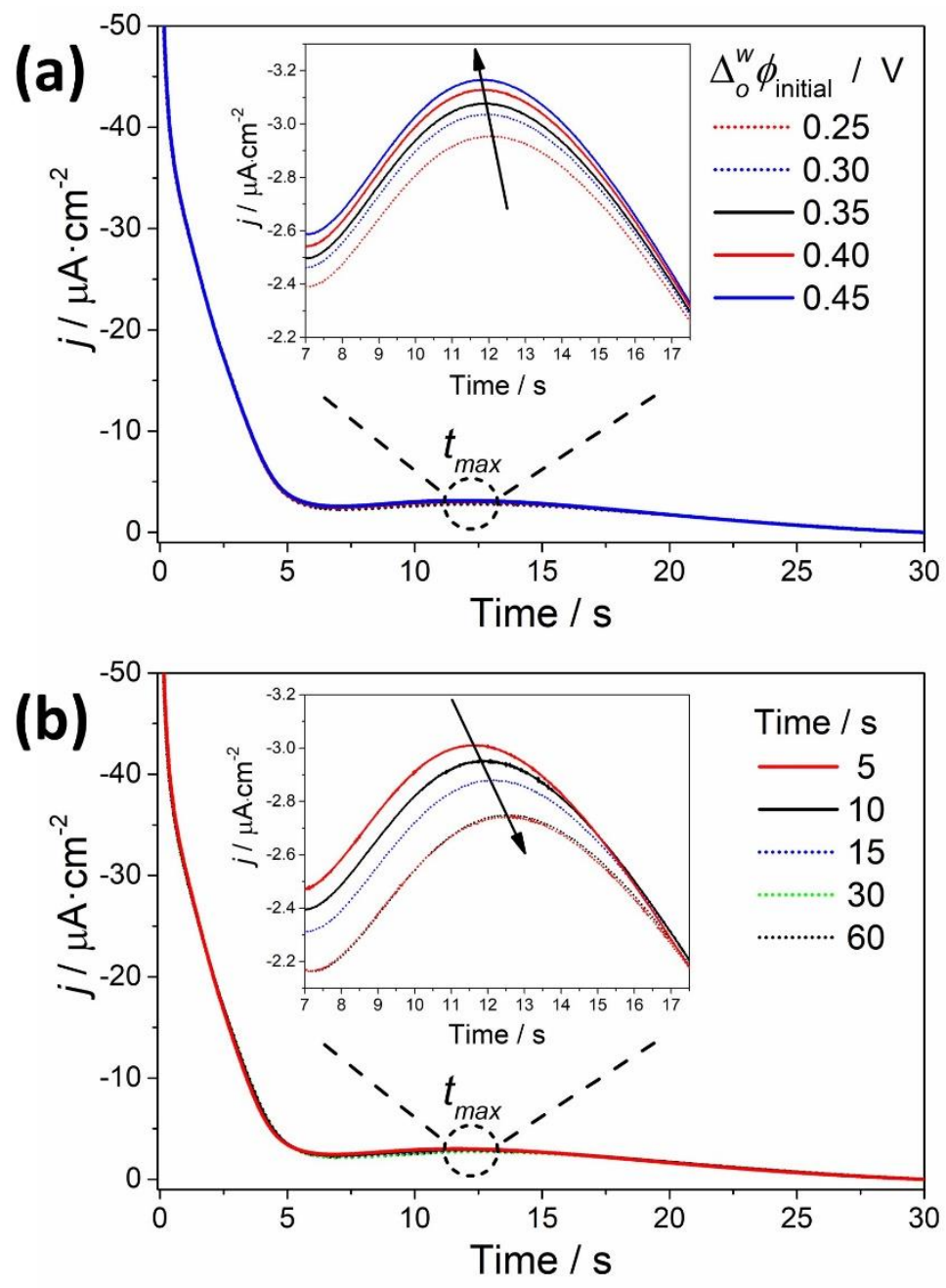

Figure S11. (a) Current transients probing the influence of $\Delta_{\mathrm{o}}^{\mathrm{w}} \phi_{\text {initial }}$ were obtained at a constant $t_{\text {initital }}$ of $30 \mathrm{~s}, \Gamma_{\mathrm{ZnPor}}$ of $4.19 \mathrm{nmol} \cdot \mathrm{cm}^{-2}$, and $\Delta_{\mathrm{o}}^{\mathrm{w}} \phi_{\text {final }}$ of $-0.25 \mathrm{~V}$. (b) Current transients probing the influence of $t_{\text {initial }}$ were obtained at a constant $\Gamma_{\mathrm{ZnPor}}$ of $4.19 \mathrm{nmol} \cdot \mathrm{cm}^{-2}, \Delta_{\mathrm{o}}^{\mathrm{w}} \phi_{\text {initial }}$ of $+0.25 \mathrm{~V}$, and $\Delta_{\mathrm{o}}^{\mathrm{w}} \phi_{\text {final }}$ of $-0.25 \mathrm{~V}$. 


\section{Supporting References}

1 A. F. Molina-Osorio, D. Cheung, C. O’Dwyer, A. A. Stewart, M. Dossot, G. Herzog and M. D. Scanlon, J. Phys. Chem. C, 2020, 124, 6929-6937.

2 E. Smirnov, P. Peljo, M. D. Scanlon and H. H. Girault, Electrochim. Acta, 2016, 197, $362-373$.

3 S. Cherian and C. C. Wamser, J. Phys. Chem. B, 2000, 104, 3624-3629.

4 J. Cervera, M. A. Gilabert and J. A. Manzanares, Am. J. Phys., 2011, 79, 206-213. 


\title{
Reversible electrochemical ion intercalation at an electrified liquid|liquid interface functionalised with porphyrin nanostructures $\dagger$
}

Andrés F. Molina-Osorio, ${ }^{\mathrm{a}}{ }^{\mathrm{J}}$ osé A. Manzanares, ${ }^{\mathrm{b}}$ Alonso Gamero-Quijano ${ }^{\mathrm{a}}$ and Micheál D Scanlon ${ }^{*, a, c}$

\footnotetext{
a The Bernal Institute and Department of Chemical Sciences, School of Natural Sciences, University of Limerick (UL), Limerick V94 T9PX, Ireland. *E-mail: micheal.scanlon@ul.ie

${ }^{b}$ Department of Thermodynamics, Faculty of Physics, University of Valencia, c/Dr. Moliner, 50, E-46100 Burjasot, Spain.

${ }^{\mathrm{c}}$ Advanced Materials and Bioengineering (AMBER) Centre, Ireland.

$\uparrow$ Electronic Supplementary Information (ESI) available: [Supplementary experimental section, electrochemical results and modelling theory].
}

\begin{abstract}
Ion intercalation into solid matrices influences the performance of key components in most energy storage devices (Li-ion batteries, supercapacitors, fuel cells, etc.). Electrochemical methods provide key information on the thermodynamics and kinetics of these ion transfer processes but are restricted to matrices supported on electronically conductive substrates. In this article, the electrified liquid|liquid interface is introduced as an ideal platform to probe the thermodynamics and kinetics of reversible ion intercalation with non-electronically active matrices. Zinc(II) meso-tetrakis(4-carboxyphenyl)porphyrins were self-assembled into floating films of ordered nanostructures at the water| $\alpha, \alpha, \alpha$-trifluorotoluene interface. Electrochemically polarising the aqueous phase negatively with respect to the organic phase lead to organic ammonium cations intercalating into the zinc porphyrin nanostructures by binding to anionic carboxyl sites and displacing protons through ion exchange at neutral carboxyl sites. The cyclic voltammograms suggested a positive cooperativity mechanism for ion intercalation linked with structural rearrangements of the porphyrins within the nanostructures, and were modelled using a Frumkin isotherm. The model also provided a robust understanding of the dependence of the voltammetry on the $\mathrm{pH}$ and organic electrolyte concentration. Kinetic analysis was performed using potential step chronoamperometry, with the current transients composed of "adsorption" and nucleation components. The latter were
\end{abstract}


associated with domains within the nanostructures where, due to structural rearrangements, ion binding and exchange took place faster. This work opens opportunities to study the thermodynamics and kinetics of purely ionic ion intercalation reactions (not induced by redox reactions) in floating solid matrices using any desired electrochemical method.

\section{Introduction}

Charge transfer reactions at electrified interfaces critically influence the performance of devices with energy-related applications. ${ }^{1,2}$ The continuous development of sustainable technologies relies on precise analysis of the thermodynamics and kinetics underlying the charge transfer reactions involved. ${ }^{3}$ Of the different charge transfer phenomena, a molecular scale understanding of electron transfer across solid-liquid interfaces is now accessible. ${ }^{4}$ However, such in-depth analysis remains a challenge for interfacial ion transfer between two different phases.

Ion transfer reactions are of major importance in many energy storage technologies. A key step during cycling of lithium ion (Li-ion) batteries is the reversible ion transfer, termed intercalation and de-intercalation, of $\mathrm{Li}^{+}$between the electrolyte and cathode material. ${ }^{4}$ For supercapacitor applications, conducting polymers exhibit pseudocapacitance through doping and de-doping of the polymer backbone, which results in intercalation and de-intercalation of electrolyte ions within the polymer film to maintain charge neutrality. ${ }^{5}$ Ion exchange membranes (IEMs) are used in combination with electrochemical potential gradients to drive intercalation and de-intercalation, typically through an ion exchange mechanism, for the selective transport of certain ionic components between phases with different chemical compositions. ${ }^{6,7}$ Such IEMs are critical to the operation of fuel cells, ${ }^{8}$ electrolysers,${ }^{9}$ redox flow batteries, ${ }^{10}$ reverse electrodialysers, ${ }^{11}$ and microbial fuel cells. ${ }^{12}$

Electrochemical methods are particularly well suited to provide key information on the thermodynamics and kinetics of these ion transfer processes. However, their use is restricted to matrices supported on electronically conductive substrates, as is the case for Li-ion battery cathodes ${ }^{13-15}$ or conducting polymer films, ${ }^{16,17}$ where reversible ion transfer is coupled with a redox reaction. Analysis of ion transfer reactions in non-electronically conductive solids, such as IEMs, is more difficult to study, given that ion transfer proceeds through an ion exchange mechanism without a flow of electrons. ${ }^{18,19}$ In this sense, the interface between two immiscible electrolyte solutions (ITIES), ${ }^{20,21}$ such as that formed between water and suitable hydrophobic 
organic solvents, offers a perfect platform to study the thermodynamics and kinetics of ion transfer reactions involving non-electronically conductive solids.

In the absence of redox active species, polarisation of the ITIES induces the movement of aqueous and organic electrolyte ions to, and across, the liquid|liquid interface. ${ }^{22,23}$ Thus, a film of solid materials floating at the interface will experience a markedly different ionic environment and interfacial aqueous $\mathrm{pH}$ depending on the applied interfacial Galvani potential difference $\left(\Delta_{\mathrm{o}}^{\mathrm{w}} \phi / \mathrm{V}\right)$. In this article, we demonstrate that interaction of charged or easily ionisable functional groups within the floating solid materials with the aqueous and organic electrolyte ions gives rise to capacitive currents associated with purely ionic reactions. Previous studies involving functionalisation of the ITIES with non-conductive inorganic materials, such as zeolites ${ }^{24-26}$ or silica, ${ }^{27-31}$ were primarily motivated to develop sensor technology through charge- or size-selective ion transfer across the interface. Dryfe and co-works have reported electrochemically driven ion exchange involving zeolites floating at an ITIES, but no in-depth thermodynamic or kinetic analysis was performed. ${ }^{32-34}$

Herein, we study the thermodynamics and kinetics of electrochemically reversible ion intercalation at a floating film of self-assembled zinc(II) 5,10,15,20-(tetra-4carboxyphenyl)porphyrin interfacial nanostructures (ZnPor-INs). The floating film effectively acts as an ion penetrable third phase separating the aqueous and organic phases. Cyclic voltammetry in the presence of the ZnPor-IN film was amenable to thermodynamic analysis using the Frumkin isotherm ${ }^{13-15}$ and kinetic analysis was performed using potential step chronoamperometry. ${ }^{35}$ These purely ionic voltammetric and current transient responses were analogous to those commonly associated with reversible ion intercalation coupled with electron transfer, as described for Li-ion battery cathodes and conducting polymer films. The distinctive shape of the cyclic voltammograms also indicated an electrochemically driven rearrangement of the porphyrin nanostructure at the liquid|liquid interface. These observations, connected with the presence of easily ionisable carboxyl groups within the ZnPor-IN film, were rationalised in terms of electrochemically-driven binding of organic cations at anionic carboxyl $\left(-\mathrm{COO}^{-}\right)$ groups and ion exchange of organic cations at neutral carboxyl $(-\mathrm{COOH})$ groups in which protons are displaced. This concept is schematically shown in Scheme 1. 


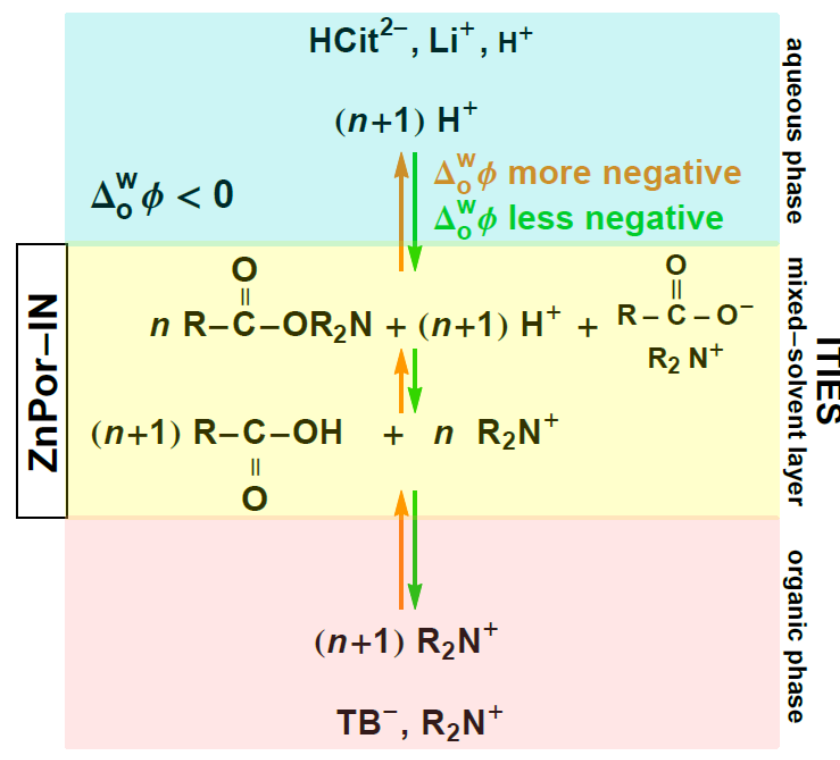

Scheme 1. Electrochemically-driven shifts in the chemical equilibria involving carboxyl groups in the ZnPor-IN film, aqueous protons $\mathrm{H}^{+}$, and organic bulky ammonium cations $\mathrm{R}_{2} \mathrm{~N}^{+}$. The peak currents in the CVs roughly correspond to negative $\Delta_{\mathrm{o}}^{\mathrm{w}} \phi$ such that the fractions of groups in $-\mathrm{COOH}$ and $-\mathrm{COOR}_{2} \mathrm{~N}$ forms are both large and similar to each other. As $\Delta_{\mathrm{o}}^{\mathrm{w}} \phi$ is scanned more negatively from the peak, $\mathrm{R}_{2} \mathrm{~N}^{+}$ions enter the film from the organic phase and the same amount of $\mathrm{H}^{+}$ions are transferred from the film to the aqueous phase. Two chemical equilibria are shifted: the acid dissociation of $-\mathrm{COOH}$ and the exchange between bound $\mathrm{H}^{+}$and bound $\mathrm{R}_{2} \mathrm{~N}^{+}$. For every $-\mathrm{COOH}$ group involved in the acid dissociation, a larger number $n$ are involved in the ion exchange reaction. When $-\mathrm{COOH}$ dissociates, the proton $\mathrm{H}^{+}$is displaced to the aqueous phase by a $\mathrm{R}_{2} \mathrm{~N}^{+}$ion that enters the film to compensate for the charge of $-\mathrm{COO}^{-}$ . Should $\Delta_{\mathrm{o}}^{\mathrm{w}} \phi$ be scanned to even more negative values, the $\mathrm{R}_{2} \mathrm{~N}^{+}$concentration in the film would be so that all carboxyl groups would be in $-\mathrm{COOR}_{2} \mathrm{~N}$ form and some $\mathrm{HCit}^{2-}$ ions would enter the film to compensate for the charge of the $\mathrm{R}_{2} \mathrm{~N}^{+}$ions. Conversely, as $\Delta_{\mathrm{o}}^{\mathrm{w}} \phi$ is scanned from the peak to less negative values, $\mathrm{H}^{+}$ions enter the film from the aqueous phase and $\mathrm{R}_{2} \mathrm{~N}^{+}$ ions are transferred from the film to the organic phase. Should $\Delta_{\mathrm{o}}^{\mathrm{w}} \phi$ be scanned to moderately positive values, $\mathrm{Li}^{+}$ions would enter the film to compensate for the charge of $-\mathrm{COO}^{-}$. For full clarity, Scheme S1 in the Electronic Supporting Information ( $†$ ESI) provides another more detailed overview of the electrochemically-driven reversible ion intercalation process.

\section{Results and Discussion}

\subsection{Electrochemistry of the floating film of ZnPor-INs at the ITIES}

The film of ZnPor-INs formed at the ITIES between a lithium citrate ( $\left.\mathrm{Li}_{2} \mathrm{HCit}\right)$ buffered aqueous solution and an organic solution of bis(triphenylphosphoranylidene)ammonium tetrakis(pentafluorophenyl)borate $\left(\mathrm{R}_{2} \mathrm{NTB}\right)$ in TFT (see cell configuration in Scheme 2). An image of the film is shown in Figure S1 (Electronic Supporting Information, $†$ ESI). The molecular liquid|liquid boundary is located within the ZnPor-IN film, which is considered as a third phase separating the aqueous and organic solutions and a mixed-solvent layer. 
Reference

electrode

$\mathrm{Ag} \mid \mathrm{AgCl}$

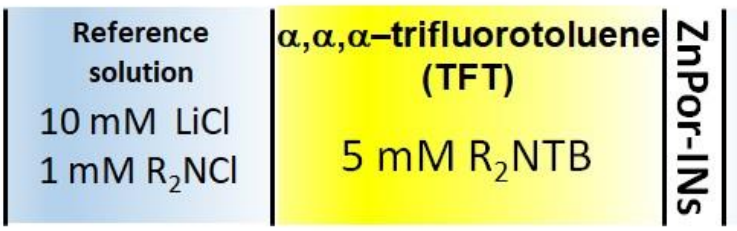

Reference

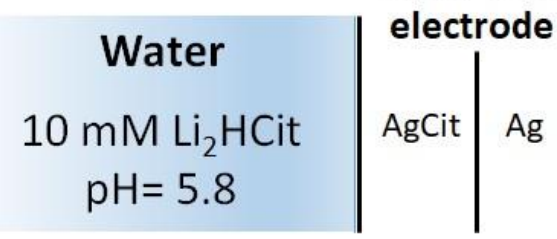

Scheme 2. The general configuration of the four-electrode cell used for electrochemical measurements at the ZnPor-IN functionalised liquid|liquid interface. The organic phase was $5 \mathrm{mM}$ bis(triphenylphosphoranylidene)ammonium tetrakis(pentafluorophenyl)borate $\left(\mathrm{R}_{2} \mathrm{NTB}\right)$ in $\alpha, \alpha, \alpha$-trifluorotoluene (TFT). The aqueous phase was lithium citrate $\left(\mathrm{Li}_{2} \mathrm{HCit}\right)$ at pH 5.8 (unless otherwise stated). The ZnPor-INs were prepared from solutions of ZnPor at concentrations in the range of 10 to $100 \mu \mathrm{M}$ in contact with the TFT for $30 \mathrm{~min}$, as described in the Experimental Section of the $\dagger$ ESI.

Cyclic voltammograms (CVs) were obtained with a four-electrode electrochemical cell, using the configuration outlined in Scheme 2, both in the absence and presence of the floating ZnPor-IN film at a scan rate of $1 \mathrm{mV} \cdot \mathrm{s}^{-1}$. The interfacial concentration $\Gamma_{\text {ZnPor }}$ of ZnPor in the film was determined spectroscopically (Figure S2) as described in the Experimental Section $(†$ ESI) prior to all electrochemical measurements. The control CV in the absence of film was essentially featureless (dashed line, Figure 1a). The only signal observed upon varying the applied interfacial Galvani potential difference $\Delta_{\mathrm{o}}^{\mathrm{w}} \phi$ was due to the aqueous background electrolyte citrate anions transferring to the organic phase at the negative extreme of the polarisable potential window (PPW). By contrast, in the presence of the ZnPor-IN film, several electrochemical signals were observed at negative potentials (solid line, Figure 1a). The absence of redox active species in either phase means that the electrochemical signals in the presence of the ZnPor-IN film were purely ionic in nature. 

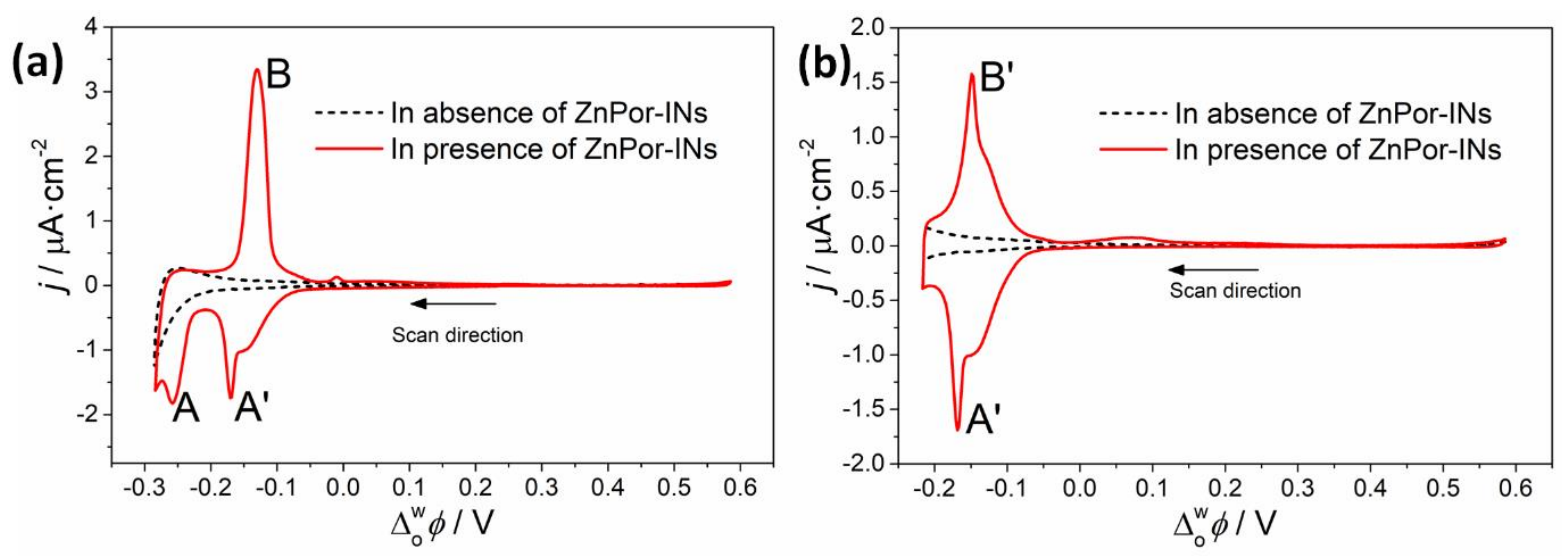

Figure 1. Cyclic voltammetry in the absence (dashed lines) and presence (solid lines) of the ZnPor-IN film at the ITIES. The electrochemical configuration of the four-electrode electrochemical cell was as described in Scheme 2. The influence of systematically varying the lower vertex potential on the CVs was investigated by switching the potential on the negative scan at (a) $-0.285 \mathrm{~V}$ and (b) $-0.215 \mathrm{~V}$. The scan rate was $1 \mathrm{mV} \cdot \mathrm{s}^{-1}$ and the start potential was $0.250 \mathrm{~V}$. The interfacial concentration of $\mathrm{ZnPor}$ was $\Gamma_{\mathrm{ZnPor}}=0.88 \mathrm{nmol} \cdot \mathrm{cm}^{-2}$.

The relationship between the two electrochemical signals on the negative scan with negative currents (labelled A and A' in Figure 1a) and the signal on the positive scan with a positive current (labelled B in Figure 1a) was investigated by systematically varying the lower vertex potential (Figure 1b). Switching the potential on the negative scan immediately after the appearance of peak A' lead to a major reduction in the magnitude of the electrochemical signal on the positive scan. Labelled B', this smaller peak was of a near identical shape and magnitude to A' (Figure 1b). Therefore, the electrochemical process giving rise to peak A' was the reverse of that giving rise to peak B'. Indeed, the ratio of the magnitude of the charge for each peak was $Q_{\mathrm{A}^{\prime}} / Q_{\mathrm{B}}, \approx 1$ for $\mathrm{CVs}$ obtained at scan rates ranging from 5 to $50 \mathrm{mV} \cdot \mathrm{s}^{-1}$ (Figure $\mathrm{S} 3$ and Table S1). Furthermore, as peaks A and A' were related with peak B, both A and A' were associated with the same species.

The peak-to-peak separation between peaks A' and B' was $5.9 \mathrm{mV}$ at a scan rate of $1 \mathrm{mV} \cdot \mathrm{s}^{-}$ ${ }^{1}$ (Table S1). Additionally, the peak current $i_{\mathrm{p}}$ for peaks A' and B' varied linearly with the scan rate (Figure S3). Thus, the kinetics of these electrochemical signals were controlled by surface processes in the presence of the ZnPor-IN film. In the electrochemical configuration described in Scheme 2, no ionic species were present capable of undergoing ion transfer across the ITIES within the PPW. Therefore, the electrochemical signals observed in the presence of the ZnPorIN film were due to a diffusion-less process, i.e., adsorption and capacitive phenomena, and not Faradaic ion transfer. 
Self-assembly of the floating ZnPor-IN film at the ITIES was optimal at $\mathrm{pH} 5.8 .{ }^{36}$ As this $\mathrm{pH}$ matched the $\mathrm{p} K_{\mathrm{a}}$ of the ZnPor carboxyl groups, statistically $50 \%$ of them were deprotonated and charged in the bulk aqueous solution. Differential capacitance measurements are a macroscopic view of the charge distribution of the back-to-back diffusion layer or mixed solvent region. ${ }^{23,37-41}$ The capacitance minimum appears at the potential of zero charge (PZC). Figure 2 a shows differential capacitance measurements obtained in the presence and absence of the ZnPor-IN film. Capacitance values were calculated from the imaginary part of the impedance at a frequency of $80 \mathrm{~Hz}$. This frequency was selected in order to suppress Faradaic contributions due to ion transfer within the PPW. This effect was demonstrated in Figure S4a where the Faradaic current due to ion transfer of tetraethylammonium cations across a bare water|TFT interface was entirely filtered out at $80 \mathrm{~Hz}$. A shift in the PZC of $+100 \mathrm{mV}$ was observed in the presence of the ZnPor-IN film (Figure 2a). This shift confirms a negative excess charge at the interface due to presence of deprotonated carboxyl groups at this $\mathrm{pH}^{36}$ The peak at $-0.15 \mathrm{~V}$ was seen at all frequencies across a range from 5 to $80 \mathrm{~Hz}$ (Figure S4b), further confirming that these electrochemical signals in the presence of the ZnPor-IN film were associated with adsorption and capacitive processes.

The electrochemical signals in Figure 1 appear at negative $\Delta_{\mathrm{o}}^{\mathrm{w}} \phi$, suggesting the binding of $\mathrm{R}_{2} \mathrm{~N}^{+}$cations to the carboxyl groups of the ZnPor. These groups may exist in three states: $\mathrm{COO}^{-},-\mathrm{COOH}$ and $-\mathrm{COOR}_{2} \mathrm{~N}$. Their concentrations $c_{\mathrm{COO}^{-}}, c_{\mathrm{COOH}}$ and $c_{\mathrm{COOR}_{2} \mathrm{~N}}$ can vary with the bulk aqueous $\mathrm{pH}$, the applied $\Delta_{\mathrm{o}}^{\mathrm{w}} \phi$, as well as with the $\mathrm{Li}_{2} \mathrm{HCit}$ and $\mathrm{R}_{2} \mathrm{NTB}$ concentrations. On the contrary, the total concentration

$c_{\mathrm{T}, \mathrm{COO}}=c_{\mathrm{COO}^{-}}+c_{\mathrm{COOH}}+c_{\mathrm{COOR}_{2} \mathrm{~N}}$

is a constant related to $\Gamma_{\mathrm{ZnPor}}$. To corroborate the relation with $c_{\mathrm{T}, \mathrm{COO}}, \Gamma_{\mathrm{ZnPor}}$ was systematically varied by increasing the bulk aqueous ZnPor concentration during the ZnPor-IN film selfassembly. A linear increase in the charge for each peak, $Q_{\mathrm{A}}$, and $Q_{\mathrm{B}}$, was observed (Figure $2 \mathrm{~b}$ ). This linear increase was obtained despite $\Gamma_{\mathrm{ZnPor}}$ far exceeding that expected for an interfacial monolayer of ZnPor (estimated as $0.095 \mathrm{nmol} \cdot \mathrm{cm}^{-2}$, see Figure S5). Thus, the electrochemical signals were due to processes involving carboxyl groups within the ZnPor-IN film, and not only at surface sites facing the aqueous and organic electrolytes. 

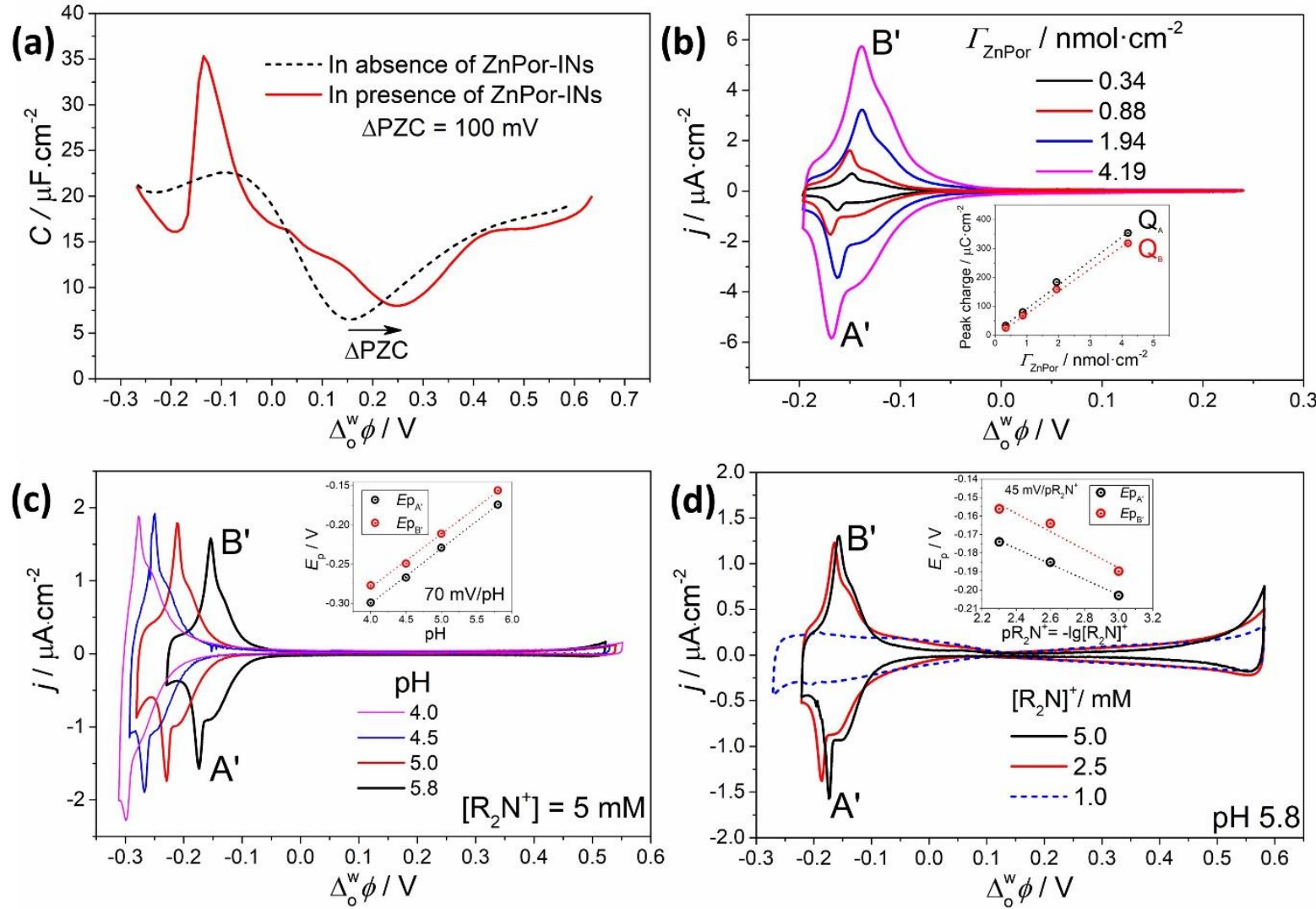

Figure 2. (a) Monitoring the potential of zero charge (PZC) by obtaining differential capacitance curves in the absence (dashed line) and presence (solid line) of the ZnPor-IN film. The capacitances were measured by AC voltammetry using a frequency of $80 \mathrm{~Hz}$. The start potential was $-0.3 \mathrm{~V}$ and $\Gamma_{\mathrm{ZnPor}}$ determined spectroscopically as $0.34 \mathrm{nmol} \cdot \mathrm{cm}^{-2}$. (b) Cyclic voltammetry in the presence of ZnPor-IN films of increasing $\Gamma_{\mathrm{ZnPor}}$. The scan rate used was 1 $\mathrm{mV} \cdot \mathrm{s}^{-1}$. Inset: dependence of the peak charge $Q$ on $\Gamma_{\mathrm{ZnPor}}$. The effect of varying (c) the $\mathrm{pH}$ and (d) $\mathrm{R}_{2} \mathrm{NTB}$ concentration on the electrochemical response was investigated in the presence of the ZnPor-IN film. The scan rate used was $5 \mathrm{mV} \cdot \mathrm{s}^{-1}$ and $\Gamma_{\mathrm{ZnPor}}$ was $0.34 \mathrm{nmol} \cdot \mathrm{cm}^{-2}$. Insets in (c) and (d): the relationships between peak potential $E_{\mathrm{p}}$ and $\mathrm{pH}$ or $\mathrm{pR}_{2} \mathrm{~N}^{+}\left(=-\lg \left[\mathrm{R}_{2} \mathrm{~N}^{+}\right]\right)$, respectively. For clarity, a zoomed in version of the $\mathrm{CV}$ obtained with $\left[\mathrm{R}_{2} \mathrm{~N}^{+}\right]=1 \mathrm{mM}$ (dashed blue line) in (d) is shown in Figure S6.

To probe the effects of the bulk aqueous $\mathrm{pH}$ and $\mathrm{R}_{2} \mathrm{~N}^{+}$concentration, both were varied independently (Figures 2c and d). As we described previously, ${ }^{36}$ the ZnPor-INs were stabilised by cooperative hydrogen bonding. Thus, $\mathrm{pH}$ conditions more alkali than the carboxyl groups $\mathrm{p} K_{\mathrm{a}}$ of 5.8 were ruled out as the ZnPor-IN film would destabilise and dissolve. The peak potentials for peaks $\mathrm{A}^{\prime}\left(E_{\mathrm{pA}}\right)$ and $\mathrm{B}^{\prime}\left(E_{\mathrm{pB}}\right)$ were found to depend on both the $\mathrm{pH}$ and $\mathrm{pR}_{2} \mathrm{~N}^{+}$ (where $\mathrm{pR}_{2} \mathrm{~N}^{+}=-\lg \left[\mathrm{R}_{2} \mathrm{~N}^{+}\right]$), confirming their role in the electrochemical processes occurring at the ZnPor-IN functionalised ITIES. Uniform shifts of $-70 \mathrm{mV} / \mathrm{pH}$ and $+45 \mathrm{mV} / \mathrm{pR}_{2} \mathrm{~N}^{+}$were observed for both $E_{\mathrm{pA}^{\prime}}$ and $E_{\mathrm{pB}}$ ' (insets, Figures $2 \mathrm{c}$ and d). The magnitude of peaks $\mathrm{A}^{\prime}$ and B' 
decreased drastically at the lowest $\mathrm{R}_{2} \mathrm{~N}^{+}$concentration investigated $\left(\left[\mathrm{R}_{2} \mathrm{~N}^{+}\right]=1 \mathrm{mM}\right)$, Figure 2d and Figure S6.

The influence of the nature of the organic anion on the electrochemical response was also investigated. Citrate anions are sensitive to $\mathrm{pH}$, with $\mathrm{p} K_{\mathrm{a}}$ 's at $3.13,4.76$ and 6.40, respectively. ${ }^{42}$ Thus, as the $\mathrm{pH}$ at the ITIES varies as a function of applied $\Delta_{\mathrm{o}}^{\mathrm{w}} \phi$, a $\mathrm{pH}$ insensitive anion was chosen for comparison by replacing $\mathrm{Li}_{2} \mathrm{HCit}$ with $\mathrm{LiCl}$. As shown in Figure S7, the nature of the anion had minimal effect on the electrochemical response. A near identical $\mathrm{CV}$ shape was observed and the trend in the shifts of $E_{\mathrm{pA}}$, and $E_{\mathrm{pB}}$ ' with $\mathrm{pH}$ replicated.

Peaks $A^{\prime}$ and $B^{\prime}$ in the CVs in Figures 1 and $2 b-d$ are formed by the superposition of a narrow peak and a broad peak. Narrow "adsorption" peaks in CVs are considered to indicate positive cooperativity, i.e., every adsorption event is facilitated by the occurrence of a previous adsorption event. In this regard, for fundamental thermodynamic reasons, the CVs can be described using the Frumkin isotherm. ${ }^{15}$ For peak B', we attribute the broad shoulders to binding of $\mathrm{R}_{2} \mathrm{~N}^{+}$at $-\mathrm{COO}^{-}$groups and ion exchange of $\mathrm{R}_{2} \mathrm{~N}^{+}$with $-\mathrm{COOH}$ groups (in which protons are displaced) near the $\mathrm{IN} \mid \mathrm{O}$ interface as $\mathrm{R}_{2} \mathrm{~N}^{+}$flows from the organic phase into the ZnPor-IN film. The sharp peak of $\mathrm{B}^{\prime}$ is attributed to binding and ion exchange of $\mathrm{R}_{2} \mathrm{~N}^{+}$at $\mathrm{COO}^{-}$and $-\mathrm{COOH}$ groups, respectively, deeper inside the ZnPor-IN film. The second electrochemical signal on the negative scan, peak A, is attributed to a second binding and ion exchange event inside the ZnPor-IN film requiring more electrochemical driving force (see Figure 1a). As detailed in the following section, all peaks are capacitive in nature and resemble "adsorption" due to a saturation limit to the concentration of $-\mathrm{COOR}_{2} \mathrm{~N}$ species that form by binding and ion exchange as $\Delta_{\mathrm{o}}^{\mathrm{w}} \phi$ is scanned negatively.

\subsection{Modelling of electrochemically-driven reversible ion intercalation in the presence of the ZnPor-IN film}

The modelling aims to clarify: (i) the capacitive nature of the electrochemical signals at negative $\Delta_{\mathrm{o}}^{\mathrm{w}} \phi$ in the presence of the ZnPor-IN film, (ii) the trends in the shifts of the peak potentials as a function of the bulk aqueous $\mathrm{pH}$ and $\mathrm{R}_{2} \mathrm{~N}^{+}$concentration, and (iii) the characteristic $\mathrm{CV}$ shapes indicative of positive cooperativity. For the electrolyte concentrations used in the electrochemical experiments, the film thickness, $L^{\mathbb{I N}} \approx 100 \mathrm{~nm},{ }^{36}$ is much larger than the aqueous and organic Debye lengths and the molecular liquid|liquid boundary is located within the ZnPor-IN film. Thus, as the film is considered as an intermediate phase (IN) 
separating the aqueous (w) and organic (o) solutions. From the point of view of ion solvation, it is a mixed-solvent layer, disliked by both aqueous ions and organic ions.

Within the PPW, no ions can transfer across the ITIES and the ZnPor-IN film behaves as a capacitor (Scheme 3 ). When $\Delta_{\mathrm{o}}^{\mathrm{w}} \phi$ is scanned progressively more negative, the $\mathrm{R}_{2} \mathrm{~N}^{+}$ions are "pushed" into the film, but cannot transfer to the aqueous phase. Then, a few $-\mathrm{COOH}$ groups are forced to dissociate, and many more transform into $-\mathrm{COOR}_{2} \mathrm{~N}$. In both cases, the released $\mathrm{H}^{+}$ions are "pulled" into the aqueous phase. The charge of the anionic carboxyl groups $-\mathrm{COO}^{-}$ is mostly compensated by $\mathrm{R}_{2} \mathrm{~N}^{+}$, which are the majority ions in the film; $\mathrm{HCit}^{2-}$ and $\mathrm{Li}^{+}$are present only when $\Delta_{\mathrm{o}}^{\mathrm{w}} \phi$ is very different to that around the peaks in Figure $2 \mathrm{~b}$. To understand the behaviour of the film as a capacitor, carboxyl groups in $-\mathrm{COOH}$ form are taken as a reference corresponding to absence of charges in the capacitor "plates". The positive plate accumulates charge in the form of free and bound $\mathrm{R}_{2} \mathrm{~N}^{+}$. That is, the charge $q^{\mathrm{o}}$ in this positive plate is basically proportional to $c_{\mathrm{COOR}_{2} \mathrm{~N}}+c_{\mathrm{R}_{2} \mathrm{~N}}^{\mathrm{IN}}$. The negative plate has a charge $q^{\mathrm{W}}<0$ which is a measure of the reduction in the amount of $-\mathrm{COOH}$ groups, and hence proportional to $c_{\mathrm{T}, \mathrm{COO}}-c_{\mathrm{COOH}}$. As $\Delta_{\mathrm{O}}^{\mathrm{w}} \phi$ is made more negative, $q^{\mathrm{o}}=-q^{\mathrm{w}}>0$ increases, but remains of the order of $c_{\mathrm{T}, \mathrm{COO}}$. The unfavourable solvation in this mixed-solvent layer bounds the free ion concentrations $c_{\mathrm{R}_{2} \mathrm{~N}}^{\mathrm{IN}}$ and $c_{\mathrm{HCit}}^{\mathrm{IN}}$ to relatively small values, even for the most negative $\Delta_{\mathrm{o}}^{\mathrm{w}} \phi$.

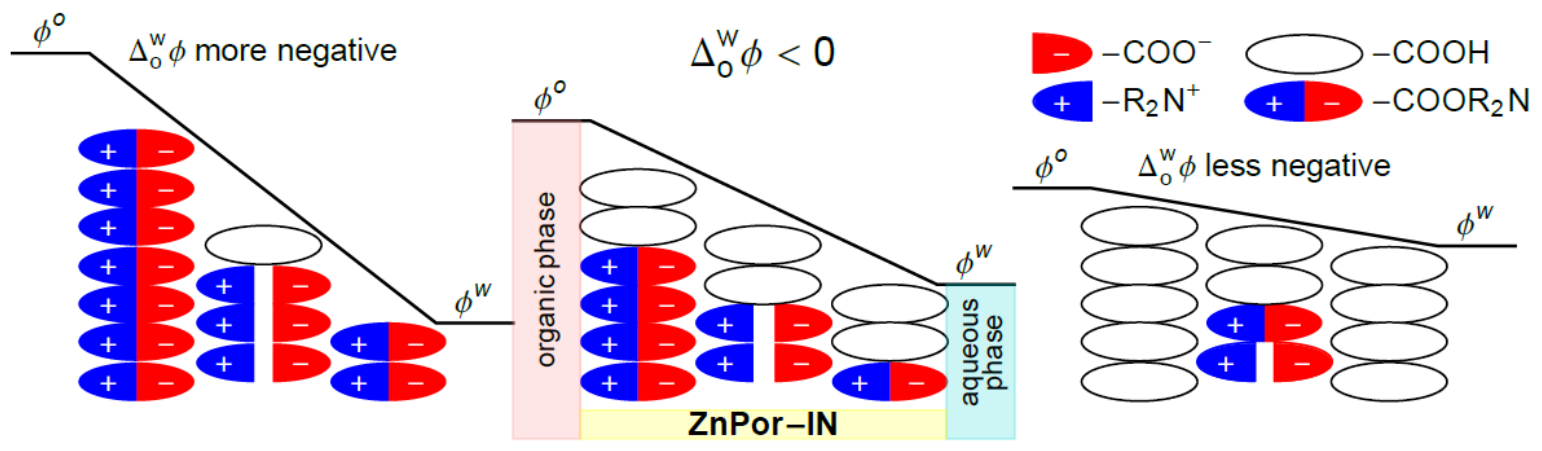

Scheme 3. The ZnPor-IN functionalised liquid|liquid interface behaves as a capacitor. Carboxyl groups in $-\mathrm{COOH}$ form are taken as a reference corresponding to absence of charges in the capacitor "plates". When $\Delta_{\mathrm{o}}^{\mathrm{w}} \phi$ is scanned progressively negative, the $\mathrm{R}_{2} \mathrm{~N}^{+}$ions are "pushed" into the film, a few - $\mathrm{COOH}$ groups are forced to dissociate, and many more transform into $-\mathrm{COOR}_{2} \mathrm{~N}$. The released $\mathrm{H}^{+}$ions are "pulled" into the aqueous phase.

The concentrations of the ionic species $\mathrm{R}_{2} \mathrm{~N}^{+}, \mathrm{TB}^{-}, \mathrm{HCit}^{2-}, \mathrm{H}^{+}$and $\mathrm{Li}^{+}$in the film (phase IN) must satisfy the local electroneutrality condition 
$c_{\mathrm{COO}^{-}}+2 c_{\mathrm{HCit}}^{\mathrm{IN}}+c_{\mathrm{TB}}^{\mathrm{IN}}=c_{\mathrm{R}_{2} \mathrm{~N}}^{\mathrm{IN}}+c_{\mathrm{Li}}^{\mathrm{IN}}+c_{\mathrm{H}}^{\mathrm{IN}}$

The local electroneutrality condition can also be presented as $q^{\mathrm{o}}+q^{\mathrm{w}}=0$ where

$q^{\mathrm{o}}=F L^{\mathrm{IN}}\left(c_{\mathrm{COOR}_{2} \mathrm{~N}}+c_{\mathrm{R}_{2} \mathrm{~N}}^{\mathrm{IN}}-c_{\mathrm{TB}}^{\mathrm{IN}}\right)$

$-q^{\mathrm{W}}=F L^{\mathrm{IN}}\left(c_{\mathrm{T}, \mathrm{COO}}-c_{\mathrm{COOH}}+2 c_{\mathrm{HCit}}^{\mathrm{IN}}-c_{\mathrm{H}}^{\mathrm{IN}}-c_{\mathrm{Li}}^{\mathrm{IN}}\right)$

are the charge densities in the capacitor and $F$ is Faraday's constant. In the potential range $-0.25 \mathrm{~V}<\Delta_{\mathrm{o}}^{\mathrm{W}} \phi<-0.05 \mathrm{~V}$, the concentrations of $\mathrm{R}_{2} \mathrm{~N}^{+}, \mathrm{HCit}^{2-}$ and $-\mathrm{COO}^{-}, c_{\mathrm{R}_{2} \mathrm{~N}}^{\mathrm{IN}}, c_{\mathrm{HCit}}^{\mathrm{IN}}$ and $c_{\mathrm{COO}^{-}}^{\mathrm{IN}}$, are the dominant terms in Equation (2). For $\Delta_{\mathrm{o}}^{\mathrm{w}} \phi>-0.05 \mathrm{~V}$, the concentrations $c_{\mathrm{Li}}^{\mathrm{IN}}$ and $c_{\mathrm{TB}}^{\mathrm{IN}}$ of the $\mathrm{Li}^{+}$and $\mathrm{TB}^{-}$species may become significant. Although some species make a negligible contribution in Equation (2), we keep them all for the sake of generality. The electrical double layers at the o|IN and IN $\mid \mathrm{w}$ interfaces extend over a fraction of the film thickness $L^{\mathrm{IN}}$, and local electroneutrality does not hold there. However, the contributions of the associated interfacial capacitances are small compared to other effects described below and, therefore, can be neglected.

The concentrations of the ionic species in phase IN are different from those in their respective phases. In absolute value, the Gibbs energy of transfer of the organic ions from phase o to phase IN is intermediate to that from phase o to phase w. Similarly, in absolute value, the Gibbs energy of transfer of the aqueous ions from phase w to phase IN is intermediate to that from phase w to phase o. Therefore, the ions have no chemical preference to enter phase IN, and their chemical partition coefficients into this phase are significantly lower than unity, $P_{i} \ll$ 1. The applied potential $\Delta_{\mathrm{o}}^{\mathrm{w}} \phi$ also affects the distribution of the ions. The potential $\phi^{\mathrm{IN}}$ is usually intermediate between those phases w and o, so that $\Delta_{\mathrm{IN}}^{\mathrm{w}} \phi=\phi^{\mathrm{w}}-\phi^{\mathrm{IN}}, \Delta_{\mathrm{o}}^{\mathrm{IN}} \phi=\phi^{\mathrm{IN}}-$ $\phi^{\mathrm{o}}$ and

$\Delta_{\mathrm{o}}^{\mathrm{w}} \phi=\Delta_{\mathrm{IN}}^{\mathrm{w}} \phi+\Delta_{\mathrm{o}}^{\mathrm{IN}} \phi$

have the same sign. The distribution equilibrium of, e.g., the organic cation $\mathrm{R}_{2} \mathrm{~N}^{+}$between phases o and IN requires $c_{\mathrm{R}_{2} \mathrm{~N}}^{\mathrm{IN}}=c^{\mathrm{o}, \mathrm{b}} P_{\mathrm{R}_{2} \mathrm{~N}} \mathrm{e}^{-f \Delta_{\mathrm{o}}^{\mathrm{IN}} \phi}$ where $c^{\mathrm{o}, \mathrm{b}}=\left[\mathrm{R}_{2} \mathrm{~N}^{+}\right]$is its concentration in the bulk organic phase. Similar equations can be formulated for the other species, as described in detail in the $†$ ESI.

The evaluation of the concentrations $c_{\mathrm{COO}^{-}}, c_{\mathrm{COOH}}$ and $c_{\mathrm{COOR}_{2} \mathrm{~N}}$ in Equations (2)-(4) require the simultaneous consideration of the ionic distribution equilibria and the chemical equilibria. Since $c_{\mathrm{H}}^{\mathrm{IN}}=c_{\mathrm{H}}^{\mathrm{w}, \mathrm{b}} P_{\mathrm{H}} \mathrm{e}^{f \Delta_{\mathrm{IN}}^{\mathrm{W}} \phi}$, both the negative $\Delta_{\mathrm{o}}^{\mathrm{w}} \phi$ and the mixed-solvent nature of 
phase IN contribute to increase the interfacial $\mathrm{pH}$ with respect to the bulk aqueous $\mathrm{pH}, \mathrm{pH}^{\mathrm{IN}}$ $\mathrm{pH}=-\lg \left(c_{\mathrm{H}}^{\mathrm{IN}} / c_{\mathrm{H}}^{\mathrm{w}, \mathrm{b}}\right)>0$. Yet, if the latter is equal or lower than the $\mathrm{p} K_{\mathrm{a}}=5.8$ of the carboxyl groups, some of these groups can be protonated according to the equilibrium

$K_{\mathrm{a}}^{\mathrm{IN}} c^{\circ}=\frac{c_{\mathrm{H}}^{\mathrm{IN}} c_{\mathrm{COO}^{-}}}{c_{\mathrm{COOH}}}$

where $c^{\circ}=1 \mathrm{M}$ and $K_{\mathrm{a}}^{\mathrm{IN}}=K_{\mathrm{a}} P_{\mathrm{H}}$, see Equation (S32) in the $\dagger$ ESI. The abundant $\mathrm{R}_{2} \mathrm{~N}^{+}$cations in phase IN can displace the bound protons and form $-\mathrm{COOR}_{2} \mathrm{~N}$ groups. The equilibrium of the ion exchange reaction

$-\mathrm{COOH}(\mathrm{IN})+\mathrm{R}_{2} \mathrm{~N}^{+}(\mathrm{IN}) \rightleftarrows-\mathrm{COOR}_{2} \mathrm{~N}(\mathrm{IN})+\mathrm{H}^{+}(\mathrm{IN})$

requires

$K_{\mathrm{IE}}^{\mathrm{o}, \mathrm{IN}}=\frac{c_{\mathrm{H}}^{\mathrm{IN}} c_{\mathrm{COOR}_{2} \mathrm{~N}}}{c_{\mathrm{R}_{2} \mathrm{~N}}^{\mathrm{IN}} c_{\mathrm{COOH}}}$

where $K_{\mathrm{IE}}^{\mathrm{o}, \mathrm{IN}}$ is the equilibrium constant. From Equations (1), (6) and (8), the fraction of charged carboxyl groups is

$\frac{c_{\mathrm{COO}^{-}}}{c_{\mathrm{T}, \mathrm{COO}}}=\frac{K_{\mathrm{a}}^{\mathrm{IN}} c^{\circ}}{K_{\mathrm{a}}^{\mathrm{IN}} c^{\circ}+c_{\mathrm{H}}^{\mathrm{IN}}+K_{\mathrm{IE}}^{\circ, \mathrm{IN}} c_{\mathrm{R}_{2} \mathrm{~N}}^{\mathrm{IN}}}$.

Substituting $c_{\mathrm{COO}^{-}}$from Equation (9) into Equation (2), and using the conditions of distribution equilibria of the ionic species, the potential drop $\Delta_{\mathrm{IN}}^{\mathrm{W}} \phi$ can be determined, see Equation (S17) in the $\dagger$ ESI. Hence, the ionic concentrations and $q^{\mathrm{o}}$ are known as functions of $\Delta_{\mathrm{o}}^{\mathrm{w}} \phi$, as well as the differential capacitance of the ZnPor-IN film

$C=-\mathrm{d} q^{\mathrm{o}} / \mathrm{d} \Delta_{\mathrm{o}}^{\mathrm{w}} \phi$

The applied potential $\Delta_{\mathrm{o}}^{\mathrm{w}} \phi$ affects the distribution of the ions, and hence also the ion exchange equilibrium. Thus, Equation (8) can be transformed to

$\frac{c_{\mathrm{COOR}_{2} \mathrm{~N}}}{c_{\mathrm{COOH}}}=K_{\mathrm{IE}}^{\mathrm{o}, \mathrm{IN}} \frac{c^{\mathrm{o}, \mathrm{b}} P_{\mathrm{R}_{2} \mathrm{~N}}}{c_{\mathrm{H}}^{\mathrm{w}, \mathrm{b}} P_{\mathrm{H}}} \mathrm{e}^{-f \Delta_{\mathrm{o}}^{\mathrm{w}} \phi}$.

As $\Delta_{\mathrm{o}}^{\mathrm{w}} \phi$ is scanned progressively negative, $q^{\mathrm{o}}=-q^{\mathrm{W}}>0$ increases. Across the $\mathrm{IN} \mid \mathrm{w}$ interface, $\mathrm{HCit}^{2-}$ ions may flow from phase w into phase IN (if $\Delta_{\mathrm{o}}^{\mathrm{w}} \phi$ is sufficiently negative); the flow of $\mathrm{Li}^{+}$and $\mathrm{H}^{+}$ions from phase $\mathrm{IN}$ to phase $\mathrm{w}$ is usually negligible. Across the o|IN interface, $\mathrm{R}_{2} \mathrm{~N}^{+}$ions flow into phase $\mathrm{IN}$; the flow of $\mathrm{TB}^{-}$ions from phase $\mathrm{IN}$ to phase $\mathrm{o}$ is usually much smaller. The increase in $c_{\mathrm{R}_{2} \mathrm{~N}}^{\mathrm{IN}}=c^{\mathrm{o}, \mathrm{b}} P_{\mathrm{R}_{2} \mathrm{~N}} \mathrm{e}^{-f \Delta_{\mathrm{o}}^{\mathrm{IN}} \phi}$ shifts the ion exchange equilibria towards the formation of $-\mathrm{COOR}_{2} \mathrm{~N}$, at the expense of reducing $c_{\mathrm{COO}^{-}}$and $c_{\mathrm{COOH}}$. 
The increase in $c_{\mathrm{COOR}_{2} \mathrm{~N}}$ gives rise to an "adsorption" peak in the $\mathrm{CV}$ because there is a saturation limit, $c_{\mathrm{COOR}_{2} \mathrm{~N}} \leq c_{\mathrm{T}, \mathrm{COO}}$. By convention, a positive charge flow from o to $\mathrm{w}$ gives rise to a peak in the $\mathrm{CV}$ of negative current. ${ }^{20,21}$ Similarly, as $\Delta_{\mathrm{o}}^{\mathrm{w}} \phi$ is made more positive, $q^{\mathrm{w}}=$ $-q^{\mathrm{o}}>0$ increases. Across the o|IN interface, $\mathrm{R}_{2} \mathrm{~N}^{+}$ions flow towards phase o. Across the IN $\mid \mathrm{w}$ interface, $\mathrm{HCit}^{2-}$ ions flow towards phase w. During such a potential scan, $c_{\mathrm{COOR}_{2} \mathrm{~N}}$ decreases as $c_{\mathrm{COO}^{-}}$and $c_{\mathrm{COOH}}$ increase. The increase in $c_{\mathrm{COO}^{-}}$gives rise to an "adsorption" peak with a positive current in the $\mathrm{CV}$ (negative charge flow from o to $\mathrm{w}$ ).

The CVs can be simulated using an equivalent electrical circuit consisting of the solution resistance $R_{\text {sol }}$ in series with the parallel combination of the film capacitance $C$ and the charge transfer resistance $R_{\mathrm{ct}}$ (see Equations $\mathrm{S} 19$ and S20, $† \mathrm{ESI}$ ). This simple theoretical model qualitatively captures the main features of the experimental CVs, such as the total charge under the peaks, the peak separation and their variation with the bulk aqueous $\mathrm{pH}$ and the organic electrolyte concentration (see Figure 3 and Tables S2 and S3). However, this model does not accurately reproduce the shape of the peaks. The experimental peaks are the superposition of a narrow peak and a broad peak, the former occurring at a more negative $\Delta_{\mathrm{o}}^{\mathrm{w}} \phi$ and having a smaller area (and hence charge) under the peak. Even the broad peak is narrower than predicted by this model.
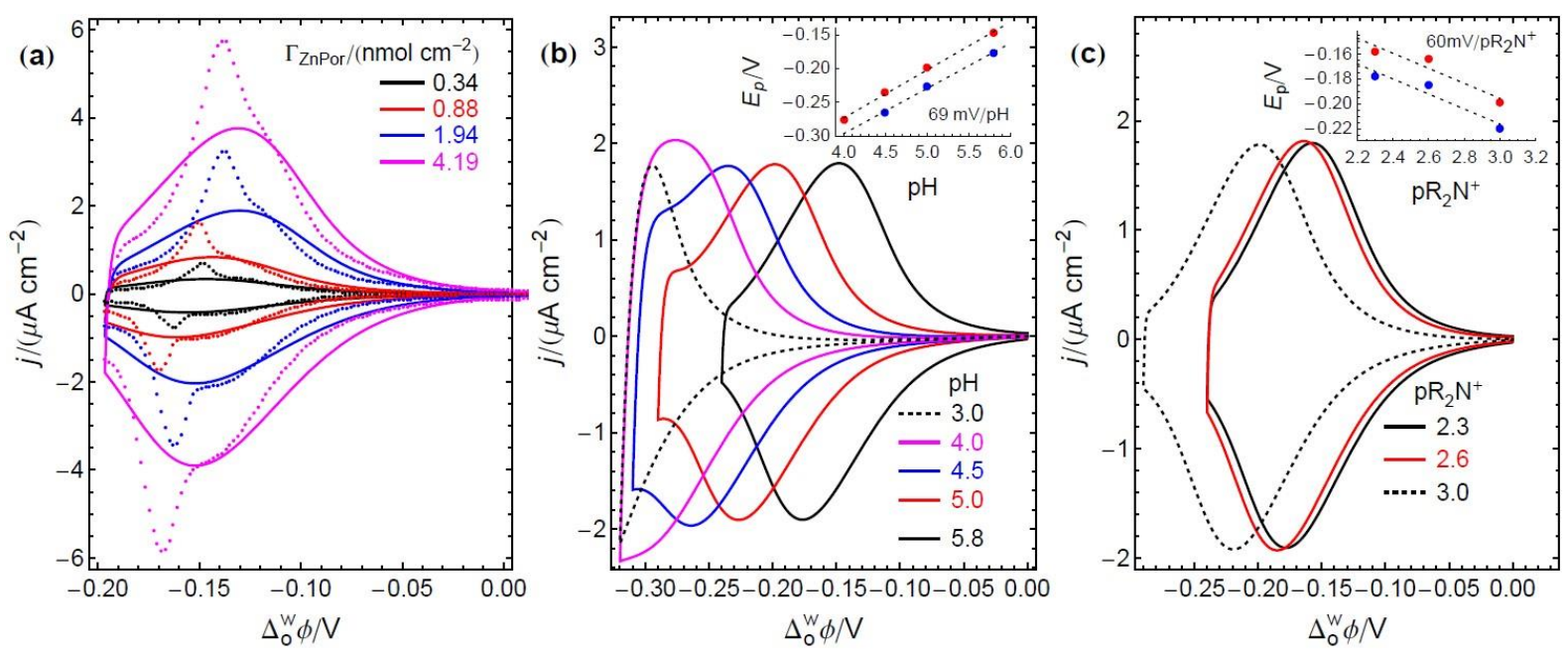

Figure 3. CVs generated using the theoretical model qualitatively capture the main features of the experimental CVs at the ITIES in the presence of a ZnPor-IN film. (a) A comparison of the simulated (lines) and experimental CVs (symbols) at $1 \mathrm{mV} \cdot \mathrm{s}^{-1}$ for the electrochemical cell described in Scheme 2 (with $5 \mathrm{mM} \mathrm{R} \mathrm{R}_{2} \mathrm{NTB}, 10 \mathrm{mM} \mathrm{Li}_{2} \mathrm{HCit}$, a bulk aqueous $\mathrm{pH}=5.8$ and varying $\left.\Gamma_{\mathrm{ZnPor}}\right)$. In particular, the peak separation and the total charge under the peaks are well reproduced, though the shape of the peaks is not. The simulated CVs accurately describe the experimentally observed values of peak potentials and their linear shift with (b) the $\mathrm{pH}$ and (c) the $\mathrm{R}_{2} \mathrm{NTB}$ concentration at $5 \mathrm{mV} \cdot \mathrm{s}^{-1}$ and $\Gamma_{\mathrm{ZnPor}}=0.34 \mathrm{nmol} \cdot \mathrm{cm}^{-2}$. The parameter values for the simulations in panels (a)-(c) are shown in Tables S2 and S3. 
Narrow "adsorption" peaks in the CVs are considered an indication of positive cooperativity. Herein, we propose that once the initial bulky $\mathrm{R}_{2} \mathrm{~N}^{+}$cations flow across the o|IN interface as $\Delta_{\mathrm{o}}^{\mathrm{w}} \phi$ is scanned negatively, they "open" space in the nanostructure due to structural rearrangements of the porphyrins allowing the later $\mathrm{R}_{2} \mathrm{~N}^{+}$species to penetrate the ZnPor-IN film much more easily. Thus, this conformational change of the ZnPor-INs is the physical reason behind the negative $g$ interaction parameters discussed vide infra, that are characteristic of positively cooperative adsorption. Furthermore, the characteristic shape of the purely capacitive CVs due to structural rearrangements of the porphyrins at the electrified liquid|liquid interface precisely resemble those of systems involving phase transitions at electrified solid|liquid interfaces, for example electrochemically driven structural changes of a copper adlayer on a $\mathrm{Au}(111)$ electrode surface. ${ }^{43}$

Cooperative binding of $\mathrm{R}_{2} \mathrm{~N}^{+}$ions can be described using the Frumkin isotherm, described in detail in the $†$ ESI. As mentioned above, the peaks in the experimental CVs are formed by the superposition of a narrow peak and a broad peak. Accordingly, we have simulated the CV by adding the theoretical curves calculated with two sets of carboxyl groups, described by Equation (S24) in the $†$ ESI. The set responsible for the narrow peak has a more negative Frumkin parameter $g_{\text {narrow }}$ and a smaller constant $K_{\mathrm{IE} \text {,narrow }}^{\circ \text {,IN }}$, so that the peak appears at more negative $\Delta_{\mathrm{o}}^{\mathrm{w}} \phi$, compared to the less negative $g_{\text {broad }}$ and larger $K_{\mathrm{IE} \text {, broad }}^{\mathrm{o}, \mathrm{N}}$ corresponding to the set responsible for the broad peak. The electrical parameters $R_{\mathrm{sol}}$ and $R_{\mathrm{ct}}$ in Equation (S20), $\dagger$ ESI, are common to both sets (Table S4). At $298 \mathrm{~K}, g_{\text {narrow }}=-3.5$ and $g_{\text {broad }}=-0.7$ correspond to attractive interaction energies $z_{\mathrm{c}} \varepsilon_{\text {narrow }}=g_{\text {narrow }} R T=-8.67 \mathrm{~kJ} \cdot \mathrm{mol}^{-1}$ and $g_{\text {broad }} R T=-1.73 \mathrm{~kJ} \cdot \mathrm{mol}^{-1}$. These $g$ values seem reasonable on the basis of the excellent agreement (Figures 4 and S7) between the simulated and the experimental CVs, given the complexity of the system under consideration. Moreover, a value $g=-4.2$ was observed for $\mathrm{a} \mathrm{Li}^{+}$intercalation process, a system with very similar underlying thermodynamics. ${ }^{13}$ 


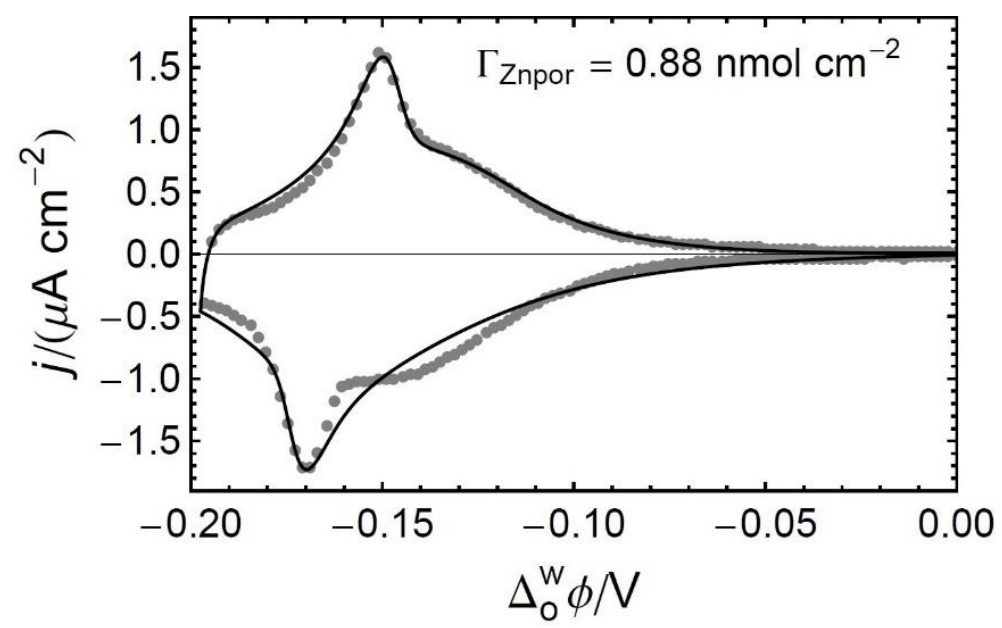

Figure 4. The consideration of two types of binding sites, described by Equation (S24), $\uparrow$ ESI, with $g_{\text {narrow }}=-3.5$ and $g_{\text {broad }}-0.7$, predicts simulated CVs (lines) at $1 \mathrm{mV} \cdot \mathrm{s}^{-1}$ and $\Gamma_{\text {ZnPor }}$ $=0.88 \mathrm{nmol} \cdot \mathrm{cm}^{-2}$ that resemble more closely the experimental observations (symbols). Comparisons are provided for CVs obtained with $\Gamma_{\text {ZnPor-INs }}$ values of $0.34,1.94$ and $4.19 \mathrm{nmol} \cdot \mathrm{cm}^{-2}$ in Figure S8. The parameter values (Table S4) have been chosen on the basis of a qualitative agreement and not using a fitting algorithm.

\subsection{Kinetics of electrochemically-driven reversible ion intercalation in the presence of the ZnPor-IN film}

As $\Delta_{\mathrm{o}}^{\mathrm{w}} \phi$ is scanned progressively negative, ion intercalation of $\mathrm{R}_{2} \mathrm{~N}^{+}$from the organic phase into the ZnPor-IN film proceeds by binding and ion exchange, with $c_{\mathrm{COOR}_{2} \mathrm{~N}}^{\mathrm{IN}}$ increasing. The aim of this section is to investigate the kinetics of this process by potential-step chronoamperometry. A particular focus is placed on the influence of both $\Delta_{\mathrm{o}}^{\mathrm{w}} \phi$ and $\Gamma_{\mathrm{ZnPor}}$ on the rates of the charge transfer processes. Current transients were obtained by maintaining a constant initial potential $\Delta_{\mathrm{o}}^{\mathrm{w}} \phi_{\text {initial }}$ for $t_{\text {initial }}=30 \mathrm{~s}$, and varying the final potential $\Delta_{\mathrm{o}}^{\mathrm{w}} \phi_{\text {final }}$ in $50 \mathrm{mV}$ increments across the region where the electrochemical signals were observed $\left(-0.05 \mathrm{~V}>\Delta_{\mathrm{o}}^{\mathrm{w}} \phi>-0.30 \mathrm{~V}\right)$, see Figure $\mathrm{S} 9$ and Figures $5 \mathrm{a}-\mathrm{b}$. The value $\Delta_{\mathrm{o}}^{\mathrm{w}} \phi_{\text {initial }}=$ $+0.25 \mathrm{~V}$ was chosen because no discernable electrochemical processes were occuring at that $\Delta_{\mathrm{o}}^{\mathrm{w}} \phi$, besides capacitive charging of the back-to-back double layers at the ITIES. Once more, four electrochemical cells with increasing $\Gamma_{\mathrm{ZnPor}}\left(0.34,0.88,1.94\right.$, and $\left.4.19 \mathrm{nmol} \cdot \mathrm{cm}^{-2}\right)$ were investigated.

Depending on $\Delta_{\mathrm{o}}^{\mathrm{w}} \phi_{\text {final }}$ and $\Gamma_{\mathrm{ZnPor}}$, the current transients presented a decay component, commonly associated to an adsorption process, and multiple rising components with current maxima, commonly associated with nucleation and growth processes. In this regard, these current transients obtained by potential-step chronoamperometry are highly reminiscent of 
those generated using the same technique to study the kinetics of structural changes during the electrochemical switching of electronically conducting polymer films, such as polypyrrole, between their reduced (insulating) and oxidised (electronically conducting) states. ${ }^{35}$ The kinetics of processes in conducting polymers that lead to a current maximum after a potentialstep are described by the electrochemically stimulated conformational relaxation (ESCR) model. ${ }^{44,45}$ In common with conducting polymer films, electrochemically driven processes (binding and ion exchange) in the ZnPor-IN film occur throughout a three-dimension volume, with ion intercalation steps linked to morphological changes in the film structures.

A key question is how do we define the meaning of "nucleation" in the context of the ZnPor-IN film at the ITIES? Herein, we propose that the presence of nucleation transients was associated with domains within the nanostructures where, due to structural rearrangements of the porphyrins, the binding and ion exchange of $\mathrm{R}_{2} \mathrm{~N}^{+}$at $-\mathrm{COO}^{-}$and $-\mathrm{COOH}$ groups, respectively, took place faster. Also, the energetically less demanding binding and ion exchange of further $\mathrm{R}_{2} \mathrm{~N}^{+}$species after these structural rearrangements of the porphyrins is the physical reason underlying the electrochemical observation of positively cooperative behaviour discussed earlier.
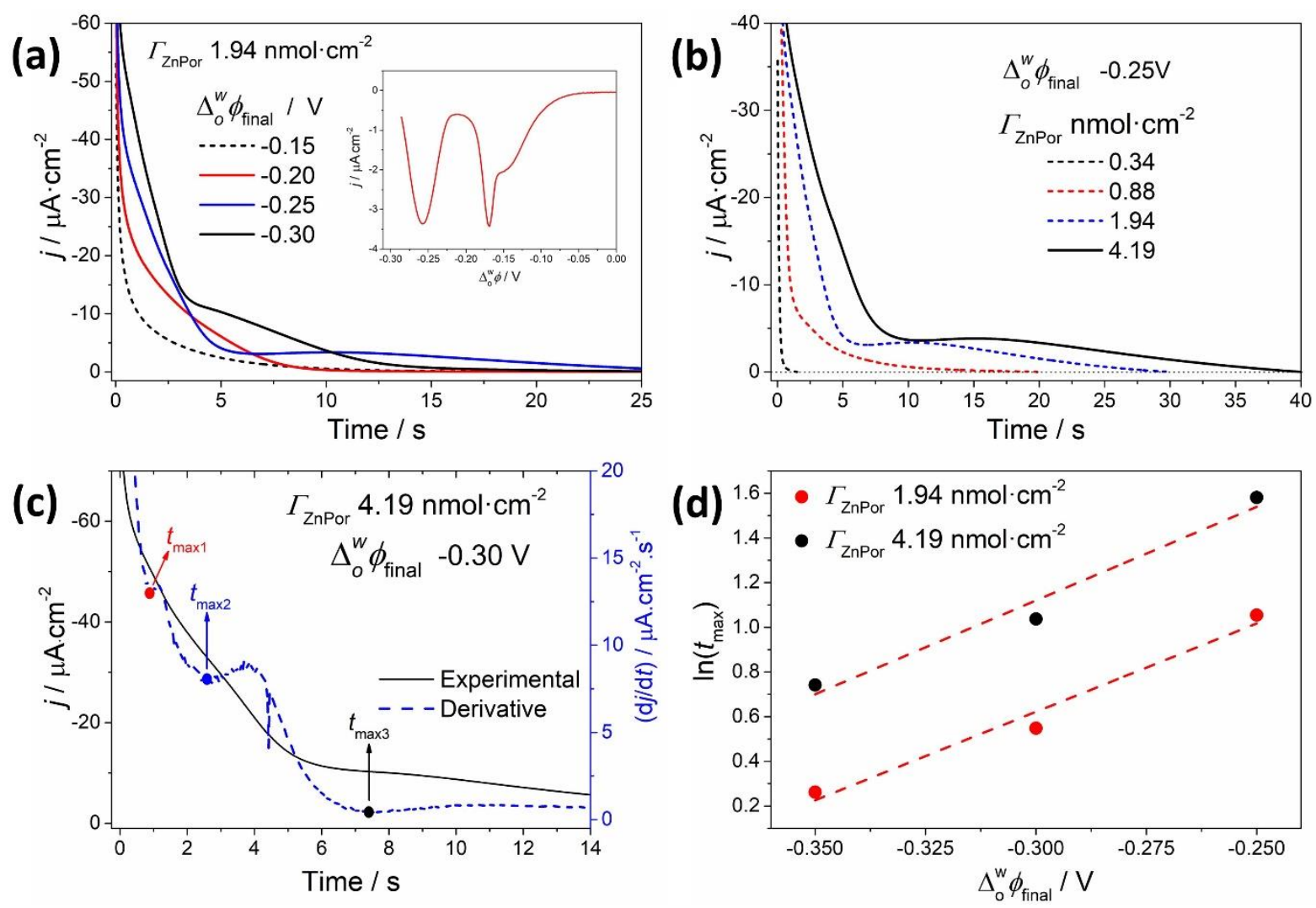
Figure 5. Kinetics of electrochemically-driven reversible ion intercalation by potential-step chronoamperometry in the presence of the ZnPor-IN film. (a) Current transients probing the influence of $\Delta_{\mathrm{o}}^{\mathrm{w}} \phi_{\text {final }}$ were obtained by varying $\Delta_{\mathrm{o}}^{\mathrm{w}} \phi_{\text {final }}$ in $50 \mathrm{mV}$ increments at a constant $\Gamma_{\text {ZnPor }}$ of $1.94 \mathrm{nmol} \cdot \mathrm{cm}^{-2}$ and $\Delta_{\mathrm{o}}^{\mathrm{w}} \phi_{\text {initial }}$ of $+0.25 \mathrm{~V}$ for $30 \mathrm{~s}\left(t_{\text {initial }}\right)$. (b) Current transients probing the influence of $\Gamma_{\mathrm{ZnPor}}$ were obtained by increasing $\Gamma_{\mathrm{ZnPor}}$ from 0.34 to $4.19 \mathrm{nmol} \cdot \mathrm{cm}^{-2}$ while maintaining a constant $\Delta_{\mathrm{o}}^{\mathrm{w}} \phi_{\text {initial }}$ of $+0.25 \mathrm{~V}$ for $30 \mathrm{~s}$ and $\Delta_{\mathrm{o}}^{\mathrm{w}} \phi_{\text {final }}$ of $-0.25 \mathrm{~V}$. (c) Deconvolution of the $t_{\max }$ values of the nucleation components from an experimental current transient (solid black line, obtained with a $\Gamma_{\mathrm{ZnPor}}$ of $4.19 \mathrm{nmol} \cdot \mathrm{cm}^{-2}, \Delta_{\mathrm{o}}^{\mathrm{w}} \phi_{\text {initial }}$ of $+0.25 \mathrm{~V}$ for $30 \mathrm{~s}$, and $\Delta_{\mathrm{o}}^{\mathrm{w}} \phi_{\text {final }}$ of $-0.30 \mathrm{~V}$ ) by obtaining the derivative (dashed blue line). (d) Plot of $\ln \left(t_{\mathrm{max}} / \mathrm{s}\right)$ versus $\Delta_{\mathrm{o}}^{\mathrm{w}} \phi_{\text {final }}$ for current transients obtained with a $\Delta_{\mathrm{o}}^{\mathrm{w}} \phi_{\text {initial }}$ of $+0.25 \mathrm{~V}$ for $30 \mathrm{~s}$ and $\Gamma_{\mathrm{ZnPor}}$ of either 1.94 (red circles) or $4.19 \mathrm{nmol} \cdot \mathrm{cm}^{-2}$ (black circles). The $t_{\max }$ data is that obtained for the second nucleation component, designated as $t_{\max 2}$ in Table S5.

Prior to kinetic analysis, the initial $50 \mathrm{~ms}$ (the value obtained from impedance measurements for the RC constant of the cell) were neglected and the residual current subtracted such that $j=0 \mathrm{~A} \cdot \mathrm{cm}^{-2}$ at $t=40 \mathrm{~s}$. For all $\Gamma_{\mathrm{ZnPor}}$ values, the transients obtained using $-0.05 \mathrm{~V},-0.10 \mathrm{~V}$ and $-0.15 \mathrm{~V}$ as $\Delta_{\mathrm{o}}^{\mathrm{w}} \phi_{\text {final }}$ (and $+0.25 \mathrm{~V}$ as $\Delta_{\mathrm{o}}^{\mathrm{w}} \phi_{\text {initial }}$ ) did not show any significant nucleation component (Figure S9). Thus, the analysis was focused on the transients obtained using $-0.25 \mathrm{~V},-0.30 \mathrm{~V}$ and $-0.35 \mathrm{~V}$ as $\Delta_{\mathrm{o}}^{\mathrm{w}} \phi_{\text {final }}$, where the nucleation features were observed (Figures 5a-b). In many cases, more than one nucleation component was observed experimentally, up to a maximum of three. The latter may be associated with binding and ion exchange at inner carboxyl sites. Therefore, the nucleation components were de-convoluted from the total current signal by plotting the derivative of the total current. From the derivative, the time $t_{\max }$ of the peak current maximum for each nucleation component within each transient was easily identified, see Figure 5c. A summary of these $t_{\max }$ values as a function of $\Gamma_{\mathrm{ZnPor}}$ and $\Delta_{\mathrm{o}}^{\mathrm{w}} \phi_{\text {final }}$ is presented in Table S5. Using these $t_{\max }$ values as a clear guide to the number of nucleation components present, the total fitted current for any transient may be obtained as a summation of the adsorption and nucleation components using exponential decay and Gaussian-type functions, respectively (Figure S10).

An increase in nucleation kinetics will be reflected in a shorter time required to reach $t_{\max }$ for each nucleation component. For all values of $\Gamma_{\mathrm{ZnPor}}$ and $\Delta_{\mathrm{o}}^{\mathrm{w}} \phi$, the shifts of $t_{\mathrm{max}}$ followed consistent trends. At a constant $\Gamma_{\mathrm{ZnPor}}$ and $\Delta_{\mathrm{o}}^{\mathrm{w}} \phi_{\text {initial }}$, an increase in nucleation kinetics (decreasing $t_{\max }$ ) was seen as $\Delta_{\mathrm{o}}^{\mathrm{w}} \phi_{\text {final }}$ was set to more negative values (Figure 5a and Table S5). In other words, conformational relaxation to the more open nanostructure is faster as more energy is applied to drive $\mathrm{R}_{2} \mathrm{~N}^{+}$species into the ZnPor-IN film, leading to the creation of more nuclei. Conversely, at a constant $\Delta_{\mathrm{o}}^{\mathrm{w}} \phi_{\text {initial }}$ of $+0.25 \mathrm{~V}$ and $\Delta_{\mathrm{o}}^{\mathrm{w}} \phi_{\text {final }}$ of $-0.25 \mathrm{~V}$, a decrease in 
nucleation kinetics (increasing $t_{\max }$ ) was seen as $\Gamma_{\mathrm{ZnPor}}$ increased (Figure $5 \mathrm{~b}$ and Table S5). The latter indicates that more energy is required to achieve conformational relaxation as $\Gamma_{\mathrm{znpor}}$ increases. A prediction of the ESCR model is that a linear relationship exists between $\ln \left(t_{\max } / \mathrm{s}\right)$ and the energy required to relax and swell the conducting polymer film by oxidation, i.e. the anodic overpotential. ${ }^{46}$ In line with this prediction, plots of $\ln \left(t_{\max } / \mathrm{s}\right)$ versus $\Delta_{\mathrm{o}}^{\mathrm{w}} \phi_{\text {final }}$ for one of the nucleation sites (designated $t_{\max 2}$ ) are linear and exhibit the same slope for the higher $\Gamma_{\text {ZnPor }}$ studied, 1.94 and $4.19 \mathrm{nmol} \cdot \mathrm{cm}^{-2}$ (Figure $5 \mathrm{~d}$ ). The latter identical slopes indicate the rate of increase in nucleation kinetics (decreasing $t_{\max }$ ) as $\Delta_{\mathrm{o}}^{\mathrm{w}} \phi_{\text {final }}$ shifts negatively is independent of $\Gamma_{\mathrm{ZnPor}}$ in the range studied.

Finally, the effect of the initial "compaction" of the ZnPor-IN film on the kinetics were evaluated using two different experimental approaches. As $\mathrm{R}_{2} \mathrm{~N}^{+}$are bulky organic cations, far larger than the protons they displace from $-\mathrm{COOH}$ groups, it can be reasonably assumed that the volume of the ZnPor-IN film swells at negative $\Delta_{\mathrm{o}}^{\mathrm{w}} \phi$ values, reducing the films compaction. First, $\Gamma_{\mathrm{ZnPor}}$ and $\Delta_{\mathrm{o}}^{\mathrm{w}} \phi_{\text {final }}$ were maintained constant at $1.94 \mathrm{nmol} \cdot \mathrm{cm}^{-2}$ and $0.25 \mathrm{~V}$, respectively, and $\Delta_{\mathrm{o}}^{\mathrm{w}} \phi_{\text {initial }}$ varied from $+0.20 \mathrm{~V}$ to $+0.45 \mathrm{~V}$ every $50 \mathrm{mV}$ with a $t_{\text {initial }}$ of $30 \mathrm{~s}$ (Figure S11a). The current transients measured were near identical for all values of $\Delta_{\mathrm{o}}^{\mathrm{w}} \phi_{\text {initial }}$ tested with no measurable difference in the absorption component and, on close inspection (see inset Figure S11a), a slight decrease of $t_{\max }$ for the prominent nucleation component. This slight increase in the nucleation kinetics is the opposite of what was expected if the film was more compact at positive values of $\Delta_{\mathrm{o}}^{\mathrm{w}} \phi_{\text {initial }}$. We attribute the minor increase in nucleation kinetics to an interaction of the organic anions, $\mathrm{TB}^{-}$, with the $\mathrm{ZnPor}-\mathrm{IN}$ film at positive potentials leading to a partial opening of the nanostructure. As the ZnPor-IN film and $\mathrm{TB}^{-}$are both negatively charged, this interaction is far weaker than that of ZnPor-IN film and the $\mathrm{R}_{2} \mathrm{~N}^{+}$species. Nevertheless, when the potential is stepped to $-0.25 \mathrm{~V}$, slightly less energy is required to open space for the penetration of the $\mathrm{R}_{2} \mathrm{~N}^{+}$species. In the second experiment, $\Gamma_{\mathrm{ZnPor}}, \Delta_{\mathrm{o}}^{\mathrm{w}} \phi_{\text {initial }}$, and $\Delta_{\mathrm{o}}^{\mathrm{w}} \phi_{\text {final }}$ were maintained constant at $1.94 \mathrm{nmol} \cdot \mathrm{cm}^{-2},+0.25 \mathrm{~V}$ and $0.25 \mathrm{~V}$ respectively, and $t_{\text {initial }}$ varied from 5 to $60 \mathrm{~s}$ (Figure $\mathrm{S} 11 \mathrm{~b}$ ). As for the previous experiment, the current transients measured were near identical for all values of $t_{\text {initial }}$ tested with no measurable difference in the absorption component and, on close inspection (see inset Figure $\mathrm{S} 11 \mathrm{~b}$ ), a slight increase of $t_{\max }$ for the prominent nucleation component. This minor decrease in the nucleation kinetics indicates a slightly more compact nature as $t_{\text {initial }}$ increased. 


\section{Conclusions}

The thermodynamics and kinetics of ion intercalation into a floating film of zinc porphyrin interfacial nanostructures (ZnPor-INs) were probed electrochemically without the need to support the ZnPor-IN film on a conductive electrode substrate. Instead, the film was supported on an electrified liquid|liquid interface, and could be regarded to a mixed-solvent layer separating the aqueous and organic solutions. The electrochemical signal was due to purely ionic processes, not linked to redox reactions.

The film behaves as a capacitor. The ZnPor-IN film is electroneutral and the concentration of free ions is relatively small because of solvation effects. On increasing the negative polarisation of the interface, $\Delta_{\mathrm{o}}^{\mathrm{w}} \phi<0$, the organic ammonium cations $\left(\mathrm{R}_{2} \mathrm{~N}^{+}\right)$from the organic phase enter the film and intercalate the ZnPor-IN. Then, a few neutral carboxyl $(-\mathrm{COOH})$ groups are forced to dissociate, and many more transform into $-\mathrm{COOR}_{2} \mathrm{~N}$. In both cases, the released $\mathrm{H}^{+}$ions leave the film and enter the aqueous phase. The charge of the anionic carboxyl groups $\left(-\mathrm{COO}^{-}\right)$is mostly compensated by free $\mathrm{R}_{2} \mathrm{~N}^{+}$ions. The total (i.e., free and bound) $\mathrm{R}_{2} \mathrm{~N}^{+}$

concentration in the film, $c_{\mathrm{COOR}_{2} \mathrm{~N}}+c_{\mathrm{R}_{2} \mathrm{~N}}^{\mathrm{IN}}$, is a measure of the positive charge accumulated in the film as a capacitor; the negative charge in the capacitor corresponds to $\mathrm{H}^{+}$ions leaving the film (where there were bound as $-\mathrm{COOH}$ ). To a lesser extent, aqueous citrate $\left(\mathrm{HCit}^{2-}\right.$ ) anions and lithium $\left(\mathrm{Li}^{+}\right)$ions may also participate in this capacitive film behaviour.

The shape of the CV was distinctive, formed by the superposition of a narrow peak and a broad peak. The former indicated a positive cooperativity mechanism for ion intercalation and was attributed to structural rearrangements of the porphyrins at the electrified liquid|liquid interface during $\mathrm{R}_{2} \mathrm{~N}^{+}$intercalation. Employing the Frumkin isotherm, experimental CVs were simulated with negative $g$ interaction parameters in line with those observed for a $\mathrm{Li}^{+}$ intercalation process, a system with very similar underlying thermodynamics. ${ }^{13}$ The kinetics of $\mathrm{R}_{2} \mathrm{~N}^{+}$intercalation were investigated by potential-step chronoamperometry. Depending on the applied interfacial Gavani potential $\Delta_{\mathrm{o}}^{\mathrm{w}} \phi$ and the interfacial concentration $\Gamma_{\mathrm{ZnPor}}$ of ZnPor, current transients presented a decay and multiple nucleation components. The latter were associated with domains where, due to structural rearrangements of the porphyrins, the electrochemically-driven binding and ion exchange of $\mathrm{R}_{2} \mathrm{~N}^{+}$took place faster. The nucleation kinetics were seen to increase as the final potential $\Delta_{\mathrm{o}}^{\mathrm{w}} \phi_{\text {final }}$ was set to more negative values and decrease as $\Gamma$ ZnPor increased. 
Overall, using electrified liquid|liquid interfaces, there is clearly significant potential to study, for the time, by electrochemical methodologies the kinetics and thermodynamics of ion intercalation into solid matrices that are non-electronically conductive and/or that operate as non-electronically connected device components (for example ion exchange membranes). Such insights may critically influence the performance of a multitude of devices (Li-ion batteries, supercapacitors, fuel cells, electrolysers, etc.) with energy-related applications.

\section{Conflicts of interest}

The authors declare no competing financial interest.

\section{Acknowledgements}

M.D.S. acknowledges Science Foundation Ireland (SFI) under Grant no. 13/SIRG/2137 and the European Research Council through a Starting Grant (Agreement no. 716792). A. G.-Q. acknowledges funding received from an Irish Research Council Government of Ireland Postdoctoral Fellowship Award (grant number GOIPD/2018/252). J.A.M. acknowledges the Ministerio de Ciencia e Innovación (Spain) and the European Regional Development Funds (FEDER), project No. PGC2018-097359-B-I00.

\section{References}

1 V. Augustyn, M. T. McDowell and A. Vojvodic, Joule, 2018, 2, 2189-2193.

2 V. R. Stamenkovic, D. Strmcnik, P. P. Lopes and N. M. Markovic, Nat. Mater., 2016, 16, 57-69.

3 M. Z. Bazant, Acc. Chem. Res., 2013, 46, 1144-1160.

4 A. M. Kuznetsov and J. Ulstrup, Electrochim. Acta, 2000, 45, 2339-2361.

$5 \quad$ K. D. Fong, T. Wang and S. K. Smoukov, Sustain. Energy Fuels, 2017, 1, 1857-1874.

6 H. Strathmann, in Comprehensive Membrane Science and Engineering, Elsevier, 2010, vol. 2, pp. 391-429.

7 H. Strathmann, A. Grabowski and G. Eigenberger, Desalination, 2006, 199, 1-3.

8 S. J. Peighambardoust, S. Rowshanzamir and M. Amjadi, Int. J. Hydrogen Energy, 2010, 35, 9349-9384.

9 B. Yuzer, H. Selcuk, G. Chehade, M. E. Demir and I. Dincer, Energy, 2020, 190, 116420 . 
10 T. D. Nguyen, A. Whitehead, N. Wai, S. J. H. Ong, G. G. Scherer and Z. J. Xu, ChemSusChem, 2019, 12, 1076-1083.

11 B. E. Logan and M. Elimelech, Nature, 2012, 488, 313-319.

12 M. Oliot, S. Galier, H. Roux de Balmann and A. Bergel, Appl. Energy, 2016, 183, 1682-1704.

13 M. D. Levi, J. Electrochem. Soc., 1999, 146, 1279.

14 M. D. Levi and D. Aurbach, Electrochim. Acta, 1999, 45, 167-185.

15 B. E. Conway, Electrochim. Acta, 1993, 38, 1249-1258.

16 M. D. Levi, Y. S. Cohen, Y. Gofer and D. Aurbach, Electrochim. Acta, 2004, 49, 3701-3710.

17 M. A. Vorotyntsev, L. I. Daikhin and M. D. Levi, J. Electroanal. Chem., 1992, 332, 213-235.

18 W. Sirisaksoontorn and M. M. Lerner, Inorg. Chem., 2013, 52, 7139-7144.

19 A. M. Fogg, J. S. Dunn, S.-G. Shyu, D. R. Cary and D. O'Hare, Chem. Mater., 1998, 10, 351-355.

20 Z. Samec, Pure Appl. Chem., 2004, 76, 2147-2180.

21 P. Peljo and H. H. Girault, in Encyclopedia of Analytical Chemistry, John Wiley \& Sons, Ltd, Chichester, UK, 2012.

22 M. F. Suárez-Herrera, P.-A. Cazade, D. Thompson and M. D. Scanlon, Electrochem. commun., 2019, 109, 106564.

23 M. F. Suárez-Herrera and M. D. Scanlon, Electrochim. Acta, 2019, 328, 135110.

24 S. Senthilkumar, R. A. W. Dryfe and R. Saraswathi, Langmuir, 2007, 23, 3455-3461.

25 R. A. W. Dryfe and S. M. Holmes, J. Electroanal. Chem., 2000, 483, 144-149.

26 G. C. Lillie, R. a Dryfe and S. M. Holmes, Analyst, 2001, 126, 1857-1860.

27 X. Jiang, K. Gao, D. Hu, H. Wang, S. Bian and Y. Chen, Analyst, 2015, 140, $2823-$ 2833.

28 X. Huang, L. Xie, X. Lin and B. Su, Anal. Chem., 2016, 88, 6563-6569.

29 L. Xie, X. Huang, X. Lin and B. Su, J. Electroanal. Chem., 2017, 784, 62-68.

30 M. C. Collins, M. Hébrant and G. Herzog, Electrochim. Acta, 2018, 282, 155-162.

31 L. Poltorak, A. Gamero-Quijano, G. Herzog and A. Walcarius, Appl. Mater. Today, 2017, 9, 533-550.

32 M. J. Stephenson, S. M. Holmes and R. A. W. Dryfe, Angew. Chemie - Int. Ed., 2005, 44, 3075-3078.

33 M. J. Stephenson, M. P. Attfield, S. M. Holmes and R. A. W. Dryfe, J. Solid State Electrochem., 2015, 19, 1985-1992.

34 M. J. Stephenson and R. A. W. Dryfe, Electrochim. Acta, 2007, 53, 1182-1188.

35 T. F. Otero, H. J. Grande and J. Rodríguez, J. Phys. Chem. B, 1997, 101, 3688-3697.

36 A. F. Molina-Osorio, D. Cheung, C. O’Dwyer, A. A. Stewart, M. Dossot, G. Herzog and M. D. Scanlon, J. Phys. Chem. C, 2020, 124, 6929-6937. 
37 C. W. Monroe, M. Urbakh and A. A. Kornyshev, J. Electroanal. Chem., 2005, 582, $28-40$.

38 T. Huber, O. Pecina and W. Schmickler, J. Electroanal. Chem., 1999, 467, 203-206.

39 G. M. Torrie and J. P. Valleau, J. Electroanal. Chem., 1986, 206, 69-79.

40 C. Yufei, V. J. Cunnane, D. J. Schiffrin, L. Murtomäki and K. Kontturi, J. Chem. Soc., Faraday Trans., 1991, 87, 107-114.

41 C. M. Pereira, A. Martins, M. Rocha, C. J. Silva and F. Silva, J. Chem. Soc. Faraday Trans., 1994, 90, 143-148.

42 R. G. Bates and G. D. Pinching, J. Am. Chem. Soc., 1949, 71, 4165-4165.

43 M. H. Hölzle, U. Retter and D. M. Kolb, J. Electroanal. Chem., 1994, 371, 101-109.

44 T. F. Otero and I. Boyano, J. Phys. Chem. B, 2003, 107, 4269-4276.

45 T. F. Otero and I. Boyano, J. Phys. Chem. B, 2003, 107, 6730-6738.

46 M. R. Nateghi and B. Savabieh, Electrochim. Acta, 2014, 121, 128-135. 


\title{
Reversible electrochemical ion intercalation at an electrified liquid|liquid interface functionalised with porphyrin nanostructures $\dagger$
}

Andrés F. Molina-Osorio, ${ }^{\mathrm{a}}$ José A. Manzanares, ${ }^{\mathrm{b}}$ Alonso Gamero-Quijano ${ }^{\mathrm{a}}$ and Micheál D Scanlon*,a,c

\footnotetext{
a The Bernal Institute and Department of Chemical Sciences, School of Natural Sciences, University of Limerick (UL), Limerick V94 T9PX, Ireland.*E-mail: micheal.scanlon@ul.ie

${ }^{\mathrm{b}}$ Department of Thermodynamics, Faculty of Physics, University of Valencia, c/Dr. Moliner, 50, E-46100 Burjasot, Spain.

${ }^{c}$ Advanced Materials and Bioengineering (AMBER) Centre, Ireland.

$\dagger$ Electronic Supplementary Information (ESI) available: [Supplementary experimental section, electrochemical results and modelling theory].
}

\begin{abstract}
Ion intercalation into solid matrices influences the performance of key components in most energy storage devices (Li-ion batteries, supercapacitors, fuel cells, etc.). Electrochemical methods provide key information on the thermodynamics and kinetics of these ion transfer processes but are restricted to matrices supported on electronically conductive substrates. In this article, the electrified liquid|liquid interface is introduced as an ideal platform to probe the thermodynamics and kinetics of reversible ion intercalation with non-electronically active matrices. Zinc(II) meso-tetrakis(4-carboxyphenyl)porphyrins were self-assembled into floating films of ordered nanostructures at the water| $\alpha, \alpha, \alpha$-trifluorotoluene interface. Electrochemically polarising the aqueous phase negatively with respect to the organic phase lead to organic ammonium cations intercalating into the zinc porphyrin nanostructures by binding to anionic carboxyl sites and displacing protons through ion exchange at neutral carboxyl sites. The cyclic voltammograms suggested a positive cooperativity mechanism for ion intercalation linked with structural rearrangements of the porphyrins within the nanostructures, and were modelled using a Frumkin isotherm. The model also provided a robust understanding of the dependence of the voltammetry on the $\mathrm{pH}$ and organic electrolyte concentration. Kinetic analysis was performed using potential step chronoamperometry, with the current transients composed of "adsorption" and nucleation components. The latter were
\end{abstract}


associated with domains within the nanostructures where, due to structural rearrangements, ion binding and exchange took place faster. This work opens opportunities to study the thermodynamics and kinetics of purely ionic ion intercalation reactions (not induced by redox reactions) in floating solid matrices using any desired electrochemical method.

\section{Introduction}

Charge transfer reactions at electrified interfaces critically influence the performance of devices with energy-related applications. ${ }^{1,2}$ The continuous development of sustainable technologies relies on precise analysis of the thermodynamics and kinetics underlying the charge transfer reactions involved. ${ }^{3}$ Of the different charge transfer phenomena, a molecular scale understanding of electron transfer across solid-liquid interfaces is now accessible. ${ }^{4}$ However, such in-depth analysis remains a challenge for interfacial ion transfer between two different phases.

Ion transfer reactions are of major importance in many energy storage technologies. A key step during cycling of lithium ion (Li-ion) batteries is the reversible ion transfer, termed intercalation and de-intercalation, of $\mathrm{Li}^{+}$between the electrolyte and cathode material. ${ }^{4}$ For supercapacitor applications, conducting polymers exhibit pseudocapacitance through doping and de-doping of the polymer backbone, which results in intercalation and de-intercalation of electrolyte ions within the polymer film to maintain charge neutrality. ${ }^{5}$ Ion exchange membranes (IEMs) are used in combination with electrochemical potential gradients to drive intercalation and de-intercalation, typically through an ion exchange mechanism, for the selective transport of certain ionic components between phases with different chemical compositions. ${ }^{6,7}$ Such IEMs are critical to the operation of fuel cells, ${ }^{8}$ electrolysers, ${ }^{9}$ redox flow batteries, ${ }^{10}$ reverse electrodialysers, ${ }^{11}$ and microbial fuel cells. ${ }^{12}$

Electrochemical methods are particularly well suited to provide key information on the thermodynamics and kinetics of these ion transfer processes. However, their use is restricted to matrices supported on electronically conductive substrates, as is the case for Li-ion battery cathodes $^{13-15}$ or conducting polymer films, ${ }^{16,17}$ where reversible ion transfer is coupled with a redox reaction. Analysis of ion transfer reactions in non-electronically conductive solids, such as IEMs, is more difficult to study, given that ion transfer proceeds through an ion exchange mechanism without a flow of electrons. ${ }^{18,19}$ In this sense, the interface between two immiscible electrolyte solutions (ITIES), ${ }^{20,21}$ such as that formed between water and suitable 
hydrophobic organic solvents, offers a perfect platform to study the thermodynamics and kinetics of ion transfer reactions involving non-electronically conductive solids.

In the absence of redox active species, polarisation of the ITIES induces the movement of aqueous and organic electrolyte ions to, and across, the liquid|liquid interface. ${ }^{22,23}$ Thus, a film of solid materials floating at the interface will experience a markedly different ionic environment and interfacial aqueous $\mathrm{pH}$ depending on the applied interfacial Galvani potential difference $\left({ }_{o}^{w} \phi / V\right)$. In this article, we demonstrate that interaction of charged or easily ionisable functional groups within the floating solid materials with the aqueous and organic electrolyte ions gives rise to capacitive currents associated with purely ionic reactions. Previous studies involving functionalisation of the ITIES with non-conductive inorganic materials, such as zeolites ${ }^{24-26}$ or silica, ${ }^{27-31}$ were primarily motivated to develop sensor technology through charge- or size-selective ion transfer across the interface. Dryfe and co-works have reported electrochemically driven ion exchange involving zeolites floating at an ITIES, but no in-depth thermodynamic or kinetic analysis was performed. ${ }^{32-34}$

Herein, we study the thermodynamics and kinetics of electrochemically reversible ion intercalation at a floating film of self-assembled zinc(II) 5,10,15,20-(tetra-4carboxyphenyl)porphyrin interfacial nanostructures (ZnPor-INs). The floating film effectively acts as an ion penetrable third phase separating the aqueous and organic phases. Cyclic voltammetry in the presence of the ZnPor-IN film was amenable to thermodynamic analysis using the Frumkin isotherm ${ }^{13-15}$ and kinetic analysis was performed using potential step chronoamperometry. ${ }^{35}$ These purely ionic voltammetric and current transient responses were analogous to those commonly associated with reversible ion intercalation coupled with electron transfer, as described for Li-ion battery cathodes and conducting polymer films. The distinctive shape of the cyclic voltammograms also indicated an electrochemically driven rearrangement of the porphyrin nanostructure at the liquid|liquid interface. These observations, connected with the presence of easily ionisable carboxyl groups within the ZnPor-IN film, were rationalised in terms of electrochemically-driven binding of organic cations at anionic carboxyl $\left(-\mathrm{COO}^{-}\right)$groups and ion exchange of organic cations at neutral carboxyl $(-\mathrm{COOH})$ groups in which protons are displaced. This concept is schematically shown in Scheme 1. 


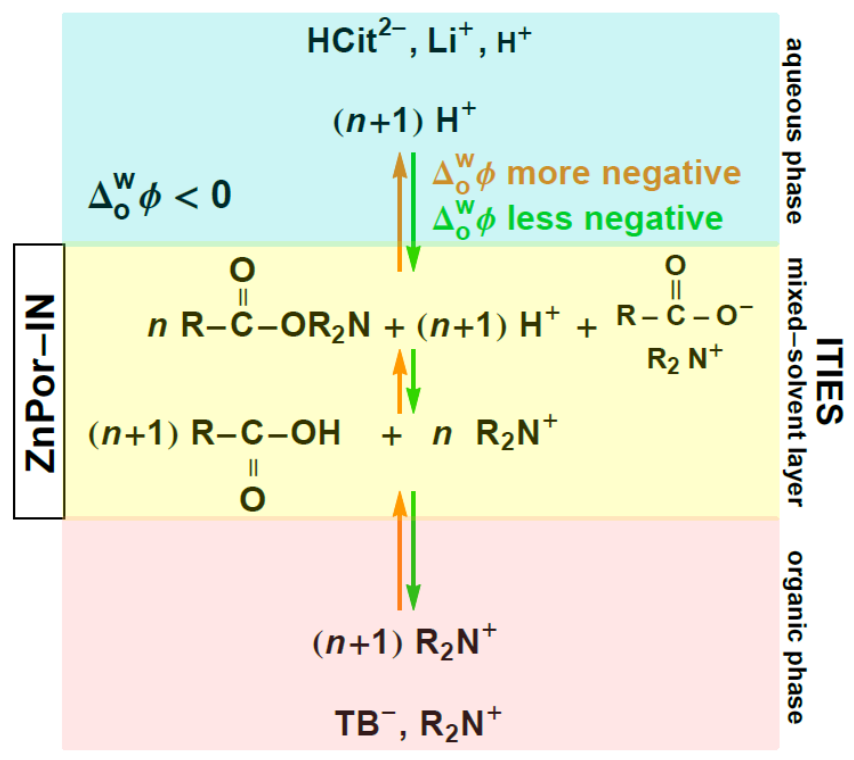

Scheme 1. Electrochemically-driven shifts in the chemical equilibria involving carboxyl groups in the ZnPor-IN film, aqueous protons $\mathrm{H}^{+}$, and organic bulky ammonium cations $\mathrm{R}_{2} \mathrm{~N}^{+}$. The peak currents in the CVs roughly correspond to negative $\square_{o}^{w} \phi$ such that the fractions of groups in $-\mathrm{COOH}$ and $-\mathrm{COOR}_{2} \mathrm{~N}$ forms are both large and similar to each other. As $\square_{o}^{w} \phi$ is scanned more negatively from the peak, $\mathrm{R}_{2} \mathrm{~N}^{+}$ions enter the film from the organic phase and the same amount of $\mathrm{H}^{+}$ions are transferred from the film to the aqueous phase. Two chemical equilibria are shifted: the acid dissociation of $-\mathrm{COOH}$ and the exchange between bound $\mathrm{H}^{+}$and bound $\mathrm{R}_{2} \mathrm{~N}^{+}$. For every -COOH group involved in the acid dissociation, a larger number $n$ are involved in the ion exchange reaction. When $-\mathrm{COOH}$ dissociates, the proton $\mathrm{H}^{+}$is displaced to the aqueous phase by a $\mathrm{R}_{2} \mathrm{~N}^{+}$ion that enters the film to compensate for the charge of $-\mathrm{COO}^{-}$. Should $\square_{o}^{w} \phi$ be scanned to even more negative values, the $\mathrm{R}_{2} \mathrm{~N}^{+}$concentration in the film would be so that all carboxyl groups would be in $\mathrm{COOR}_{2} \mathrm{~N}$ form and some $\mathrm{HCit}^{2-}$ ions would enter the film to compensate for the charge of the $\mathrm{R}_{2} \mathrm{~N}^{+}$ions. Conversely, as $\square_{o}^{w} \phi$ is scanned from the peak to less negative values, $\mathrm{H}^{+}$ions enter the film from the aqueous phase and $\mathrm{R}_{2} \mathrm{~N}^{+}$ions are transferred from the film to the organic phase. Should $\square_{o}^{w} \phi$ be scanned to moderately positive values, $\mathrm{Li}^{+}$ions would enter the film to compensate for the charge of $-\mathrm{COO}^{-}$. For full clarity, Scheme S1 in the Electronic Supporting Information (†ESI) provides another more detailed overview of the electrochemically-driven reversible ion intercalation process.

\section{Results and Discussion}

\subsection{Electrochemistry of the floating film of ZnPor-INs at the ITIES}

The film of ZnPor-INs formed at the ITIES between a lithium citrate ( $\mathrm{Li}_{2} \mathrm{HCit}$ ) buffered aqueous solution and an organic solution of bis(triphenylphosphoranylidene)ammonium tetrakis(pentafluorophenyl)borate $\left(\mathrm{R}_{2} \mathrm{NTB}\right)$ in TFT (see cell configuration in Scheme 2). An image of the film is shown in Figure S1 (Electronic Supporting Information, †ESI). The 
molecular liquid|liquid boundary is located within the ZnPor-IN film, which is considered as a third phase separating the aqueous and organic solutions and a mixed-solvent layer.

Reference

electrode

Ag $\mid \mathrm{AgCl}$

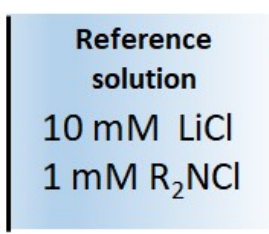

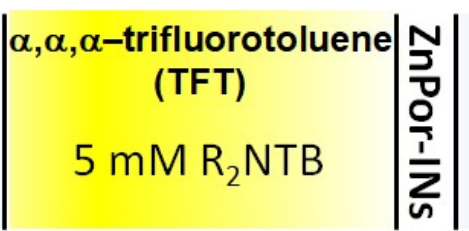

Reference

electrode

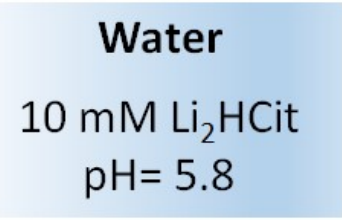

Scheme 2. The general configuration of the four-electrode cell used for electrochemical measurements at the ZnPor-IN functionalised liquid|liquid interface. The organic phase was $5 \mathrm{mM}$ bis(triphenylphosphoranylidene)ammonium tetrakis(pentafluorophenyl)borate $\left(\mathrm{R}_{2} \mathrm{NTB}\right.$ ) in $\alpha, \alpha, \alpha$-trifluorotoluene (TFT). The aqueous phase was lithium citrate ( $\mathrm{Li}_{2} \mathrm{HCit}$ ) at $\mathrm{pH} 5.8$ (unless otherwise stated). The ZnPor-INs were prepared from solutions of ZnPor at concentrations in the range of 10 to $100 \mu \mathrm{M}$ in contact with the TFT for $30 \mathrm{~min}$, as described in the Experimental Section of the †ESI.

Cyclic voltammograms (CVs) were obtained with a four-electrode electrochemical cell, using the configuration outlined in Scheme 2, both in the absence and presence of the floating ZnPor-IN film at a scan rate of $1 \mathrm{mV} \cdot \mathrm{s}^{-1}$. The interfacial concentration $\Gamma_{\mathrm{ZnPor}}$ of ZnPor in the film was determined spectroscopically (Figure S2) as described in the Experimental Section (†ESI) prior to all electrochemical measurements. The control CV in the absence of film was essentially featureless (dashed line, Figure 1a). The only signal observed upon varying the applied interfacial Galvani potential difference ${ }_{o}^{w} \phi$ was due to the aqueous background electrolyte citrate anions transferring to the organic phase at the negative extreme of the polarisable potential window (PPW). By contrast, in the presence of the ZnPor-IN film, several electrochemical signals were observed at negative potentials (solid line, Figure 1a). The absence of redox active species in either phase means that the electrochemical signals in the presence of the ZnPor-IN film were purely ionic in nature. 

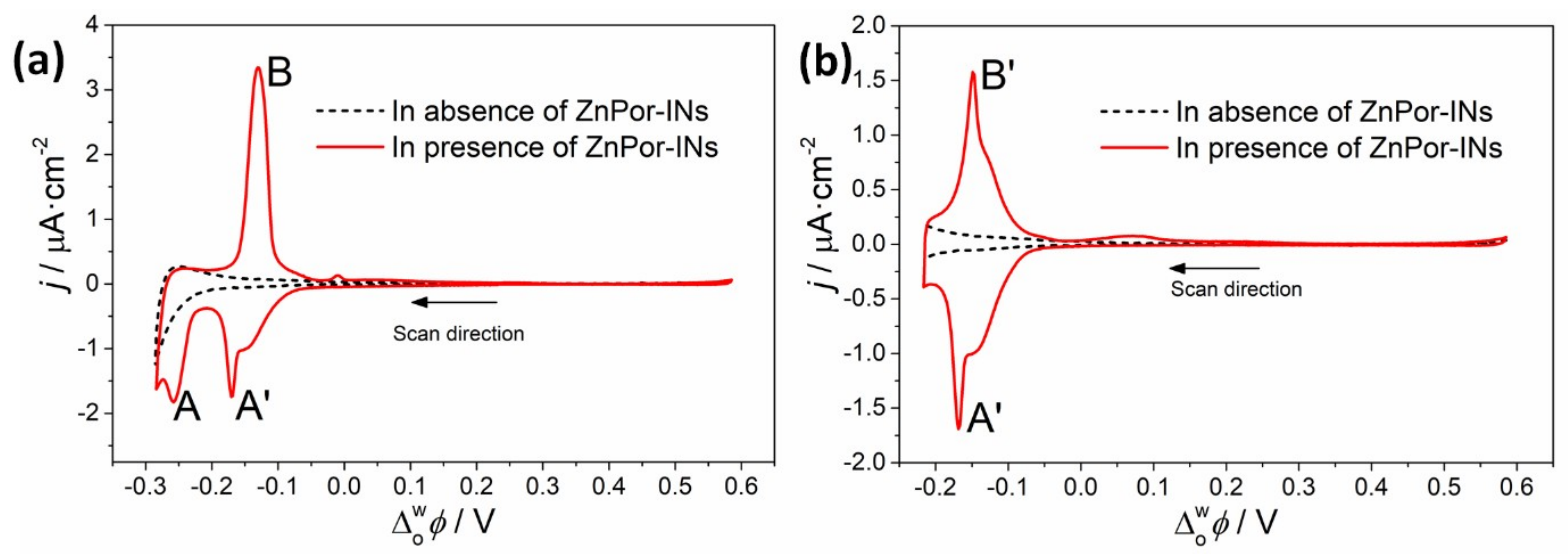

Figure 1. Cyclic voltammetry in the absence (dashed lines) and presence (solid lines) of the ZnPor-IN film at the ITIES. The electrochemical configuration of the four-electrode electrochemical cell was as described in Scheme 2. The influence of systematically varying the lower vertex potential on the CVs was investigated by switching the potential on the negative scan at (a) $-0.285 \mathrm{~V}$ and (b) $-0.215 \mathrm{~V}$. The scan rate was $1 \mathrm{mV} \cdot \mathrm{s}^{-1}$ and the start potential was $0.250 \mathrm{~V}$. The interfacial concentration of ZnPor was $\Gamma_{\mathrm{ZnPor}}=0.88 \mathrm{nmol} \cdot \mathrm{cm}^{-2}$.

The relationship between the two electrochemical signals on the negative scan with negative currents (labelled A and A' in Figure 1a) and the signal on the positive scan with a positive current (labelled B in Figure 1a) was investigated by systematically varying the lower vertex potential (Figure 1b). Switching the potential on the negative scan immediately after the appearance of peak A' lead to a major reduction in the magnitude of the electrochemical signal on the positive scan. Labelled B', this smaller peak was of a near identical shape and magnitude to A' (Figure 1b). Therefore, the electrochemical process giving rise to peak A' was the reverse of that giving rise to peak B'. Indeed, the ratio of the magnitude of the charge for each peak was $Q_{\mathrm{A}^{\prime}} / Q_{\mathrm{B}}, \approx 1$ for CVs obtained at scan rates ranging from 5 to $50 \mathrm{mV} \cdot \mathrm{s}^{-1}$ (Figure S3 and Table S1). Furthermore, as peaks A and A' were related with peak B, both $\mathrm{A}$ and $\mathrm{A}^{\prime}$ were associated with the same species.

The peak-to-peak separation between peaks A' and B' was $5.9 \mathrm{mV}$ at a scan rate of 1 $\mathrm{mV} \cdot \mathrm{s}^{-1}$ (Table S1). Additionally, the peak current $i_{\mathrm{p}}$ for peaks A' and B' varied linearly with the scan rate (Figure S3). Thus, the kinetics of these electrochemical signals were controlled by surface processes in the presence of the ZnPor-IN film. In the electrochemical configuration described in Scheme 2, no ionic species were present capable of undergoing ion transfer across the ITIES within the PPW. Therefore, the electrochemical signals observed in the presence of the ZnPor-IN film were due to a diffusion-less process, i.e., adsorption and capacitive phenomena, and not Faradaic ion transfer. 
Self-assembly of the floating ZnPor-IN film at the ITIES was optimal at $\mathrm{pH} 5.8 .{ }^{36}$ As this $\mathrm{pH}$ matched the $\mathrm{p} K_{\mathrm{a}}$ of the ZnPor carboxyl groups, statistically $50 \%$ of them were deprotonated and charged in the bulk aqueous solution. Differential capacitance measurements are a macroscopic view of the charge distribution of the back-to-back diffusion layer or mixed solvent region. ${ }^{23,37-41}$ The capacitance minimum appears at the potential of zero charge (PZC). Figure 2a shows differential capacitance measurements obtained in the presence and absence of the ZnPor-IN film. Capacitance values were calculated from the imaginary part of the impedance at a frequency of $80 \mathrm{~Hz}$. This frequency was selected in order to suppress Faradaic contributions due to ion transfer within the PPW. This effect was demonstrated in Figure S4a where the Faradaic current due to ion transfer of tetraethylammonium cations across a bare water|TFT interface was entirely filtered out at 80 Hz. A shift in the PZC of $+100 \mathrm{mV}$ was observed in the presence of the ZnPor-IN film (Figure 2a). This shift confirms a negative excess charge at the interface due to presence of deprotonated carboxyl groups at this $\mathrm{pH}^{36}$ The peak at $-0.15 \mathrm{~V}$ was seen at all frequencies across a range from 5 to $80 \mathrm{~Hz}$ (Figure S4b), further confirming that these electrochemical signals in the presence of the ZnPor-IN film were associated with adsorption and capacitive processes.

The electrochemical signals in Figure 1 appear at negative ${ }_{o}^{w} \phi$, suggesting the binding of $\mathrm{R}_{2} \mathrm{~N}^{+}$cations to the carboxyl groups of the ZnPor. These groups may exist in three states: $\mathrm{COO}^{-},-\mathrm{COOH}$ and $-\mathrm{COOR}_{2} \mathrm{~N}$. Their concentrations $\begin{gathered}\mathrm{COO}^{-i} \\ c_{i}\end{gathered}, \quad c_{\mathrm{COOH}}$ and $c_{\mathrm{COO}_{2} \mathrm{~N}}$ can vary with the bulk aqueous $\mathrm{pH}$, the applied $\wedge{ }_{o}^{w} \phi$, as well as with the $\mathrm{Li}_{2} \mathrm{HCit}$ and $\mathrm{R}_{2} \mathrm{NTB}$ concentrations. On the contrary, the total concentration

$$
\begin{gathered}
\mathrm{COO}^{-i}+c_{\mathrm{COOH}}+c_{\mathrm{COOR}_{2} \mathrm{~N}} \\
c_{T, \mathrm{COO}}=c_{i}
\end{gathered}
$$

is a constant related to $\Gamma_{\mathrm{ZnPor}}$. To corroborate the relation with $c_{T, \mathrm{COO}}, \Gamma_{\mathrm{ZnPor}}$ was systematically varied by increasing the bulk aqueous ZnPor concentration during the ZnPorIN film self-assembly. A linear increase in the charge for each peak, $Q_{A^{\prime}}$ and $Q_{B^{\prime}}$, was observed (Figure 2b). This linear increase was obtained despite $\Gamma_{\mathrm{ZnPor}}$ far exceeding that expected for an interfacial monolayer of ZnPor (estimated as $0.095 \mathrm{nmol} \cdot \mathrm{cm}^{-2}$, see Figure S5). Thus, the electrochemical signals were due to processes involving carboxyl groups 
within the ZnPor-IN film, and not only at surface sites facing the aqueous and organic electrolytes.
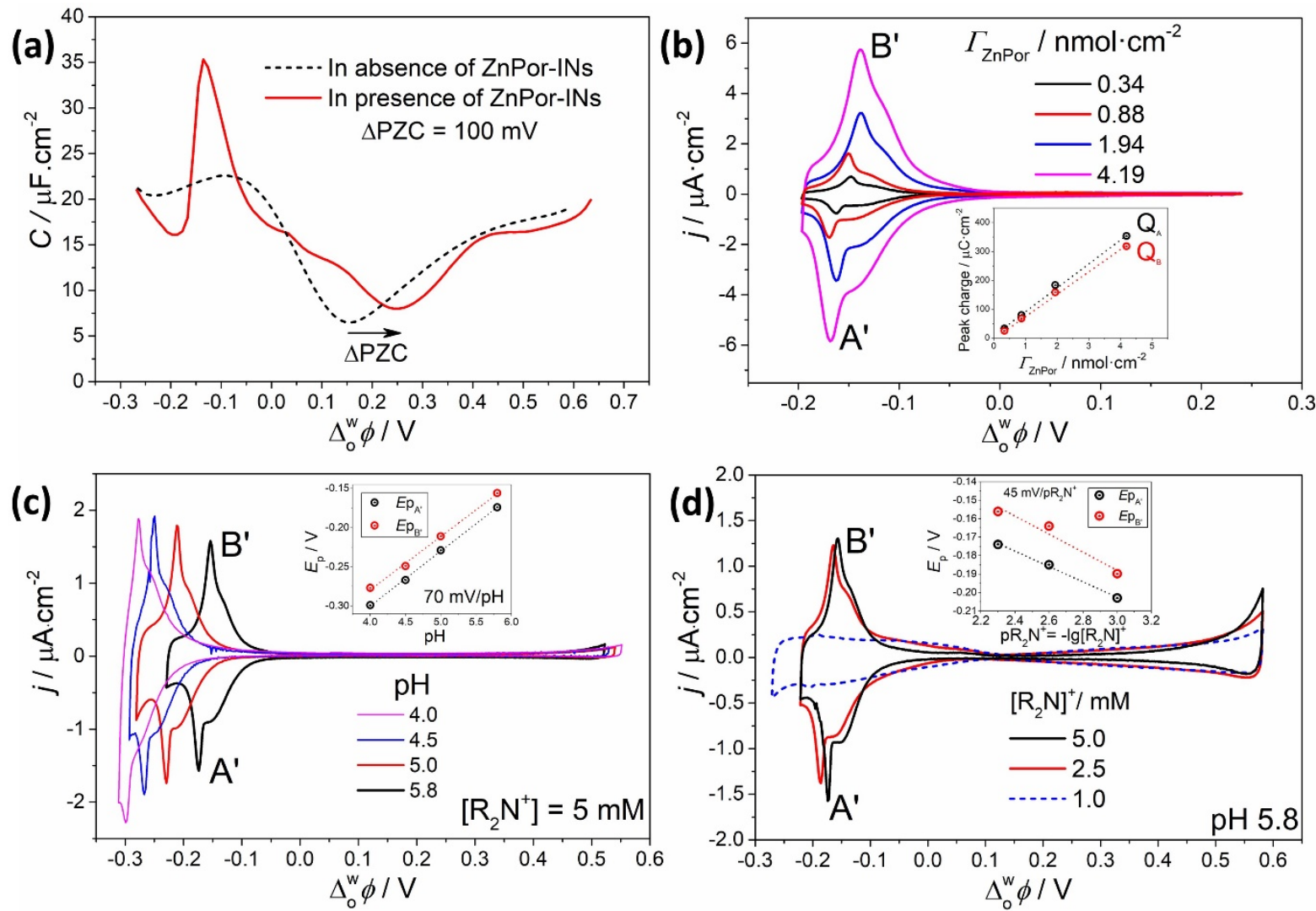

Figure 2. (a) Monitoring the potential of zero charge (PZC) by obtaining differential capacitance curves in the absence (dashed line) and presence (solid line) of the ZnPor-IN film. The capacitances were measured by AC voltammetry using a frequency of $80 \mathrm{~Hz}$. The start potential was $-0.3 \mathrm{~V}$ and $\Gamma_{\text {ZnPor }}$ determined spectroscopically as $0.34 \mathrm{nmol} \cdot \mathrm{cm}^{-2}$. (b) Cyclic voltammetry in the presence of ZnPor-IN films of increasing $\Gamma_{\mathrm{ZnPor}}$. The scan rate used was $1 \mathrm{mV} \cdot \mathrm{s}^{-1}$. Inset: dependence of the peak charge $Q$ on $\Gamma_{\mathrm{ZnPor}}$. The effect of varying (c) the $\mathrm{pH}$ and (d) $\mathrm{R}_{2} \mathrm{NTB}$ concentration on the electrochemical response was investigated in the presence of the ZnPor-IN film. The scan rate used was $5 \mathrm{mV} \cdot \mathrm{s}^{-1}$ and $\Gamma_{\mathrm{ZnPor}}$ was $0.34 \mathrm{nmol} \cdot \mathrm{cm}^{-}$ ${ }^{2}$. Insets in (c) and (d): the relationships between peak potential $E_{\mathrm{p}}$ and $\mathrm{pH}$ or $\mathrm{pR}_{2} \mathrm{~N}^{+}(=-$ $\lg \left[\mathrm{R}_{2} \mathrm{~N}^{+}\right]$), respectively. For clarity, a zoomed in version of the CV obtained with $\left[\mathrm{R}_{2} \mathrm{~N}^{+}\right]=1$ $\mathrm{mM}$ (dashed blue line) in (d) is shown in Figure S6.

To probe the effects of the bulk aqueous $\mathrm{pH}$ and $\mathrm{R}_{2} \mathrm{~N}^{+}$concentration, both were varied independently (Figures 2c and d). As we described previously, ${ }^{36}$ the ZnPor-INs were stabilised by cooperative hydrogen bonding. Thus, $\mathrm{pH}$ conditions more alkali than the carboxyl groups $\mathrm{p} K_{\mathrm{a}}$ of 5.8 were ruled out as the ZnPor-IN film would destabilise and dissolve. The peak potentials for peaks $\mathrm{A}^{\prime}\left(E_{\mathrm{pA}^{\prime}}\right)$ and $\mathrm{B}^{\prime}\left(E_{\mathrm{pB}}\right)$ were found to depend on both the $\mathrm{pH}$ and $\mathrm{pR}_{2} \mathrm{~N}^{+}$(where $\mathrm{pR}_{2} \mathrm{~N}^{+}=-\lg \left[\mathrm{R}_{2} \mathrm{~N}^{+}\right]$), confirming their role in the electrochemical 
processes occurring at the ZnPor-IN functionalised ITIES. Uniform shifts of $-70 \mathrm{mV} / \mathrm{pH}$ and $+45 \mathrm{mV} / \mathrm{pR}_{2} \mathrm{~N}^{+}$were observed for both $E_{\mathrm{pA}}$ and $E_{\mathrm{pB}}$ ' (insets, Figures 2c and d). The magnitude of peaks $A^{\prime}$ and $B^{\prime}$ decreased drastically at the lowest $R_{2} N^{+}$concentration investigated $\left(\left[\mathrm{R}_{2} \mathrm{~N}^{+}\right]\right.$ $=1 \mathrm{mM}$ ), Figure 2d and Figure S6.

The influence of the nature of the organic anion on the electrochemical response was also investigated. Citrate anions are sensitive to $\mathrm{pH}$, with $\mathrm{p} K_{\mathrm{a}}$ 's at $3.13,4.76$ and 6.40, respectively. ${ }^{42}$ Thus, as the $\mathrm{pH}$ at the ITIES varies as a function of applied ${ }_{o}^{w} \phi$, a pH insensitive anion was chosen for comparison by replacing $\mathrm{Li}_{2} \mathrm{HCit}$ with $\mathrm{LiCl}$. As shown in Figure S7, the nature of the anion had minimal effect on the electrochemical response. A near identical $\mathrm{CV}$ shape was observed and the trend in the shifts of $E_{\mathrm{pA}}$ and $E_{\mathrm{pB}}$, with $\mathrm{pH}$ replicated.

Peaks A' and B' in the CVs in Figures 1 and 2b-d are formed by the superposition of a narrow peak and a broad peak. Narrow "adsorption" peaks in CVs are considered to indicate positive cooperativity, i.e., every adsorption event is facilitated by the occurrence of a previous adsorption event. In this regard, for fundamental thermodynamic reasons, the CVs can be described using the Frumkin isotherm. ${ }^{15}$ For peak B', we attribute the broad shoulders to binding of $\mathrm{R}_{2} \mathrm{~N}^{+}$at $-\mathrm{COO}^{-}$groups and ion exchange of $\mathrm{R}_{2} \mathrm{~N}^{+}$with $-\mathrm{COOH}$ groups (in which protons are displaced) near the IN $\mid 0$ interface as $\mathrm{R}_{2} \mathrm{~N}^{+}$flows from the organic phase into the ZnPor-IN film. The sharp peak of B' is attributed to binding and ion exchange of $\mathrm{R}_{2} \mathrm{~N}^{+}$at $-\mathrm{COO}^{-}$and $-\mathrm{COOH}$ groups, respectively, deeper inside the ZnPor-IN film. The second electrochemical signal on the negative scan, peak A, is attributed to a second binding and ion exchange event inside the ZnPor-IN film requiring more electrochemical driving force (see Figure 1a). As detailed in the following section, all peaks are capacitive in nature and resemble "adsorption" due to a saturation limit to the concentration of $-\mathrm{COOR}_{2} \mathrm{~N}$ species that form by binding and ion exchange as ${ }_{o}^{w} \phi$ is scanned negatively.

\subsection{Modelling of electrochemically-driven reversible ion intercalation in the presence of the ZnPor-IN film}

The modelling aims to clarify: (i) the capacitive nature of the electrochemical signals at negative ${ }_{o}^{w} \phi \quad$ in the presence of the ZnPor-IN film, (ii) the trends in the shifts of the peak potentials as a function of the bulk aqueous $\mathrm{pH}$ and $\mathrm{R}_{2} \mathrm{~N}^{+}$concentration, and (iii) the characteristic CV shapes indicative of positive cooperativity. For the electrolyte concentrations used in the electrochemical experiments, the film thickness, $L^{\mathrm{IN}} \approx 100 \mathrm{~nm},{ }^{36}$ is 
much larger than the aqueous and organic Debye lengths and the molecular liquid|liquid boundary is located within the ZnPor-IN film. Thus, as the film is considered as an intermediate phase (IN) separating the aqueous (w) and organic (o) solutions. From the point of view of ion solvation, it is a mixed-solvent layer, disliked by both aqueous ions and organic ions.

Within the PPW, no ions can transfer across the ITIES and the ZnPor-IN film behaves as a capacitor (Scheme 3). When ${ }_{o}^{w} \phi \quad$ is scanned progressively more negative, the $\mathrm{R}_{2} \mathrm{~N}^{+}$ions are "pushed" into the film, but cannot transfer to the aqueous phase. Then, a few -COOH groups are forced to dissociate, and many more transform into $-\mathrm{COOR}_{2} \mathrm{~N}$. In both cases, the released $\mathrm{H}^{+}$ions are "pulled" into the aqueous phase. The charge of the anionic carboxyl groups $-\mathrm{COO}^{-}$is mostly compensated by $\mathrm{R}_{2} \mathrm{~N}^{+}$, which are the majority ions in the film; $\mathrm{HCit}^{2-}$ and $\mathrm{Li}^{+}$are present only when ${ }_{o}^{w} \phi$ is very different to that around the peaks in Figure $2 \mathrm{~b}$. To understand the behaviour of the film as a capacitor, carboxyl groups in - $\mathrm{COOH}$ form are taken as a reference corresponding to absence of charges in the capacitor "plates". The positive plate accumulates charge in the form of free and bound $\mathrm{R}_{2} \mathrm{~N}^{+}$. That is, the charge $q^{o}$ in this positive plate is basically proportional to $C_{\mathrm{COO}_{2} \mathrm{~N}}+c_{R_{2} N}^{i}$. The negative plate has a charge $q^{w}<0$ which is a measure of the reduction in the amount of - $\mathrm{COOH}$ groups, and hence proportional to $c_{T, \mathrm{COO}}-c_{\mathrm{COOH}}$. As $\square_{o}^{w} \phi$ is made more negative, $q^{o}=-q^{w}>0$ increases, but remains of the order of $c_{T, \text { COO }}$. The unfavourable solvation in this mixed-solvent layer bounds the free ion concentrations $c_{R_{2} N}^{i}$ and $c_{H C i t}^{i}$ to relatively small values, even for the most negative ${ }_{o}^{w} \phi$.

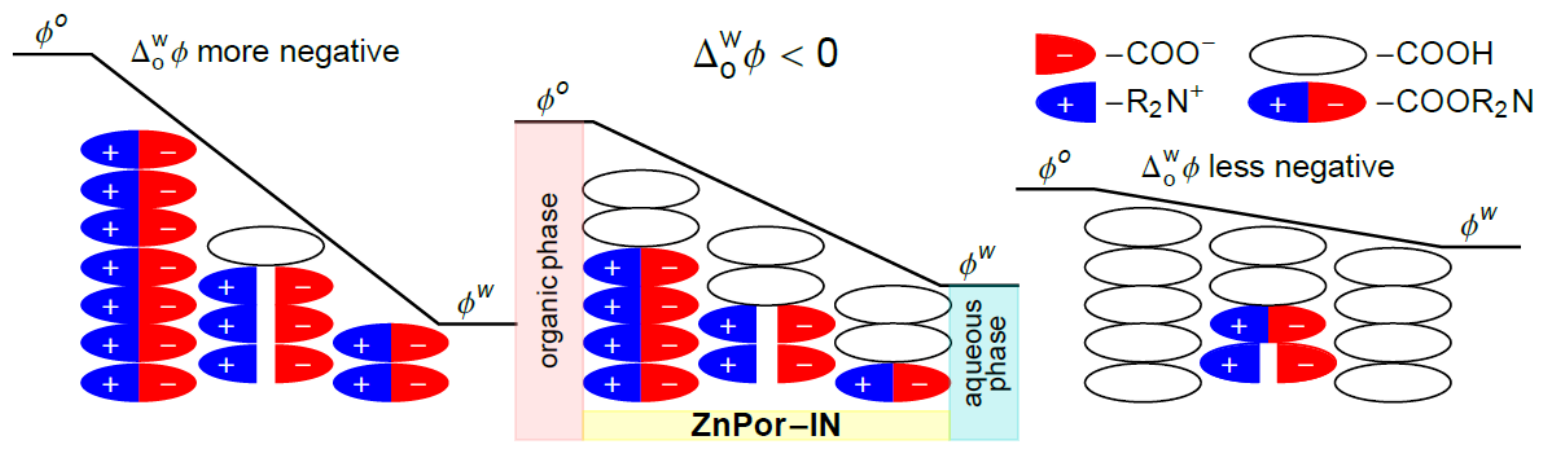

Scheme 3. The ZnPor-IN functionalised liquid|liquid interface behaves as a capacitor. Carboxyl groups in $-\mathrm{COOH}$ form are taken as a reference corresponding to absence of charges in the capacitor "plates". When ${ }_{o}^{w} \phi$ is scanned progressively negative, the $\mathrm{R}_{2} \mathrm{~N}^{+}$ 
ions are "pushed" into the film, a few $-\mathrm{COOH}$ groups are forced to dissociate, and many more transform into $-\mathrm{COOR}_{2} \mathrm{~N}$. The released $\mathrm{H}^{+}$ions are "pulled" into the aqueous phase.

The concentrations of the ionic species $\mathrm{R}_{2} \mathrm{~N}^{+}, \mathrm{TB}^{-}, \mathrm{HCit}^{2-}, \mathrm{H}^{+}$and $\mathrm{Li}^{+}$in the film (phase IN) must satisfy the local electroneutrality condition

$$
\begin{gathered}
\mathrm{COO}^{-i}+2 c_{H C i t}^{i}+c_{T B}^{i}=c_{R_{2} N}^{i}+c_{L i}^{i}+c_{H}^{i} \\
c_{i}
\end{gathered}
$$

The local electroneutrality condition can also be presented as $q^{o}+q^{w}=i \quad 0$ where

$$
\begin{aligned}
& q^{o}=F L^{i}\left(c_{\mathrm{COO} R_{2} N}+c_{R_{2} N}^{i}-c_{T B}^{i}\right) \\
& -q^{w}=F L^{i}\left(c_{T, \mathrm{COO}}-c_{\mathrm{COOH}}+2 c_{\mathrm{HCit}}^{i}-c_{H}^{i}-c_{L i}^{i}\right)
\end{aligned}
$$

are the charge densities in the capacitor and $F$ is Faraday's constant. In the potential range $-0.25 V<{ }_{o}^{w} \phi \leftarrow 0.05 V^{\text {x }} \quad$ the concentrations of $\mathrm{R}_{2} \mathrm{~N}^{+}, \mathrm{HCit}^{2-}$ and $-\mathrm{COO}^{-}, c_{R_{2} N}^{i}$, $c_{H C i t}^{i}$ and $\operatorname{COO}_{c_{i}}^{i}$, are the dominant terms in Equation (2). For $\wedge{ }_{o}^{w} \phi>-0.05 \mathrm{~V}$, the

concentrations $C_{L i}^{i}$ and $c_{T B}^{i}$ of the $\begin{aligned} & +\dot{i} \\ & L i^{i}\end{aligned}$ and $\frac{-i}{T B^{i}}$ species may become significant. Although some species make a negligible contribution in Equation (2), we keep them all for the sake of generality. The electrical double layers at the o|IN and IN|w interfaces extend over a fraction of the film thickness $L^{\mathrm{IN}}$, and local electroneutrality does not hold there. However, the contributions of the associated interfacial capacitances are small compared to other effects described below and, therefore, can be neglected.

The concentrations of the ionic species in phase IN are different from those in their respective phases. In absolute value, the Gibbs energy of transfer of the organic ions from phase o to phase IN is intermediate to that from phase o to phase w. Similarly, in absolute value, the Gibbs energy of transfer of the aqueous ions from phase $\mathrm{w}$ to phase IN is intermediate to that from phase $\mathrm{w}$ to phase o. Therefore, the ions have no chemical preference to enter phase IN, and their chemical partition coefficients into this phase are significantly lower than unity, $\quad P_{i} \ll 1$. The applied potential ${ }_{o}^{w} \phi$ also affects the distribution of the ions. The potential $\phi^{i}$ is usually intermediate between those phases $\mathrm{w}$ and o, so that ${ }_{i}^{w} \phi=\phi^{w}-\phi^{i}, \quad{ }_{o}^{i} \phi=\phi^{i}-\phi^{o} \quad$ and 


$$
{ }_{o}^{w} \phi={ }_{i}^{w} \phi+{ }_{o}^{i} \phi
$$

have the same sign. The distribution equilibrium of, e.g., the organic cation $\mathrm{R}_{2} \mathrm{~N}^{+}$between phases o and IN requires $\quad c_{R_{2} N}^{i}=c^{o, b} P_{R_{2} N} e^{-f \square_{o}^{i} \phi} \quad \begin{gathered}+i \\ \text { where } \\ R_{2} N^{i} \\ c^{o, b}=i\end{gathered}$ is its concentration in the bulk organic phase. Similar equations can be formulated for the other species, as described in detail in the $† E S I$.

The evaluation of the concentrations $\begin{gathered}\mathrm{COO}^{-i} \\ c_{i}\end{gathered}, c_{\mathrm{COOH}}$ and $c_{\mathrm{COOR}_{2} \mathrm{~N}}$ in Equations (2)-(4) require the simultaneous consideration of the ionic distribution equilibria and the chemical equilibria. Since $c_{H}^{b}=c_{H}^{w, b} P_{H} e^{f \square_{i}^{w} \phi}$, both the negative ${ }_{o}^{w} \phi$ and the mixedsolvent nature of phase IN contribute to increase the interfacial $\mathrm{pH}$ with respect to the bulk aqueous $\mathrm{pH}, \quad p H^{i}-p H=-\lg \left(c_{H}^{i} / c_{H}^{w, b}\right)>0$. Yet, if the latter is equal or lower than the $p K_{a}=5.8$ of the carboxyl groups, some of these groups can be protonated according to the equilibrium

$$
\begin{gathered}
C_{H}^{i} \frac{C_{\mathrm{COO}^{-i}}}{c_{\mathrm{COOH}}} \\
K_{a}^{i} C^{\circ}=\dot{i}
\end{gathered}
$$

where $c^{\circ}=1 M$ and $K_{a}^{b}=K_{a} P_{H}$, see Equation (S32) in the †ESI. The abundant $\mathrm{R}_{2} \mathrm{~N}^{+}$ cations in phase IN can displace the bound protons and form $-\mathrm{COOR}_{2} \mathrm{~N}$ groups. The equilibrium of the ion exchange reaction

$$
\begin{gathered}
+\dot{+}(\dot{i}) \underset{(i)}{\rightleftarrows}-\mathrm{COO} R_{2} N(\dot{i})+H^{i} \\
-\mathrm{COOH}(\dot{i})+R_{2} N^{i}
\end{gathered}
$$

requires

$$
\begin{gathered}
\circ, \in i=\frac{C_{H}^{i} c_{\mathrm{COOR}_{2} N}}{C_{R_{2} N}^{i} c_{\mathrm{COOH}}} \\
K_{I E}^{i}
\end{gathered}
$$

where $\underset{K_{I E}^{i}}{\stackrel{\circ}{i}}$ is the equilibrium constant. From Equations (1), (6) and (8), the fraction of charged carboxyl groups is 


$$
\begin{gathered}
K_{a}^{i} C^{\circ}+C_{H}^{i}+K_{I E}^{0, \in i C_{R_{2} N}^{i}} \\
\frac{C_{C O O^{-i}}}{C_{T, C O O}}=\frac{K_{a}^{i} C^{\circ}}{\dot{i}}
\end{gathered}
$$

Substituting $\begin{gathered}\mathrm{COO}^{-i} \\ c_{i}\end{gathered}$ from Equation (9) into Equation (2), and using the conditions of distribution equilibria of the ionic species, the potential drop $\square_{\zeta}^{w} \phi \quad$ can be determined, see Equation (S17) in the †ESI. Hence, the ionic concentrations and $q^{o}$ are known as functions of $\square_{o}^{w} \phi$, as well as the differential capacitance of the ZnPor-IN film

$$
C=-d q^{o} / d \square_{o}^{w} \phi
$$

The applied potential ${ }_{o}^{w} \phi$ affects the distribution of the ions, and hence also the ion exchange equilibrium. Thus, Equation (8) can be transformed to

$$
\begin{gathered}
\circ, \in \dot{i} \frac{c^{o, b} P_{R_{2} N}}{c_{H}^{w, b} P_{H}} e^{-f \square_{o}^{w} \phi} \\
\frac{c_{\mathrm{COO}_{2} N}}{c_{\mathrm{COOH}}}=K_{I E}^{i}
\end{gathered}
$$

As $\Delta_{o}^{w} \phi$ is scanned progressively negative, $q^{o}=-q^{w}>0$ increases. Across the IN $\mid \mathrm{w}$ interface, $\quad \begin{gathered}2-i \\ H C i t^{i}\end{gathered}$ ions may flow from phase w into phase IN (if $\square_{o}^{w} \phi$ is sufficiently negative); the flow of $\mathrm{Li}^{+}$and $\mathrm{H}^{+}$ions from phase $\mathrm{IN}$ to phase $\mathrm{w}$ is usually negligible. Across the o|IN interface, $\mathrm{R}_{2} \mathrm{~N}^{+}$ions flow into phase IN; the flow of $\mathrm{TB}^{-}$ions from phase IN to phase o is usually much smaller. The increase in $c_{R_{2} N}^{i}=c^{o, b} P_{R_{2} N} e^{-f \square_{o}^{b} \phi}$ shifts the ion exchange equilibria towards the formation of $-\mathrm{COOR}_{2} \mathrm{~N}$, at the expense of reducing $\begin{gathered}\mathrm{COO}^{-i} \\ \mathrm{c}_{i}\end{gathered}$ and $C_{\mathrm{COOH}}$. The increase in $C_{\mathrm{COO}_{2} \mathrm{~N}}$ gives rise to an "adsorption" peak in the $\mathrm{CV}$ because there is a saturation limit, $\quad c_{\mathrm{COO}_{2} \mathrm{~N}} \leq C_{T, \mathrm{COO}}$. By convention, a positive charge flow from o to $\mathrm{w}$ gives rise to a peak in the CV of negative current. ${ }^{20,21}$ Similarly, as $\square_{o}^{w} \phi$ is made more positive, $q^{w}=-q^{o}>0$ increases. Across the o|IN interface, $\mathrm{R}_{2} \mathrm{~N}^{+}$ions flow towards phase 0 . Across the IN|w interface, $\mathrm{HCit}^{2-}$ ions flow towards phase w. During such a potential scan, $c_{\mathrm{COOR}_{2} \mathrm{~N}}$ decreases as $\begin{gathered}\mathrm{COO}^{-i} \\ c_{i}\end{gathered}$ and $c_{\mathrm{COOH}}$ increase. The increase in $\begin{gathered}\mathrm{COO}^{-i} \\ c_{i}\end{gathered}$ 
gives rise to an "adsorption" peak with a positive current in the CV (negative charge flow from o to $\mathrm{w})$.

The CVs can be simulated using an equivalent electrical circuit consisting of the solution resistance $R_{\text {sol }}$ in series with the parallel combination of the film capacitance $C$ and the charge transfer resistance $\quad R_{c t}$ (see Equations S19 and S20, †ESI). This simple theoretical model qualitatively captures the main features of the experimental CVs, such as the total charge under the peaks, the peak separation and their variation with the bulk aqueous $\mathrm{pH}$ and the organic electrolyte concentration (see Figure 3 and Tables S2 and S3). However, this model does not accurately reproduce the shape of the peaks. The experimental peaks are the superposition of a narrow peak and a broad peak, the former occurring at a more negative

$\square_{o}^{w} \phi \quad$ and having a smaller area (and hence charge) under the peak. Even the broad peak is narrower than predicted by this model.
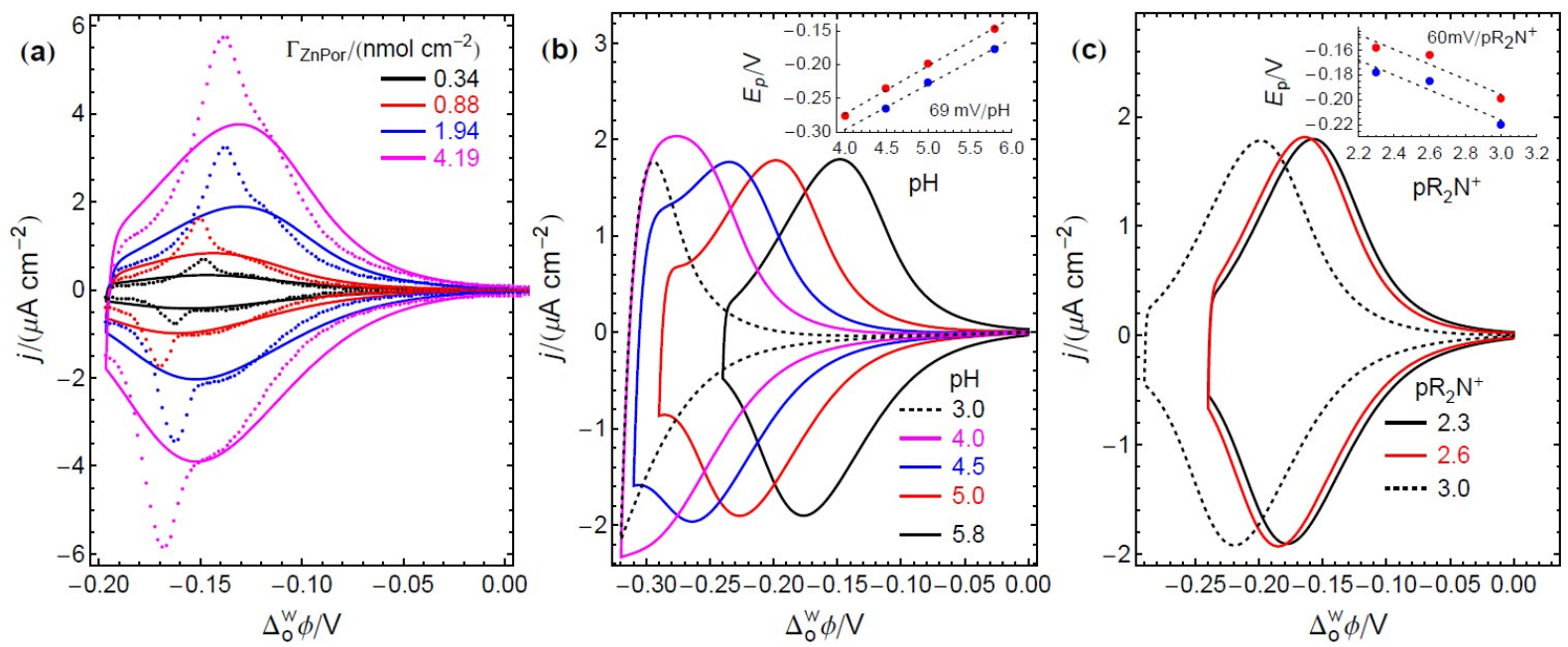

Figure 3. CVs generated using the theoretical model qualitatively capture the main features of the experimental CVs at the ITIES in the presence of a ZnPor-IN film. (a) A comparison of the simulated (lines) and experimental CVs (symbols) at $1 \mathrm{mV} \cdot \mathrm{s}^{-1}$ for the electrochemical cell described in Scheme 2 (with $5 \mathrm{mM} \mathrm{R} \mathrm{R}_{2} \mathrm{NTB}, 10 \mathrm{mM} \mathrm{Li}_{2} \mathrm{HCit}$, a bulk aqueous $\mathrm{pH}=5.8$ and varying $\Gamma_{\text {ZnPor }}$ ). In particular, the peak separation and the total charge under the peaks are well reproduced, though the shape of the peaks is not. The simulated CVs accurately describe the experimentally observed values of peak potentials and their linear shift with (b) the $\mathrm{pH}$ and (c) the $\mathrm{R}_{2} \mathrm{NTB}$ concentration at $5 \mathrm{mV} \cdot \mathrm{s}^{-1}$ and $\Gamma_{\mathrm{ZnPor}}=0.34 \mathrm{nmol} \cdot \mathrm{cm}^{-2}$. The parameter values for the simulations in panels (a)-(c) are shown in Tables S2 and S3.

Narrow "adsorption" peaks in the CVs are considered an indication of positive cooperativity. Herein, we propose that once the initial bulky $\mathrm{R}_{2} \mathrm{~N}^{+}$cations flow across the o| IN interface as $\square_{o}^{w} \phi \quad$ is scanned negatively, they "open" space in the nanostructure due to 
structural rearrangements of the porphyrins allowing the later $\mathrm{R}_{2} \mathrm{~N}^{+}$species to penetrate the ZnPor-IN film much more easily. Thus, this conformational change of the ZnPor-INs is the physical reason behind the negative $g$ interaction parameters discussed vide infra, that are characteristic of positively cooperative adsorption. Furthermore, the characteristic shape of the purely capacitive CVs due to structural rearrangements of the porphyrins at the electrified liquid|liquid interface precisely resemble those of systems involving phase transitions at electrified solid|liquid interfaces, for example electrochemically driven structural changes of a copper adlayer on a $\mathrm{Au}(111)$ electrode surface. ${ }^{43}$

Cooperative binding of $\mathrm{R}_{2} \mathrm{~N}^{+}$ions can be described using the Frumkin isotherm, described in detail in the †ESI. As mentioned above, the peaks in the experimental CVs are formed by the superposition of a narrow peak and a broad peak. Accordingly, we have simulated the CV by adding the theoretical curves calculated with two sets of carboxyl groups, described by Equation (S24) in the †ESI. The set responsible for the narrow peak has a more negative

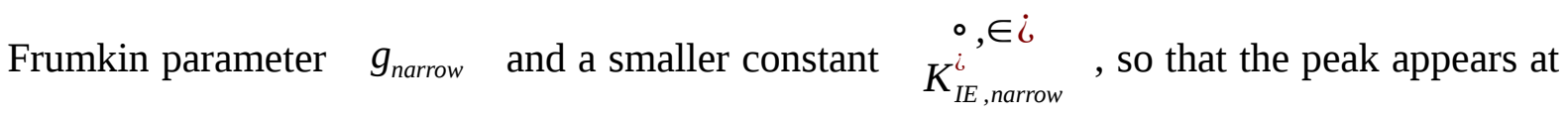
more negative $\square_{o}^{w} \phi$, compared to the less negative $g_{\text {broad }}$ and larger $\begin{gathered}\circ, \in \dot{i} \\ K_{I E, \text { broad }}^{i}\end{gathered}$ corresponding to the set responsible for the broad peak. The electrical parameters $R_{\text {sol }}$ and $R_{c t}$ in Equation (S20), †ESI, are common to both sets (Table S4). At $298 \mathrm{~K}$, $g_{\text {narrow }}=-3.5$ and $g_{\text {broad }}=-0.7$ correspond to attractive interaction energies $z_{c} \varepsilon_{\text {narrow }}=g_{\text {narrow }} R T=-8.67 \mathrm{~kJ} \cdot \mathrm{mol}^{-1} \quad$ and $\quad g_{\text {broad }} R T=-1.73 \mathrm{~kJ} \cdot \mathrm{mol}^{-1}$. These $g$ values seem reasonable on the basis of the excellent agreement (Figures 4 and S7) between the simulated and the experimental CVs, given the complexity of the system under consideration. Moreover, a value $g=-4.2$ was observed for a $\mathrm{Li}^{+}$intercalation process, a system with very similar underlying thermodynamics. ${ }^{13}$ 


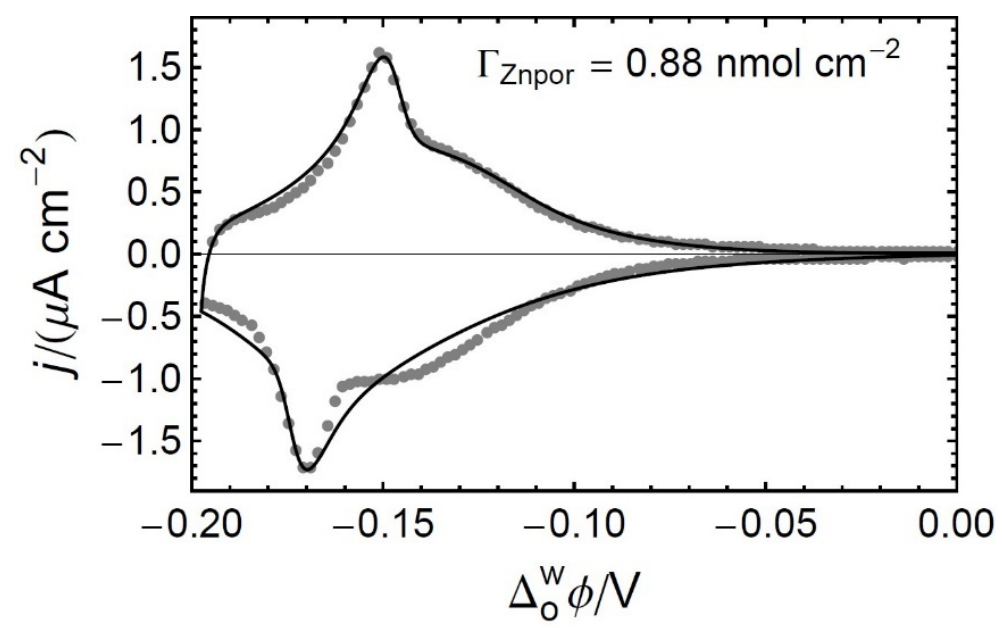

Figure 4. The consideration of two types of binding sites, described by Equation (S24), †ESI, with $g_{\text {narrow }}=-3.5$ and $g_{\text {broad }}-0.7$, predicts simulated CVs (lines) at $1 \mathrm{mV} \cdot \mathrm{s}^{-1}$ and $\Gamma_{\mathrm{ZnPor}}$ $=0.88 \mathrm{nmol} \cdot \mathrm{cm}^{-2}$ that resemble more closely the experimental observations (symbols). Comparisons are provided for CVs obtained with $\Gamma_{\text {ZnPor-INs }}$ values of $0.34,1.94$ and $4.19 \mathrm{nmol} \cdot \mathrm{cm}^{-2}$ in Figure S8. The parameter values (Table S4) have been chosen on the basis of a qualitative agreement and not using a fitting algorithm.

\subsection{Kinetics of electrochemically-driven reversible ion intercalation in the presence of the ZnPor-IN film}

As $\quad \Delta_{o}^{w} \phi$ is scanned progressively negative, ion intercalation of $\mathrm{R}_{2} \mathrm{~N}^{+}$from the organic phase into the ZnPor-IN film proceeds by binding and ion exchange, with $c_{\mathrm{COOR}_{2} \mathrm{~N}}^{i}$ increasing. The aim of this section is to investigate the kinetics of this process by potentialstep chronoamperometry. A particular focus is placed on the influence of both $\Delta_{o}^{w} \phi$ and $\Gamma_{\mathrm{ZnPor}}$ on the rates of the charge transfer processes. Current transients were obtained by maintaining a constant initial potential $\Delta_{o}^{w} \phi_{\text {initial }}$ for $t_{\text {initial }}=30 \mathrm{~s}$, and varying the final potential $\Delta_{o}^{w} \phi_{\text {final }}$ in $50 \mathrm{mV}$ increments across the region where the electrochemical signals were observed $\left(-0.05 V>\Delta_{o}^{w} \phi>-0.30 \mathrm{~V}\right)$, see Figure S9 and Figures 5a-b. The value $\Delta_{o}^{w} \phi_{\text {initial }}=+0.25 \mathrm{~V}$ was chosen because no discernable electrochemical processes were occuring at that $\Delta_{o}^{w} \phi$, besides capacitive charging of the back-to-back double layers at the ITIES. Once more, four electrochemical cells with increasing $\Gamma_{\text {ZnPor }}(0.34,0.88,1.94$, and $4.19 \mathrm{nmol} \cdot \mathrm{cm}^{-2}$ ) were investigated.

Depending on $\Delta_{o}^{w} \phi_{\text {final }}$ and $\Gamma_{\text {ZnPor }}$, the current transients presented a decay component, commonly associated to an adsorption process, and multiple rising components with current 
maxima, commonly associated with nucleation and growth processes. In this regard, these current transients obtained by potential-step chronoamperometry are highly reminiscent of those generated using the same technique to study the kinetics of structural changes during the electrochemical switching of electronically conducting polymer films, such as polypyrrole, between their reduced (insulating) and oxidised (electronically conducting) states. $^{35}$ The kinetics of processes in conducting polymers that lead to a current maximum after a potential-step are described by the electrochemically stimulated conformational relaxation (ESCR) model. ${ }^{44,45}$ In common with conducting polymer films, electrochemically driven processes (binding and ion exchange) in the ZnPor-IN film occur throughout a threedimension volume, with ion intercalation steps linked to morphological changes in the film structures.

A key question is how do we define the meaning of "nucleation" in the context of the ZnPor-IN film at the ITIES? Herein, we propose that the presence of nucleation transients was associated with domains within the nanostructures where, due to structural rearrangements of the porphyrins, the binding and ion exchange of $\mathrm{R}_{2} \mathrm{~N}^{+}$at $-\mathrm{COO}^{-}$and $\mathrm{COOH}$ groups, respectively, took place faster. Also, the energetically less demanding binding and ion exchange of further $\mathrm{R}_{2} \mathrm{~N}^{+}$species after these structural rearrangements of the porphyrins is the physical reason underlying the electrochemical observation of positively cooperative behaviour discussed earlier. 

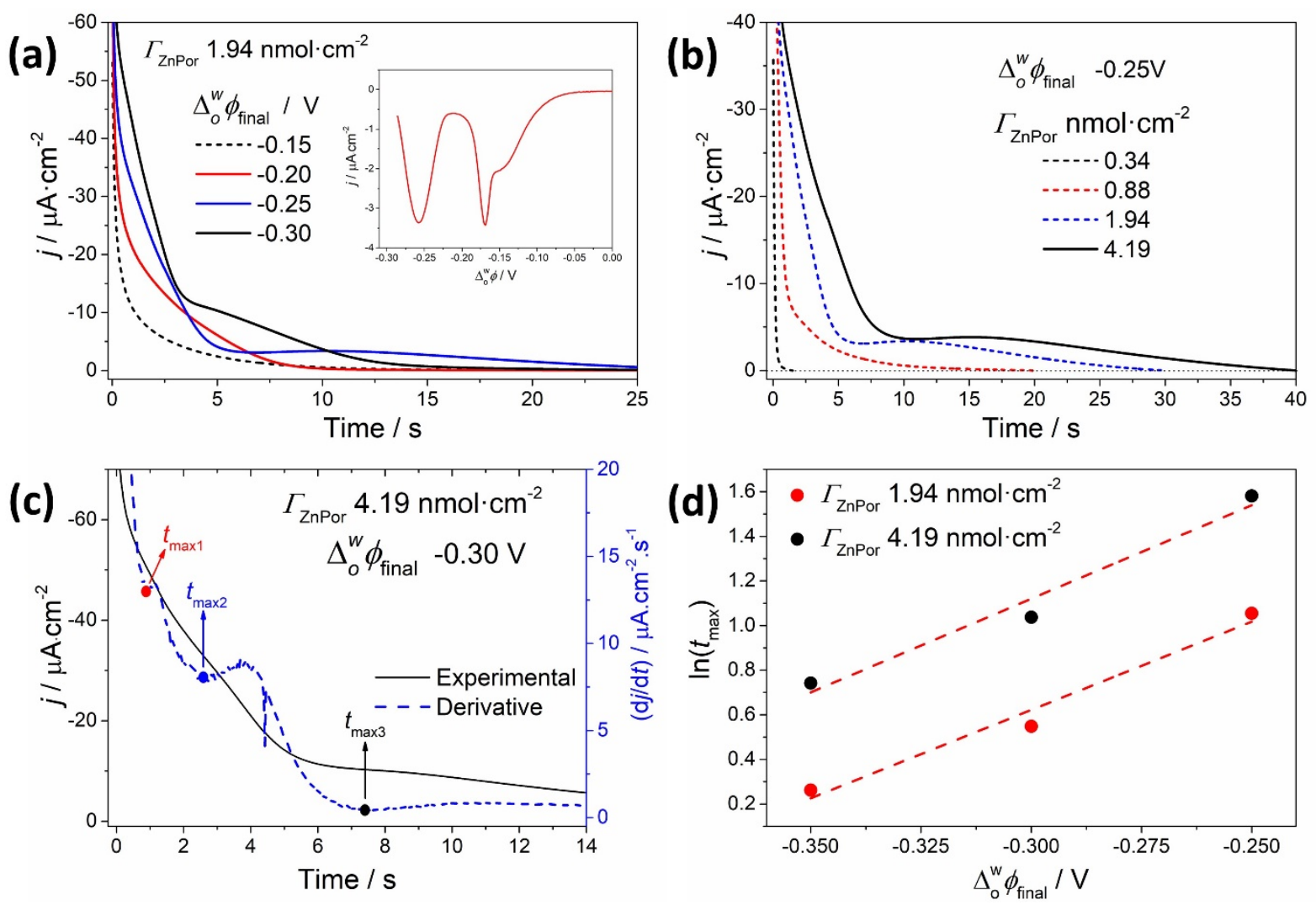

Figure 5. Kinetics of electrochemically-driven reversible ion intercalation by potential-step chronoamperometry in the presence of the ZnPor-IN film. (a) Current transients probing the influence of $\Delta_{o}^{w} \phi_{\text {final }}$ were obtained by varying $\Delta_{o}^{w} \phi_{\text {final }}$ in $50 \mathrm{mV}$ increments at a constant $\Gamma_{\text {ZnPor }}$ of $1.94 \mathrm{nmol} \cdot \mathrm{cm}^{-2}$ and $\Delta_{o}^{w} \phi_{\text {initial }}$ of $+0.25 \mathrm{~V}$ for $30 \mathrm{~s}\left(t_{\text {initial }}\right)$. (b) Current transients probing the influence of $\Gamma_{\text {ZnPor }}$ were obtained by increasing $\Gamma_{\text {ZnPor }}$ from 0.34 to 4.19 $\mathrm{nmol} \cdot \mathrm{cm}^{-2}$ while maintaining a constant $\Delta_{o}^{w} \phi_{\text {initial }}$ of $+0.25 \mathrm{~V}$ for $30 \mathrm{~s}$ and $\Delta_{o}^{w} \phi_{\text {final }}$ of $0.25 \mathrm{~V}$. (c) Deconvolution of the $t_{\max }$ values of the nucleation components from an experimental current transient (solid black line, obtained with a $\Gamma_{\text {ZnPor }}$ of $4.19 \mathrm{nmol} \cdot \mathrm{cm}^{-2}$, $\Delta_{o}^{w} \phi_{\text {initial }}$ of $+0.25 \mathrm{~V}$ for $30 \mathrm{~s}$, and $\Delta_{o}^{w} \phi_{\text {final }}$ of $-0.30 \mathrm{~V}$ ) by obtaining the derivative (dashed blue line). (d) Plot of $\ln \left(t_{\max } / \mathrm{s}\right)$ versus $\Delta_{o}^{w} \phi_{\text {final }}$ for current transients obtained with a $\Delta_{o}^{w} \phi_{\text {initial }}$ of $+0.25 \mathrm{~V}$ for $30 \mathrm{~s}$ and $\Gamma_{\text {ZnPor }}$ of either 1.94 (red circles) or $4.19 \mathrm{nmol} \cdot \mathrm{cm}^{-2}$ (black circles). The $t_{\max }$ data is that obtained for the second nucleation component, designated as $t_{\max 2}$ in Table S5.

Prior to kinetic analysis, the initial $50 \mathrm{~ms}$ (the value obtained from impedance measurements for the RC constant of the cell) were neglected and the residual current subtracted such that $j=0 \mathrm{~A} \cdot \mathrm{cm}^{-2}$ at $t=40 \mathrm{~s}$. For all $\Gamma_{\text {ZnPor }}$ values, the transients obtained using $-0.05 \mathrm{~V},-0.10 \mathrm{~V}$ and $-0.15 \mathrm{~V}$ as $\Delta_{o}^{w} \phi_{\text {final }} \quad$ (and $+0.25 \mathrm{~V}$ as $\Delta_{o}^{w} \phi_{\text {initial }}$ ) did not show any significant nucleation component (Figure S9). Thus, the analysis was focused on the transients obtained using $-0.25 \mathrm{~V},-0.30 \mathrm{~V}$ and $-0.35 \mathrm{~V}$ as $\Delta_{o}^{w} \phi_{\text {final }}$, where the nucleation features were observed (Figures 5a-b). In many cases, more than one nucleation component 
was observed experimentally, up to a maximum of three. The latter may be associated with binding and ion exchange at inner carboxyl sites. Therefore, the nucleation components were de-convoluted from the total current signal by plotting the derivative of the total current. From the derivative, the time $t_{\max }$ of the peak current maximum for each nucleation component within each transient was easily identified, see Figure $5 \mathrm{c}$. A summary of these $t_{\max }$ values as a function of $\Gamma_{\text {znPor }}$ and $\Delta_{o}^{w} \phi_{\text {final }}$ is presented in Table S5. Using these $t_{\max }$ values as a clear guide to the number of nucleation components present, the total fitted current for any transient may be obtained as a summation of the adsorption and nucleation components using exponential decay and Gaussian-type functions, respectively (Figure S10).

An increase in nucleation kinetics will be reflected in a shorter time required to reach $t_{\max }$ for each nucleation component. For all values of $\Gamma_{\mathrm{ZnPor}}$ and $\Delta_{o}^{w} \phi$, the shifts of $t_{\max }$ followed consistent trends. At a constant $\Gamma_{\mathrm{ZnPor}}$ and $\Delta_{o}^{w} \phi_{\text {initial }}$, an increase in nucleation kinetics (decreasing $t_{\max }$ ) was seen as $\Delta_{o}^{w} \phi_{\text {final }}$ was set to more negative values (Figure 5a and Table S5). In other words, conformational relaxation to the more open nanostructure is faster as more energy is applied to drive $\mathrm{R}_{2} \mathrm{~N}^{+}$species into the ZnPor-IN film, leading to the creation of more nuclei. Conversely, at a constant $\Delta_{o}^{w} \phi_{\text {initial }}$ of $+0.25 \mathrm{~V}$ and $\quad \Delta_{o}^{w} \phi_{\text {final }}$ of $-0.25 \mathrm{~V}$, a decrease in nucleation kinetics (increasing $t_{\max }$ ) was seen as $\Gamma_{\mathrm{ZnPor}}$ increased (Figure $5 \mathrm{~b}$ and Table S5). The latter indicates that more energy is required to achieve conformational relaxation as $\Gamma_{\text {znpor }}$ increases. A prediction of the ESCR model is that a linear relationship exists between $\ln \left(t_{\max } / \mathrm{s}\right)$ and the energy required to relax and swell the conducting polymer film by oxidation, i.e. the anodic overpotential. ${ }^{46}$ In line with this prediction, plots of $\ln \left(t_{\max } / \mathrm{s}\right)$ versus $\Delta_{o}^{w} \phi_{\text {final }}$ for one of the nucleation sites (designated $t_{\max 2}$ ) are linear and exhibit the same slope for the higher $\Gamma_{\mathrm{ZnPor}}$ studied, 1.94 and $4.19 \mathrm{nmol} \cdot \mathrm{cm}^{-2}$ (Figure $5 \mathrm{~d}$ ). The latter identical slopes indicate the rate of increase in nucleation kinetics (decreasing $t_{\max }$ ) as $\Delta_{o}^{w} \phi_{\text {final }}$ shifts negatively is independent of $\Gamma_{\mathrm{ZnPor}}$ in the range studied.

Finally, the effect of the initial "compaction” of the ZnPor-IN film on the kinetics were evaluated using two different experimental approaches. As $\mathrm{R}_{2} \mathrm{~N}^{+}$are bulky organic cations, far larger than the protons they displace from - $\mathrm{COOH}$ groups, it can be reasonably assumed that the volume of the ZnPor-IN film swells at negative $\Delta_{o}^{w} \phi \quad$ values, reducing the films compaction. First, $\Gamma_{\mathrm{ZnPor}}$ and $\Delta_{o}^{w} \phi_{\text {final }} \quad$ were maintained constant at $1.94 \mathrm{nmol} \cdot \mathrm{cm}^{-2}$ and $0.25 \mathrm{~V}$, respectively, and $\Delta_{o}^{w} \phi_{\text {initial }}$ varied from $+0.20 \mathrm{~V}$ to $+0.45 \mathrm{~V}$ every $50 \mathrm{mV}$ with a 
$t_{\text {initial }}$ of $30 \mathrm{~s}$ (Figure S11a). The current transients measured were near identical for all values of $\Delta_{o}^{w} \phi_{\text {initial }}$ tested with no measurable difference in the absorption component and, on close inspection (see inset Figure S11a), a slight decrease of $t_{\max }$ for the prominent nucleation component. This slight increase in the nucleation kinetics is the opposite of what was expected if the film was more compact at positive values of $\Delta_{o}^{w} \phi_{\text {initial }}$. We attribute the minor increase in nucleation kinetics to an interaction of the organic anions, $\mathrm{TB}^{-}$, with the ZnPor-IN film at positive potentials leading to a partial opening of the nanostructure. As the ZnPor-IN film and $\mathrm{TB}^{-}$are both negatively charged, this interaction is far weaker than that of ZnPor-IN film and the $\mathrm{R}_{2} \mathrm{~N}^{+}$species. Nevertheless, when the potential is stepped to $-0.25 \mathrm{~V}$, slightly less energy is required to open space for the penetration of the $\mathrm{R}_{2} \mathrm{~N}^{+}$species. In the

second experiment, $\Gamma_{\mathrm{ZnPor}}, \quad \Delta_{o}^{w} \phi_{\text {initial }}$, and $\Delta_{o}^{w} \phi_{\text {final }}$ were maintained constant at 1.94 $\mathrm{nmol} \cdot \mathrm{cm}^{-2},+0.25 \mathrm{~V}$ and $-0.25 \mathrm{~V}$ respectively, and $t_{\text {initial }}$ varied from 5 to $60 \mathrm{~s}$ (Figure S11b). As for the previous experiment, the current transients measured were near identical for all values of $t_{\text {initial }}$ tested with no measurable difference in the absorption component and, on close inspection (see inset Figure S11b), a slight increase of $t_{\max }$ for the prominent nucleation component. This minor decrease in the nucleation kinetics indicates a slightly more compact nature as $t_{\text {initial }}$ increased.

\section{Conclusions}

The thermodynamics and kinetics of ion intercalation into a floating film of zinc porphyrin interfacial nanostructures (ZnPor-INs) were probed electrochemically without the need to support the ZnPor-IN film on a conductive electrode substrate. Instead, the film was supported on an electrified liquid|liquid interface, and could be regarded to a mixed-solvent layer separating the aqueous and organic solutions. The electrochemical signal was due to purely ionic processes, not linked to redox reactions.

The film behaves as a capacitor. The ZnPor-IN film is electroneutral and the concentration of free ions is relatively small because of solvation effects. On increasing the negative polarisation of the interface, $\Delta_{o}^{w} \phi<0$, the organic ammonium cations $\left(\mathrm{R}_{2} \mathrm{~N}^{+}\right)$from the organic phase enter the film and intercalate the ZnPor-IN. Then, a few neutral carboxyl ($\mathrm{COOH})$ groups are forced to dissociate, and many more transform into $-\mathrm{COOR}_{2} \mathrm{~N}$. In both cases, the released $\mathrm{H}^{+}$ions leave the film and enter the aqueous phase. The charge of the 
anionic carboxyl groups $\left(-\mathrm{COO}^{-}\right)$is mostly compensated by free $\mathrm{R}_{2} \mathrm{~N}^{+}$ions. The total (i.e., free and bound) $\mathrm{R}_{2} \mathrm{~N}^{+}$concentration in the film, $c_{\mathrm{COO}_{2} N}+c_{R_{2} N}^{i}$, is a measure of the positive charge accumulated in the film as a capacitor; the negative charge in the capacitor corresponds to $\mathrm{H}^{+}$ions leaving the film (where there were bound as $-\mathrm{COOH}$ ). To a lesser extent, aqueous citrate $\left(\mathrm{HCit}^{2-}\right)$ anions and lithium $\left(\mathrm{Li}^{+}\right)$ions may also participate in this capacitive film behaviour.

The shape of the CV was distinctive, formed by the superposition of a narrow peak and a broad peak. The former indicated a positive cooperativity mechanism for ion intercalation and was attributed to structural rearrangements of the porphyrins at the electrified liquid| liquid interface during $\mathrm{R}_{2} \mathrm{~N}^{+}$intercalation. Employing the Frumkin isotherm, experimental CVs were simulated with negative $g$ interaction parameters in line with those observed for a $\mathrm{Li}^{+}$intercalation process, a system with very similar underlying thermodynamics. ${ }^{13}$ The kinetics of $\mathrm{R}_{2} \mathrm{~N}^{+}$intercalation were investigated by potential-step chronoamperometry. Depending on the applied interfacial Gavani potential $\Delta_{o}^{w} \phi$ and the interfacial concentration $\Gamma_{\mathrm{ZnPor}}$ of ZnPor, current transients presented a decay and multiple nucleation components. The latter were associated with domains where, due to structural rearrangements of the porphyrins, the electrochemically-driven binding and ion exchange of $\mathrm{R}_{2} \mathrm{~N}^{+}$took place faster. The nucleation kinetics were seen to increase as the final potential $\Delta_{o}^{w} \phi_{\text {final }}$ was set to more negative values and decrease as $\Gamma_{\mathrm{ZnPor}}$ increased.

Overall, using electrified liquid|liquid interfaces, there is clearly significant potential to study, for the time, by electrochemical methodologies the kinetics and thermodynamics of ion intercalation into solid matrices that are non-electronically conductive and/or that operate as non-electronically connected device components (for example ion exchange membranes). Such insights may critically influence the performance of a multitude of devices (Li-ion batteries, supercapacitors, fuel cells, electrolysers, etc.) with energy-related applications.

\section{Conflicts of interest}

The authors declare no competing financial interest.

\section{Acknowledgements}


M.D.S. acknowledges Science Foundation Ireland (SFI) under Grant no. 13/SIRG/2137 and the European Research Council through a Starting Grant (Agreement no. 716792). A. G.-Q. acknowledges funding received from an Irish Research Council Government of Ireland Postdoctoral Fellowship Award (grant number GOIPD/2018/252). J.A.M. acknowledges the Ministerio de Ciencia e Innovación (Spain) and the European Regional Development Funds (FEDER), project No. PGC2018-097359-B-I00.

\section{References}

1 V. Augustyn, M. T. McDowell and A. Vojvodic, Joule, 2018, 2, 2189-2193.

2 V. R. Stamenkovic, D. Strmcnik, P. P. Lopes and N. M. Markovic, Nat. Mater., 2016, 16, 57-69.

3 M. Z. Bazant, Acc. Chem. Res., 2013, 46, 1144-1160.

4 A. M. Kuznetsov and J. Ulstrup, Electrochim. Acta, 2000, 45, 2339-2361.

$5 \quad$ K. D. Fong, T. Wang and S. K. Smoukov, Sustain. Energy Fuels, 2017, 1, 1857-1874.

6 H. Strathmann, in Comprehensive Membrane Science and Engineering, Elsevier, 2010, vol. 2, pp. 391-429.

7 H. Strathmann, A. Grabowski and G. Eigenberger, Desalination, 2006, 199, 1-3.

8 S. J. Peighambardoust, S. Rowshanzamir and M. Amjadi, Int. J. Hydrogen Energy, 2010, 35, 9349-9384.

9 B. Yuzer, H. Selcuk, G. Chehade, M. E. Demir and I. Dincer, Energy, 2020, 190, 116420.

10 T. D. Nguyen, A. Whitehead, N. Wai, S. J. H. Ong, G. G. Scherer and Z. J. Xu, ChemSusChem, 2019, 12, 1076-1083.

11 B. E. Logan and M. Elimelech, Nature, 2012, 488, 313-319.

12 M. Oliot, S. Galier, H. Roux de Balmann and A. Bergel, Appl. Energy, 2016, 183, 1682-1704.

13 M. D. Levi, J. Electrochem. Soc., 1999, 146, 1279.

14 M. D. Levi and D. Aurbach, Electrochim. Acta, 1999, 45, 167-185.

15 B. E. Conway, Electrochim. Acta, 1993, 38, 1249-1258.

16 M. D. Levi, Y. S. Cohen, Y. Gofer and D. Aurbach, Electrochim. Acta, 2004, 49, 37013710.

17 M. A. Vorotyntsev, L. I. Daikhin and M. D. Levi, J. Electroanal. Chem., 1992, 332, 213-235.

18 W. Sirisaksoontorn and M. M. Lerner, Inorg. Chem., 2013, 52, 7139-7144.

19 A. M. Fogg, J. S. Dunn, S.-G. Shyu, D. R. Cary and D. O’Hare, Chem. Mater., 1998, 10, 351-355. 
21 P. Peljo and H. H. Girault, in Encyclopedia of Analytical Chemistry, John Wiley \& Sons, Ltd, Chichester, UK, 2012.

22 M. F. Suárez-Herrera, P.-A. Cazade, D. Thompson and M. D. Scanlon, Electrochem. commun., 2019, 109, 106564.

23 M. F. Suárez-Herrera and M. D. Scanlon, Electrochim. Acta, 2019, 328, 135110.

24 S. Senthilkumar, R. A. W. Dryfe and R. Saraswathi, Langmuir, 2007, 23, 3455-3461.

25 R. A. W. Dryfe and S. M. Holmes, J. Electroanal. Chem., 2000, 483, 144-149.

26 G. C. Lillie, R. a Dryfe and S. M. Holmes, Analyst, 2001, 126, 1857-1860.

27 X. Jiang, K. Gao, D. Hu, H. Wang, S. Bian and Y. Chen, Analyst, 2015, 140, 28232833.

28 X. Huang, L. Xie, X. Lin and B. Su, Anal. Chem., 2016, 88, 6563-6569.

29 L. Xie, X. Huang, X. Lin and B. Su, J. Electroanal. Chem., 2017, 784, 62-68.

30 M. C. Collins, M. Hébrant and G. Herzog, Electrochim. Acta, 2018, 282, 155-162.

31 L. Poltorak, A. Gamero-Quijano, G. Herzog and A. Walcarius, Appl. Mater. Today, 2017, 9, 533-550.

32 M. J. Stephenson, S. M. Holmes and R. A. W. Dryfe, Angew. Chemie - Int. Ed., 2005, 44, 3075-3078.

33 M. J. Stephenson, M. P. Attfield, S. M. Holmes and R. A. W. Dryfe, J. Solid State Electrochem., 2015, 19, 1985-1992.

34 M. J. Stephenson and R. A. W. Dryfe, Electrochim. Acta, 2007, 53, 1182-1188.

35 T. F. Otero, H. J. Grande and J. Rodríguez, J. Phys. Chem. B, 1997, 101, 3688-3697.

36 A. F. Molina-Osorio, D. Cheung, C. O’Dwyer, A. A. Stewart, M. Dossot, G. Herzog and M. D. Scanlon, J. Phys. Chem. C, 2020, 124, 6929-6937.

37 C. W. Monroe, M. Urbakh and A. A. Kornyshev, J. Electroanal. Chem., 2005, 582, 2840.

38 T. Huber, O. Pecina and W. Schmickler, J. Electroanal. Chem., 1999, 467, 203-206.

39 G. M. Torrie and J. P. Valleau, J. Electroanal. Chem., 1986, 206, 69-79.

40 C. Yufei, V. J. Cunnane, D. J. Schiffrin, L. Murtomäki and K. Kontturi, J. Chem. Soc., Faraday Trans., 1991, 87, 107-114.

41 C. M. Pereira, A. Martins, M. Rocha, C. J. Silva and F. Silva, J. Chem. Soc. Faraday Trans., 1994, 90, 143-148.

42 R. G. Bates and G. D. Pinching, J. Am. Chem. Soc., 1949, 71, 4165-4165.

43 M. H. Hölzle, U. Retter and D. M. Kolb, J. Electroanal. Chem., 1994, 371, 101-109.

44 T. F. Otero and I. Boyano, J. Phys. Chem. B, 2003, 107, 4269-4276.

45 T. F. Otero and I. Boyano, J. Phys. Chem. B, 2003, 107, 6730-6738.

46 M. R. Nateghi and B. Savabieh, Electrochim. Acta, 2014, 121, 128-135. 
